
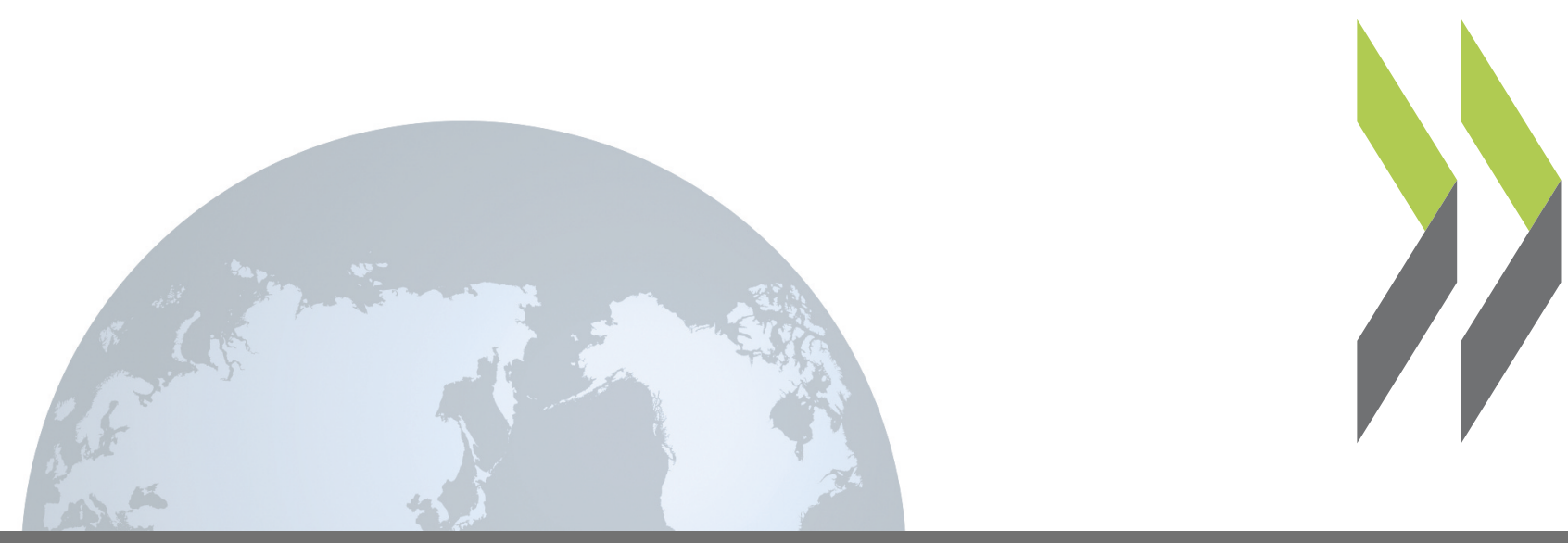

OECD Economics Department Working Papers No. 970

\title{
International Capital Mobility
} and Financial Fragility - Part

7. Enhancing Financial Stability: Country-Specific Evidence on Financial Account and Structural Policy Positions

Rudiger Ahrend, Carla Valdivia 
Organisation de Coopération et de Développement Économiques

Organisation for Economic Co-operation and Development

20-Jun-2012

ECONOMICS DEPARTMENT

English - Or. English

INTERNATIONAL CAPITAL MOBILITY AND FINANCIAL FRAGILITY: PART 7.

ENHANCING FINANCIAL STABILITY: COUNTRY-SPECIFIC EVIDENCE

ON FINANCIAL ACCOUNT AND STRUCTURAL POLICY POSITIONS

ECONOMICS DEPARTMENT WORKING PAPER No. 970

by Rudiger Ahrend and Carla Valdivia

All Economics Department Working Papers are available through OECD's Internet website at www.oecd.org/eco/workingpapers

JT03323996

Complete document available on OLIS in its original format

This document and any map included herein are without prejudice to the status of or sovereignty over any territory, to the delimitation of international frontiers and boundaries and to the name of any territory, city or area. 


\section{ABSTRACT / RÉSUMÉ \\ International capital mobility and financial fragility: Part 7. Enhancing Financial Stability: Country-specific evidence on Financial Account and Structural Policy Positions}

This paper brings together the results from new empirical analysis on how - under international capital mobility - financial account structure and structural policies can contribute to financial stability. More specifically, the analysis has identified features of financial accounts and structural policy settings that are associated with financial fragility, and this paper presents information on these features and policy settings across a wide set of countries. A first set of charts present stability-relevant dimensions of the financial account for OECD economies and the BRIICS. A second set of charts shows how countries' financial account structure evolved in the decade prior to the global financial crisis, highlighting substantial increases in financial vulnerability in countries that were subsequently strongly affected by the crisis. Finally, a third set of charts presents countries' stances on selected structural policies that are conducive to financial stability.

JEL classification codes: E44; F34; F36; G01; G18

Keywords: financial stability; financial account; structural policies; external debt; bank debt; capital controls; banking regulations; FDI restrictions.

\section{Flux de capitaux internationaux et fragilité financière : Partie 7. Améliorer la stabilité financière : Analyse empirique du compte financier et des politiques structurelles par pays}

Cet article rassemble les résultats d'une nouvelle analyse empirique des effets de la composition du compte financier et des politiques structurelles sur la stabilité financière. L'analyse empirique a identifié des caractéristiques des comptes financiers et un ensemble de politiques structurelles qui ont contribué à des fragilités financières. Ces caractéristiques et politiques structurelles sont présentées pour un grand nombre de pays. Un premier ensemble de graphiques présente les caractéristiques des comptes financiers des pays qui sont pertinentes quant à la stabilité financière des pays de l'OCDE et du BRIICS. Un second ensemble de graphiques examine comment la structure des comptes financiers des pays a évolué lors de la décennie ayant précédé la crise financière globale de 2008-09. Cette analyse souligne que les facteurs de vulnérabilité financière avaient augmenté significativement dans les pays qui ont été les plus affectés par la crise. Enfin, les derniers graphiques présentent la situation des pays pour une sélection de politiques structurelles qui sont apparues contribuer à la stabilité financière.

Codes JEL : E44; F34; F36; G01; G18.

Mots-clés : stabilité financière ; compte financier ; politiques structurelles ; dette externe ; dette bancaire ; contrôle des flux de capitaux; réglementation bancaire; réglementation des Investissements Directs Étrangers. 


\section{TABLE OF CONTENTS}

\section{INTERNATIONAL CAPITAL MOBILITY AND FINANCIAL FRAGILITY: PART 7. ENHANCING FINANCIAL STABILITY: COUNTRY-SPECIFIC EVIDENCE ON FINANCIAL ACCOUNT

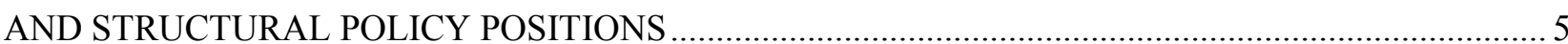

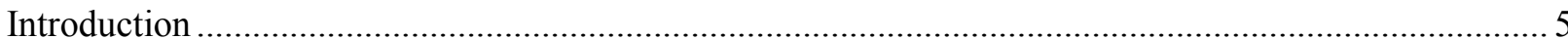

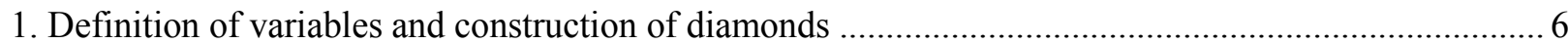

2. Descriptive statistics for selected countries, the OECD and the BRIICS ........................................ 8

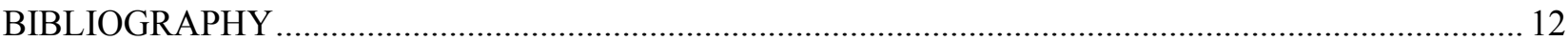

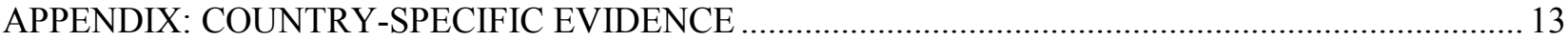

\section{Figures}

1. Financial account structure of selected countries in 2007 9

2. In 2007, the financial account structure of the BRIICS was more conducive to financial stability than that of the OECD

3. In the decade prior to the recent financial crisis, financial account structure became more conducive to financial stability in the BRIICS while it became riskier in the OECD

4. In 2007, neither the BRIICS nor the OECD had a set of structural policies that looked a priori more conducive to financial stability 
ECO/WKP(2012)47 
ECO/WKP(2012)47

\title{
INTERNATIONAL CAPITAL MOBILITY AND FINANCIAL FRAGILITY: PART 7. ENHANCING FINANCIAL STABILITY: COUNTRY-SPECIFIC EVIDENCE ON FINANCIAL ACCOUNT AND STRUCTURAL POLICY POSITIONS
}

\author{
By Rudiger Ahrend and Carla Valdivia ${ }^{1}$
}

\section{Introduction}

1. The recent financial crisis has underlined the need to prevent excessive financial fragility. To contribute to this purpose, recent OECD work covering OECD and emerging economies over the past three decades has examined what features of countries' financial account structure reduce financial crisis risk (Ahrend and Goujard, 2011). Related work has explored which structural policies are conducive to financial stability, typically through their effects on financial account structure, or on vulnerability to contagion-induced financial shocks (Ahrend et al., 2012; Ahrend and Goujard, 2012; Ahrend and Schwellnus, 2012a;b). This paper draws on the results of this work aiming to provide - for the OECD and the BRIICS - a snapshot of how much each country's financial account structure and its stance on selected structural policies have been conducive to financial stability. For each country, this information is aggregated into three diamond-charts. For a given country, these charts show stability-relevant aspects of its financial account structure in the wake of the global financial crisis in 2007, developments in its financial account in the decade prior to the global financial crisis, as well as its pre-crisis stance on selected stability-relevant structural policies.

2. The financial account features presented in the diamond charts have been selected based on the following empirical findings from Ahrend and Goujard (2011):

- Greater (short-term) borrowing from external banks or a skew in external liabilities towards debt has substantially increased the risk of suffering financial crises (external bank debt being defined as debt to a foreign bank).

- A larger share of FDI in gross external liabilities has decreased the risk of financial crisis.

- Shorter banking debt maturities have increased crisis risk, mainly by increasing exposure to financial contagion.

- The size of foreign reserve holdings has reduced the probability of crises.

- Total external assets (excluding reserves) or liabilities have not been found to affect risk for standard countries. However, external assets have reduced, and external liabilities have increased crisis risk when they have been large.

1. The authors are indebted to Romain Duval, Jørgen Elmeskov, Antoine Goujard, Jean-Luc Schneider, Cyrille Schwellnus and Alain de Serres as well as to delegates to the Working Party No. 1 on Macroeconomic and Structural Policy Analysis and to the Economic Policy Committee, and to colleagues in the OECD economics department for useful comments. The authors would like to thank Celia Rutkoski for first rate editorial support. The views expressed here are those of the authors, and do not necessarily reflect those of the OECD or its member countries; nor the Central Bank of Chile or its board members (Carla Valdivia is seconded from the Central Bank of Chile and works at the Economics Department of the OECD). 
3. Diamonds that document countries' stance on selected structural policies reflect the following empirical findings from Ahrend and Goujard (2012) and Ahrend and Schwellnus (2012a,b):

- Better banking supervision, stricter information disclosure rules, or stricter capital requirements have reduced countries' financial crisis risk.

- Countries which are more open to foreign bank entry have been less affected by capital outflows in response to reversals in investor sentiment (possibly an indication that foreign investors have better information about the country).

- Countries where the banking sector is less leveraged have been less affected by financial contagion, further underlining the importance of strict financial regulation.

- Regulatory burdens on foreign direct investment, as well as more generally stricter product market regulations, have biased external liabilities away from FDI and towards (bank) debt, thereby increasing financial vulnerability.

- Countries that rely more on tax treaties (in the sense of covering a larger share of the world economy through them) have had a larger share of their external liabilities in the form of FDI, thereby reducing crisis risk.

- Differentiated capital controls have affected the structure of external liabilities and thereby financial stability: openness to FDI and equity flows has reduced external bank debt, whereas openness to inflows from credit operations has increased it. In addition, countries open to inflows from credit operations have been more strongly affected when hit by financial contagion.

4. The remainder of this paper proceeds as follows. Section 1 defines more precisely the presented variables and explains the construction of the diamonds. To illustrate possible uses of the policy diamonds, Section 2 provides some descriptive statistics for selected countries and for the OECD and the BRIICS as a group. The Appendix contains the diamond charts for each country of the OECD and the BRIICS.

\section{Definition of variables and construction of diamonds}

5. Eight dimensions of financial account structure which have been found to increase financial risk have been retained to be presented in country diamonds. ${ }^{2}$ These dimensions of financial account structure are:

- External debt as a share of external liabilities.

- External bank debt as a share of GDP.

- Short-term external bank debt as a share of GDP.

- Shorter maturity of external bank debt (short-term external bank debt / external bank debt).

- External liabilities as a share of GDP.

- Low external assets as a share of GDP.

- Low foreign currency reserves as a share of GDP.

- Low FDI as a share of external liabilities.

2. Currency mismatch was also found to increase financial crisis risk (see Ahrend and Goujard, 2011), but is not included in the country diamonds as data are only available up to 2004 . 
6. External bank debt and short-term external debt are taken from the BIS and measured by total debt liabilities and debt liabilities with residual maturity below one year towards BIS reporting banks. The BIS consolidated banking statistics (on the immediate borrower basis) report banks' on-balance-sheet financial claims on the rest of the world and provide a measure of the risk exposure of lenders' national banking systems. The remaining variables are constructed from Lane and Milesi-Ferretti (2007) and the IMF International Financial Statistics. Variables are constructed so that larger values indicate greater financial stability risk.

7. The diamonds that show the pre-crisis situation and evolution are based on end-of-year data for 2007 and 1997/2007, respectively, with the exception in the latter case of some countries for which data are not available until $1999 .^{3}$

8. For structural policies, ten dimensions are identified as increasing financial stability:

- Strength of banking supervision taken from Abiad et al. (2010).

- Openness to foreign bank entry taken from Abiad et al. (2010).

- Information disclosure requirements taken from Ahrend et al. (2009).

- Capital adequacy requirements taken from Ahrend et al. (2009).

- Low banking sector leverage, derived from the capital to asset ratio of the banking sector taken from OECD and World Bank statistics.

- Restrictions on credit inflows, based on a measure of openness to inflows of credit operations from Brune (2006).

- Openness to FDI inflows, based on a measure of openness to inward direct investment (equity, joint ventures and FDI) from Brune (2006).

- Openness to FDI (operational issues), as measured by the OECD FDI Regulatory Restrictiveness Index. This index covers foreign equity limitations, screening or approval mechanisms, restrictions on the employment of foreigners as key personnel, and operational restrictions (e.g. restrictions on branching).

- Pro-competitive product market regulation, based on the OECD aggregate indicator of regulation in energy, transport and communications (ETCR).

- Tax treaties: The indicator is constructed from the OECD tax treaty database, with last available data in 2002. Tax treaties are taken into account from the date of their signing, and are weighted by partner countries' (lagged) GDP in current USD from IMF International Financial Statistics.

9. Structural policy variables are constructed such that larger values indicate a policy stance that is more conducive to financial stability. Due to data limitations, only one structural policy diamond is presented for each country. It compares the country's position along each structural policy dimensions; relative to the OECD median value for 2007 as for many of the variables more recent data is unavailable. ${ }^{4}$

3. Austria, Belgium, Canada, Denmark, Finland, France, Germany, Ireland, Italy, Japan, Luxembourg, Netherlands, Norway, Spain, Sweden, Switzerland, United Kingdom and United States.

4. For some of the variables, the last available data is earlier than 2007, e.g. for tax treaties it is 2002. 
10. For all country diamonds, indicators are measured in multiples of the standard deviation across countries for the variable in question. As mentioned, for the financial account structure diamonds, larger values indicate a larger risk to financial stability, whereas for the structural policy diamonds, larger values indicates policy stances more conducive to financial stability.

\section{Descriptive statistics for selected countries, the OECD and the BRIICS}

11. To illustrate possible uses of the policy diamonds, this section examines the financial account structure of selected countries, as well as of the OECD and the BRIICS as a group before the last financial crisis, identifying areas of relative fragility. It also looks at the extent to which current structural policy settings in these countries may be conducive to financial stability.

12. Figure 1 shows the position of selected countries along various dimensions of their financial account structure in 2007, prior to the global financial crisis (relative to the OECD median value on each dimension, for simplicity and without any normative implications). ${ }^{5}$ The diamonds show for instance that Chile had a safer financial account structure than most other OECD countries prior to the global financial crisis - a typical feature for commodity exporting countries (Panel A). In contrast, Ireland had a riskier financial account structure - a typical feature for countries with a large financial sector (Panel A). Higher fragility resulted from increased leverage of the external balance sheet, which occurred through increased external bank debt, often of short maturity. China had a pre-crisis financial account structure that appeared fairly safe - a typical feature for countries that were running large current account surpluses prior to the crisis (Panel B). On the contrary, the 2007 financial account structure of Greece appeared relatively risky a typical feature for countries with sizeable current account deficits in the years preceding the global financial crisis (Panel B).

5. By comparing the various indicator values to those in the median country, Figures 1 to 4 are robust to outliers, such as Iceland or Ireland where the increase in financial-account structure related fragility was far larger than in the median OECD country. 
Figure 1. Financial account structure of selected countries in 2007

Panel A. In 2007, commodity-exporting countries generally had a safer, and countries with a large financial sector, a riskier financial account structure than the typical OECD country

Financial account related risk factors to financial stability

Chile 2007

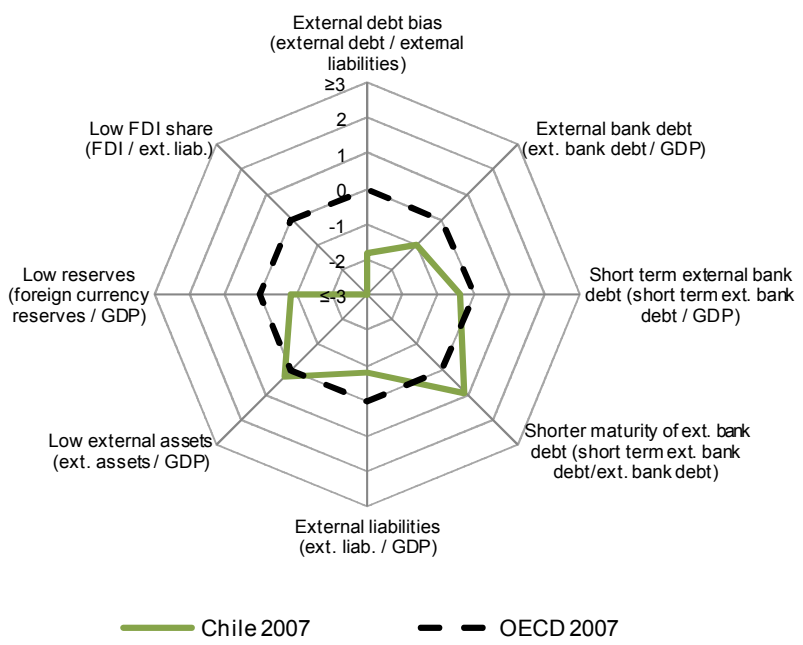

Ireland 2007

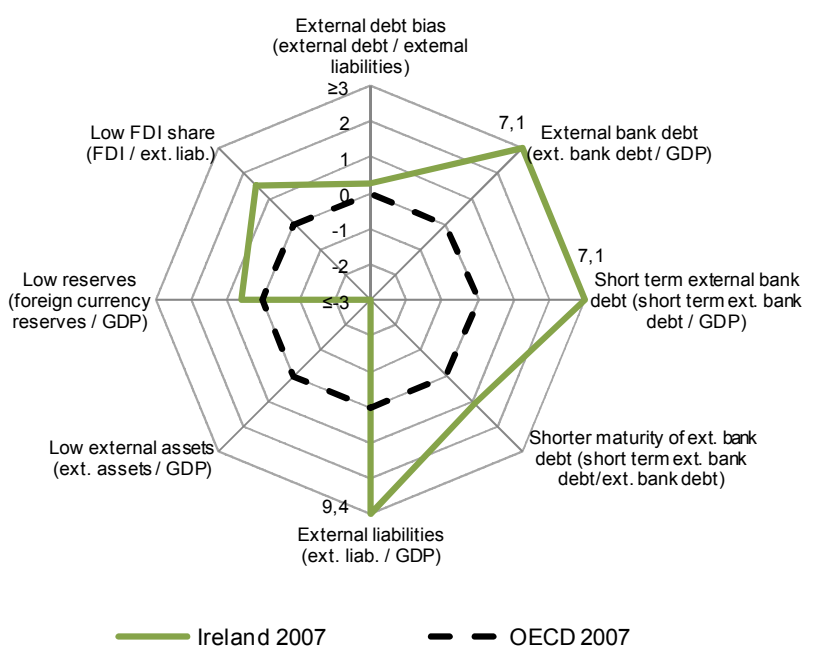

Panel B. Countries with large current account surpluses prior to 2007 generally had a safer, and countries with large current account deficits a riskier financial account structure than the typical OECD country

China 2007

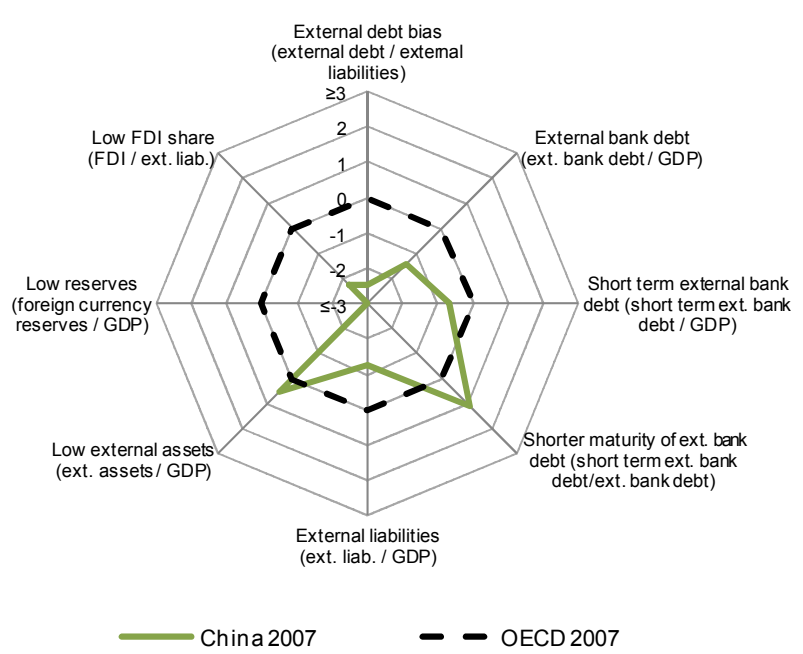

Greece 2007

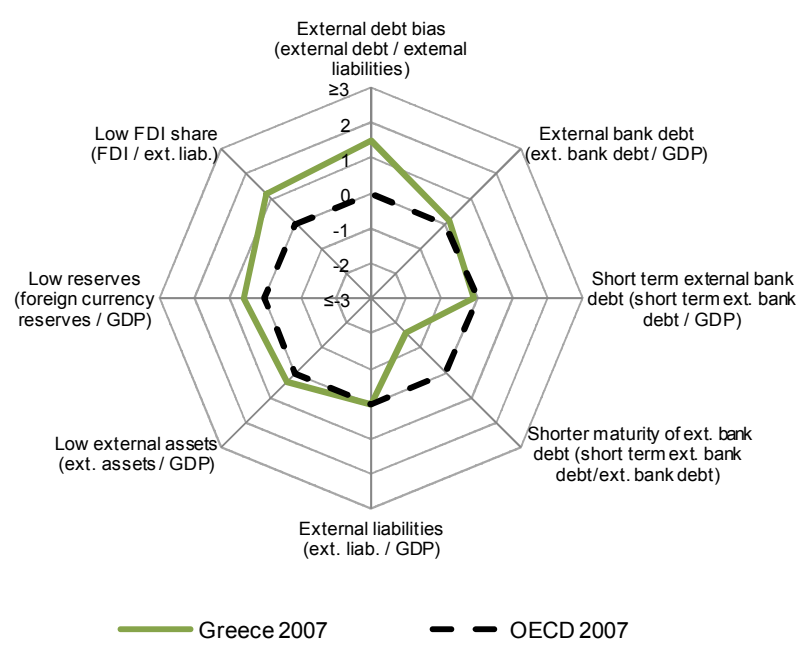

Note: For each variable, a larger value indicates a riskier financial account position. Indicators are measured in multiples of the standard deviation across countries for the variable in question. Each variable is presented for the country in question, compared to the OECD median (which is normalised to zero).

13. More generally, prior to the recent global financial crisis, the BRIICS had a much safer financial account structure than OECD countries along most dimensions, the main exception being that OECD countries held larger external assets (as a share of GDP) than the BRIICS (Figure 2). This is in sharp contrast with the situation a decade earlier, as in 1997 OECD countries still had a similar financial account structure to that of the BRIICS. 
Figure 2. In 2007, the financial account structure of the BRIICS was more conducive to financial stability than that of the OECD

Financial account related risk factors to financial stability, BRIICS compared with OECD

BRIICS vs. OECD 2007

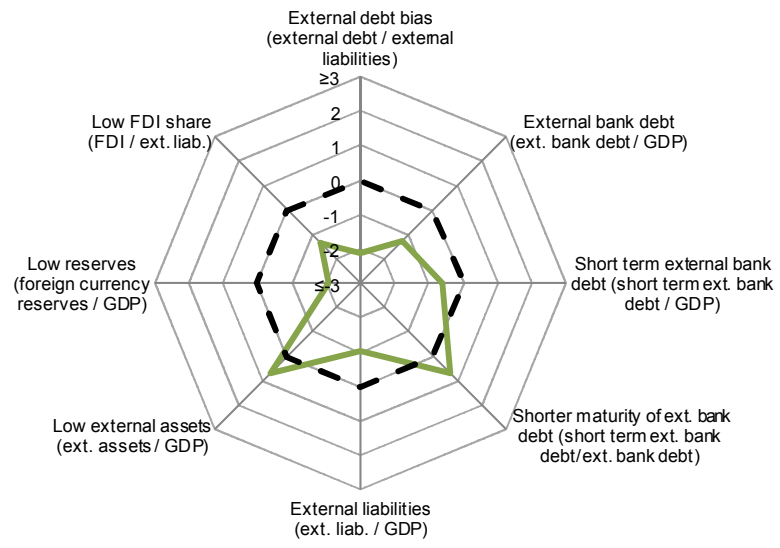

$\longrightarrow$ BRIICS 2007
BRIICS vs. OECD 1997

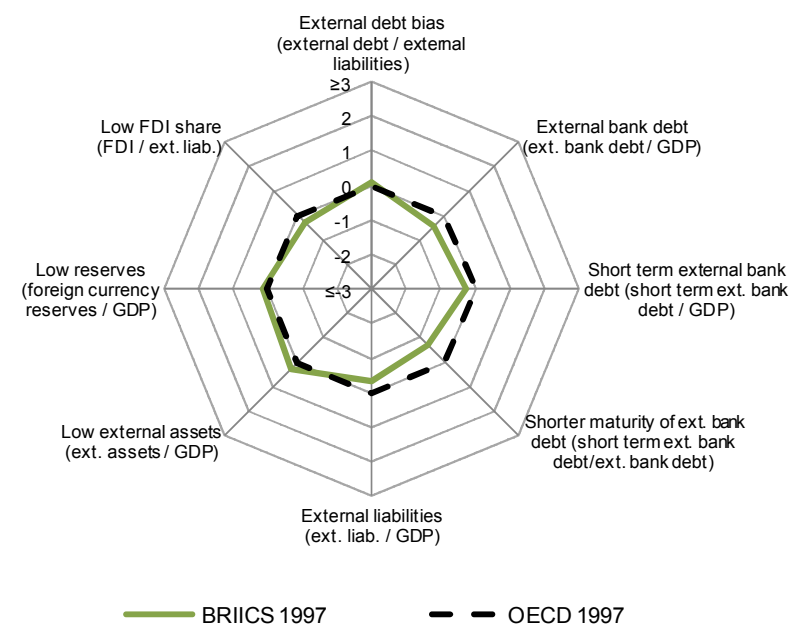

Note: Each variable is presented for the BRIICS median country, compared to the OECD median country (which is normalised to zero). For each variable, a larger value indicates a riskier financial account position. Indicators are measured in multiples of the standard deviation across countries for the variable in question.

14. This change came in part from major efforts on the side of the BRIICS in the decade prior to the recent crisis to reduce their financial fragility, likely driven in part by the experience of the Asian and other ensuing emerging market crises. Most notable changes were a shift in external liabilities from debt towards FDI and an increase in external assets, especially foreign currency reserves (Figure 3). Over the same period, OECD countries increased their financial fragility along several dimensions, leveraging up their external balance sheet and building up bank debt.

Figure 3. In the decade prior to the recent financial crisis, financial account structure became more conducive to financial stability in the BRIICS while it became riskier in the OECD

Financial account related risk factors to financial stability, 2007 compared with 1997

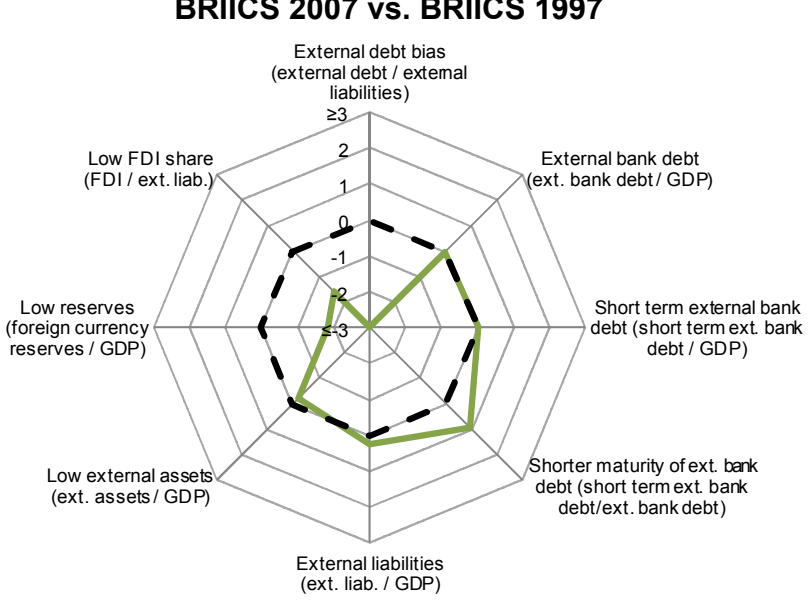

BRIICS $2007 \quad-$ BRIICS 1997
OECD 2007 vs. OECD 1997

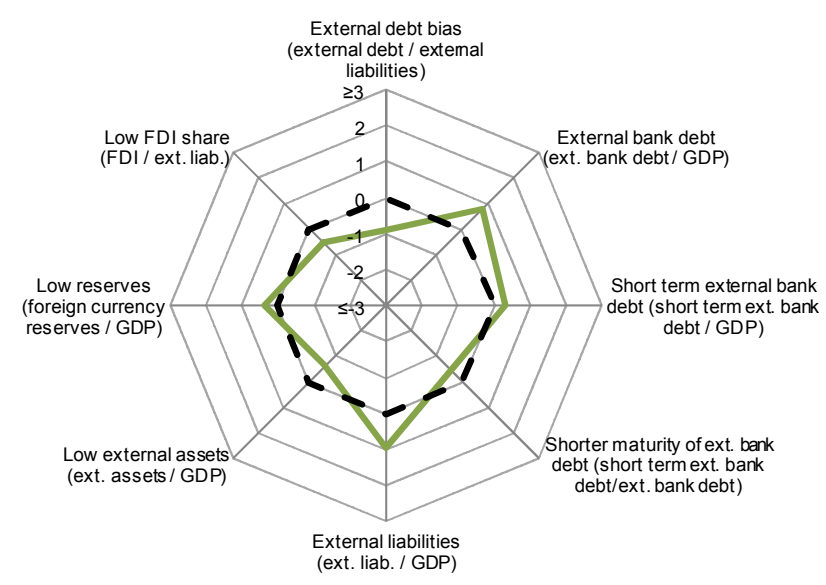

OECD $2007 \quad-\quad$ OECD 1997

Note: Each variable is presented for the BRIICS (respectively OECD) median country in 2007, compared to the situation in 1997 (which is normalised to zero). For each variable, a larger value indicates a riskier financial account position. Indicators are measured in multiples of the standard deviation across countries for the variable in question. 
15. Turning to structural policies, Figure 4 compares average policy settings in the BRIICS to those in the OECD. Even though there are marked differences between the policy stances, no group has a set of policies that looks a priori more conducive to financial stability on all dimensions. Whereas greater FDI openness and stricter banking regulation should further financial stability in the OECD, BRIICS relied more on capital controls on credit inflows to prevent financial instability, and more generally had lower levels of leverage in the banking sector (mirroring high capital ratios). However, even on those dimensions where policies in the BRIICS were less conducive to financial stability than in the OECD - such as FDI openness and financial regulation and supervision - the resulting financial account structure was more conducive to financial stability relative to the OECD. This may point to specific policies on the part of the BRIICS, e.g. prudential policies not captured in available indicators or macroeconomic policies that may have played an important role for achieving a relatively safe financial account structure. However, it could also reflect that more advanced economies usually have more developed and leveraged financial sectors.

Figure 4. In 2007, neither the BRIICS nor the OECD had a set of structural policies that looked a priori more conducive to financial stability

Selected structural policies conducive to financial stability, BRIICS compared to OECD

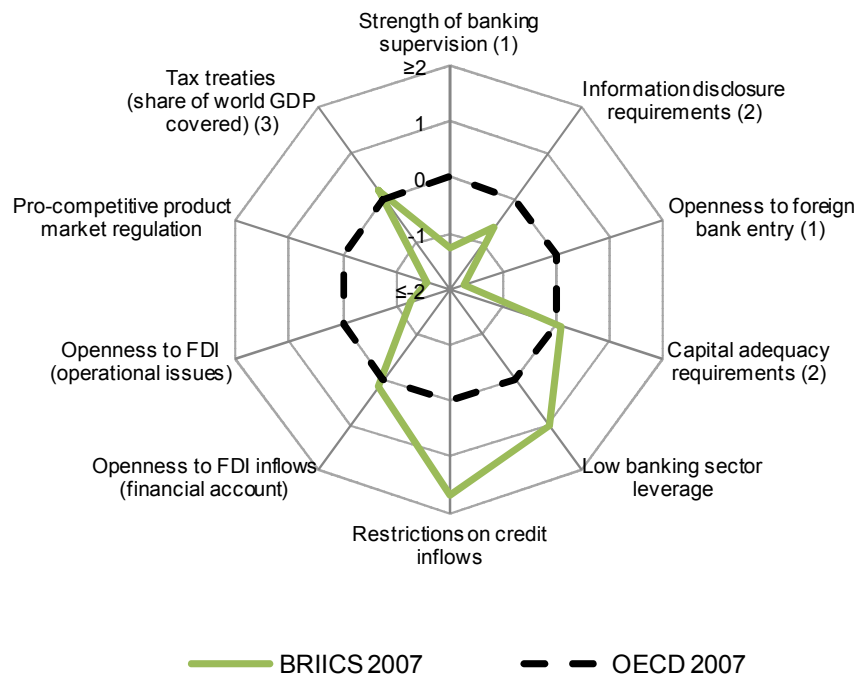

1. Last available data 2005.

2. Last available data 2006.

3. Last available data 2002.

Note: Each variable is presented for the BRIICS median country, compared to the OECD median country (which is normalised to zero). For each variable, a larger value indicates a policy stance that is more conducive to financial stability. Indicators are measured in multiples of the standard deviation across countries for the variable in question. 


\section{BIBLIOGRAPHY}

Abiad A., E. Detragiache and T. Tressel, (2010), "A New Database of Financial Reforms," IMF Staff Papers, 57(2), 281-302.

Ahrend, R. and A. Goujard (2011), "International Capital Mobility and Financial Fragility: Part 1. Drivers of Systemic Banking Crises: The Role of Bank-Balance-Sheet Contagion and Financial Account Structure", OECD Economics Department Working Papers, No. 902, OECD Publishing.

Ahrend, R. and A. Goujard (2012), "International Capital Mobility and Financial Fragility: Part 3. How Do Structural Policies Affect Financial Crisis Risk? Evidence from Past Crises Across OECD and Emerging Economies", OECD Economics Department Working Papers, No. 966, OECD Publishing.

Ahrend, R. and C. Schwellnus (2012a) "International Capital Mobility and Financial Fragility: Part 4. Which Structural Policies Stabilise Capital Flows when Investors Change their Mind? Evidence from Bilateral Bank Data", OECD Economics Department Working Papers, No. 967, OECD Publishing.

Ahrend, R. and C. Schwellnus (2012b) "International Capital Mobility and Financial Fragility: Part 5. Foreign Asset Re-Allocation under Increased Uncertainty: Did Investors Disproportionately Shed Assets of Geographically Distant Countries during the Global Financial Crisis?", OECD Economics Department Working Papers, No. 968, OECD Publishing.

Ahrend, R., A. Goujard and C. Schwellnus (2012), "International Capital Mobility: Which Structural Policies Reduce Financial Fragility?”, OECD Economic Policy Papers, No. 2, OECD Publishing.

Brune, N. B., (2006), Financial Liberalization and Governance in the Developing World, Ph.D. dissertation Yale University.

Lane, P. R. and G. M. Milesi-Ferretti, (2001), The External Wealth of Nations: Measures of Foreign Assets and Liabilities for Industrial and Developing Countries, Journal of International Economics, 55 , 263-294.

Lane, P. R. and G. M. Milesi-Ferretti, (2007), "External Wealth of Nations Mark II: Revised and Extended Estimates of Foreign Assets and Liabilities 1970-2004", Journal of International Economics, 73, $223-250$ 


\section{APPENDIX: COUNTRY-SPECIFIC EVIDENCE}

\section{AUSTRALIA}

\section{Financial account related risk factors to financial stability}

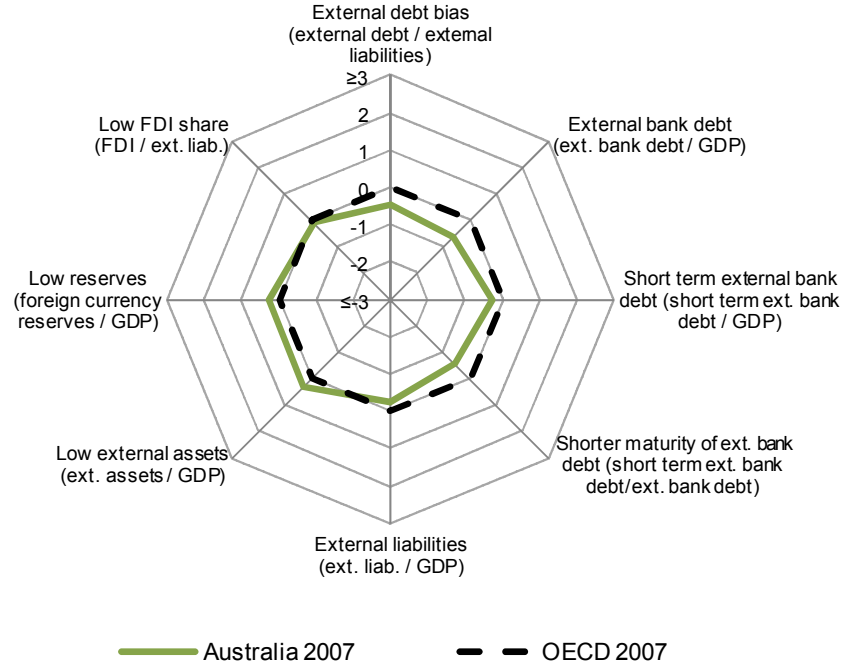

Each variable is presented relative to the OECD median (which is normalised to zero).

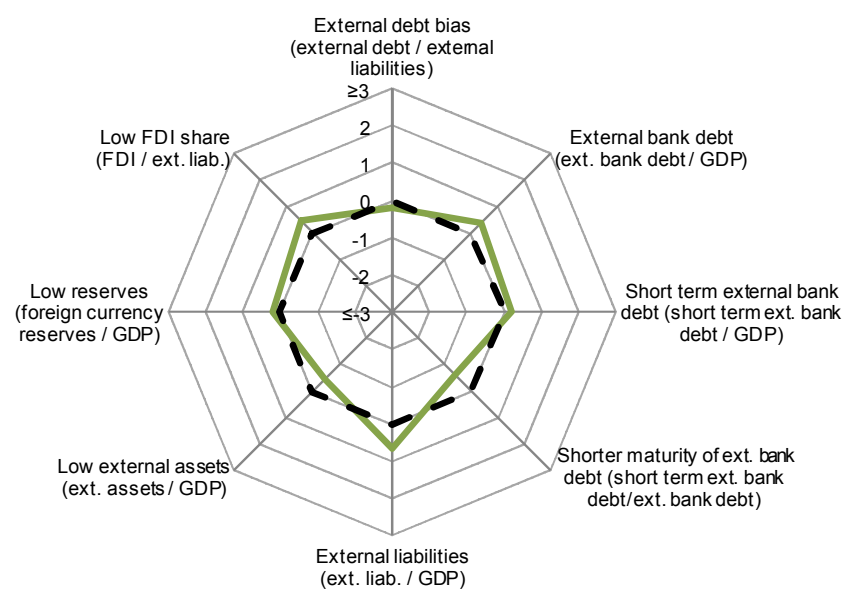

Australia $2007 \quad-$ Australia 1997

Each variable is presented in 2007 relative to the its situation in 1997 (which is normalised to zero).

Note: For each variable, a larger value indicates a riskier financial account position. Indicators are measured in multiples of the standard deviation across countries for the variable in question.

\section{Selected structural policies conducive to financial stability}

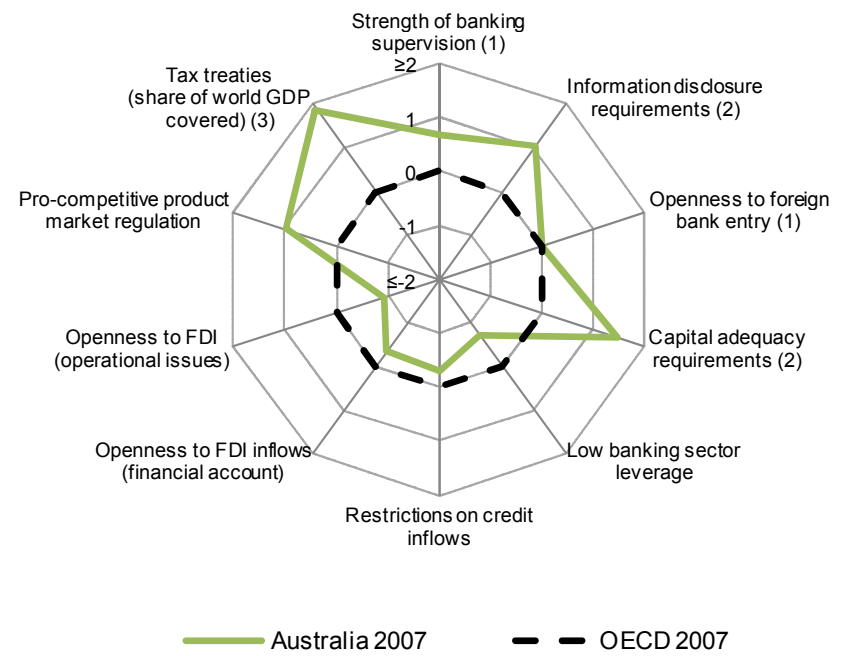

Note: For each variable, a larger value indicates a policy stance that is comparatively more conducive to financial stability. Indicators are measured in multiples of the standard deviation across countries for the variable in queation. Each variable is presented relative to the OECD average (which is normalised to zero).

(1) Last available data, 2005

(2) Last available data, 2006

(3) Last available data, 2002 


\section{AUSTRIA}

\section{Financial account related risk factors to financial stability}

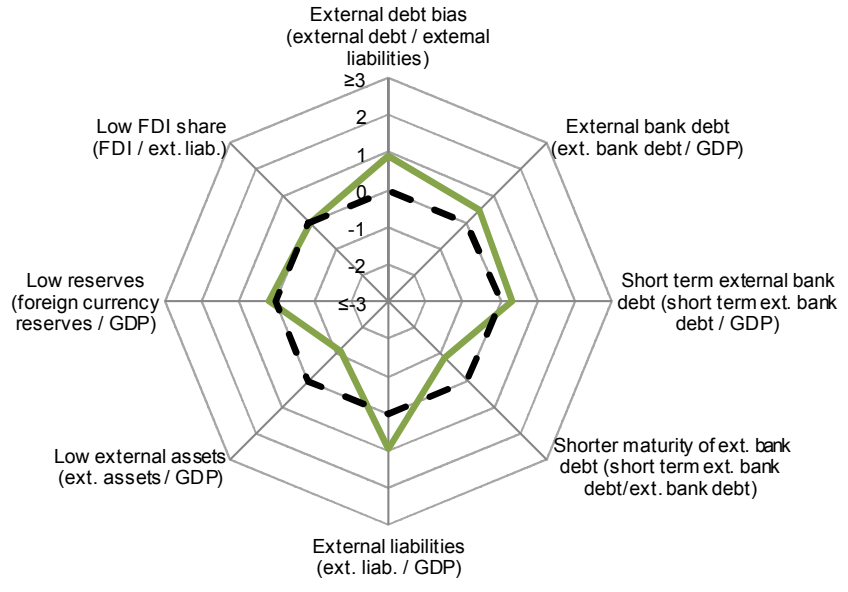

Austria $2007 \quad-$ OECD 2007

Each variable is presented relative to the OECD median (which is normalised to zero).

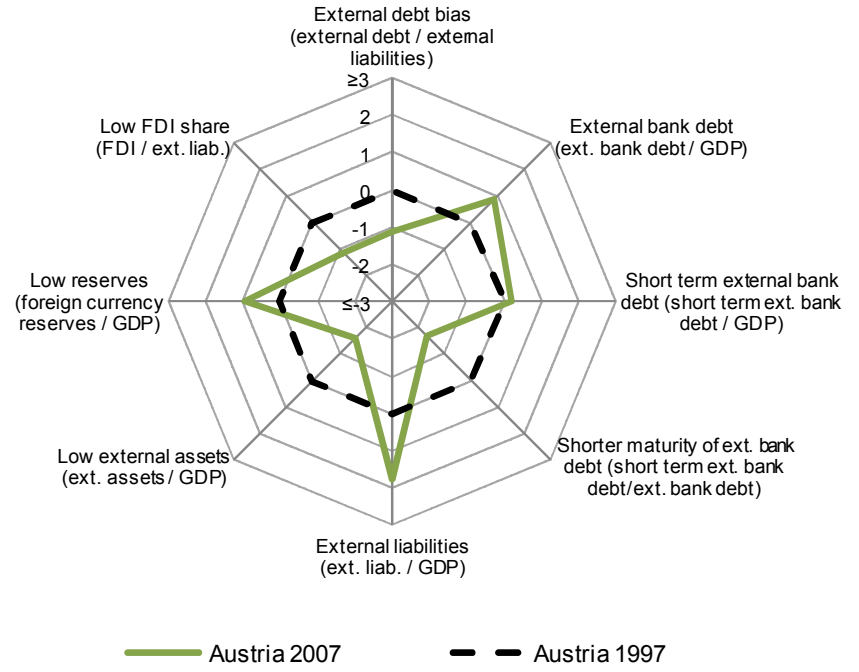

Each variable is presented in 2007 relative to the its situation in 1997 (which is normalised to zero).

Note: For each variable, a larger value indicates a riskier financial account position. Indicators are measured in multiples of the standard deviation across countries for the variable in question.

\section{Selected structural policies conducive to financial stability}

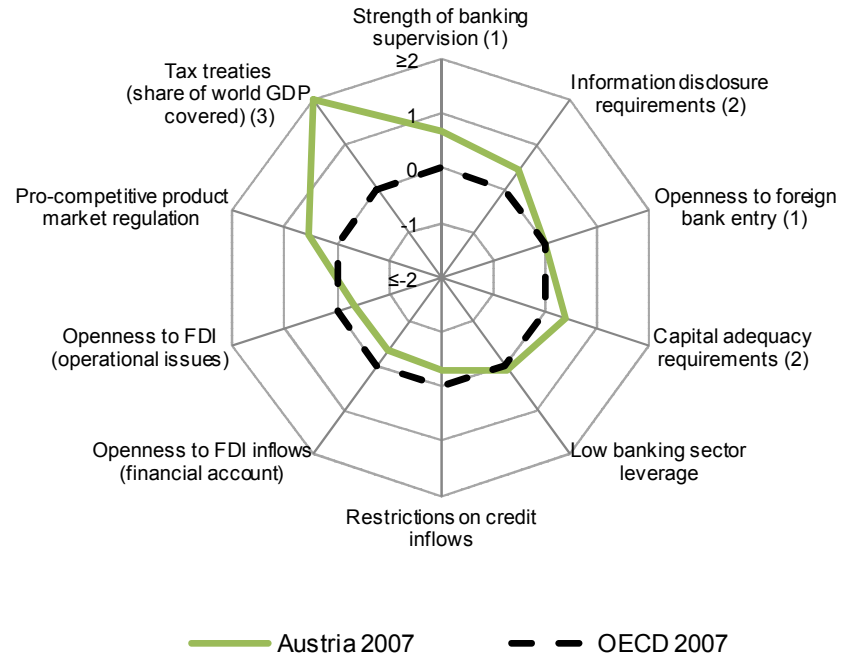

Note: For each variable, a larger value indicates a policy stance that is comparatively more conducive to financial stability. Indicators are measured in multiples of the standard deviation across countries for the variable in queation. Each variable is presented relative to the OECD average (which is normalised to zero).

(1) Last available data, 2005

(2) Last available data, 2006

(3) Last available data, 2002 


\section{BELGIUM}

\section{Financial account related risk factors to financial stability}

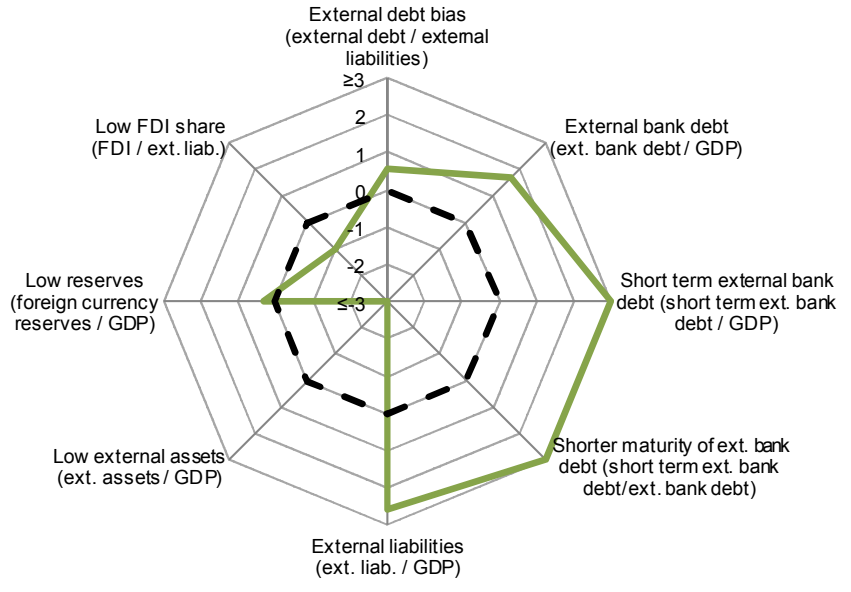

Belgium $2007 \quad$ - OECD 2007

Each variable is presented relative to the OECD median (which is normalised to zero).

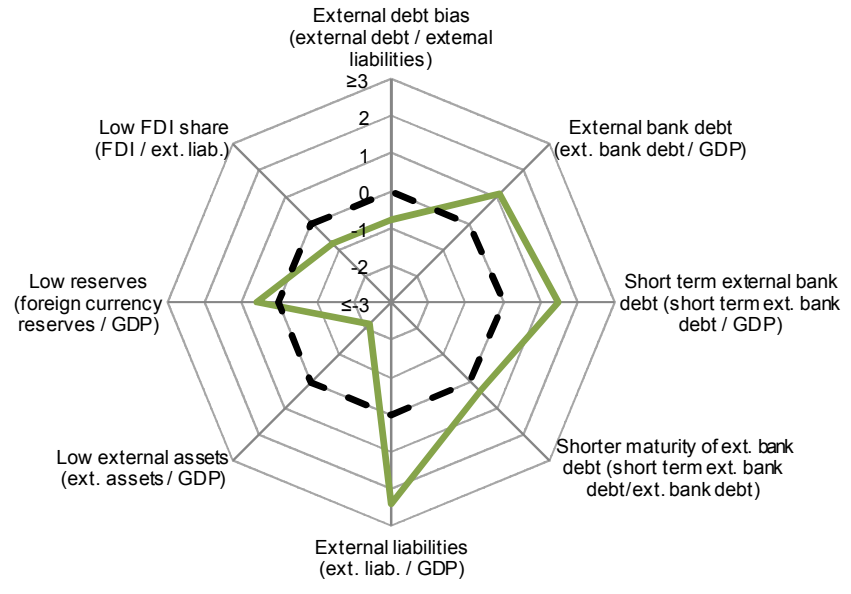

Each variable is presented in 2007 relative to the its situation in 1997 (which is normalised to zero).

Note: For each variable, a larger value indicates a riskier financial account position. Indicators are measured in multiples of the standard deviation across countries for the variable in question.

\section{Selected structural policies conducive to financial stability}

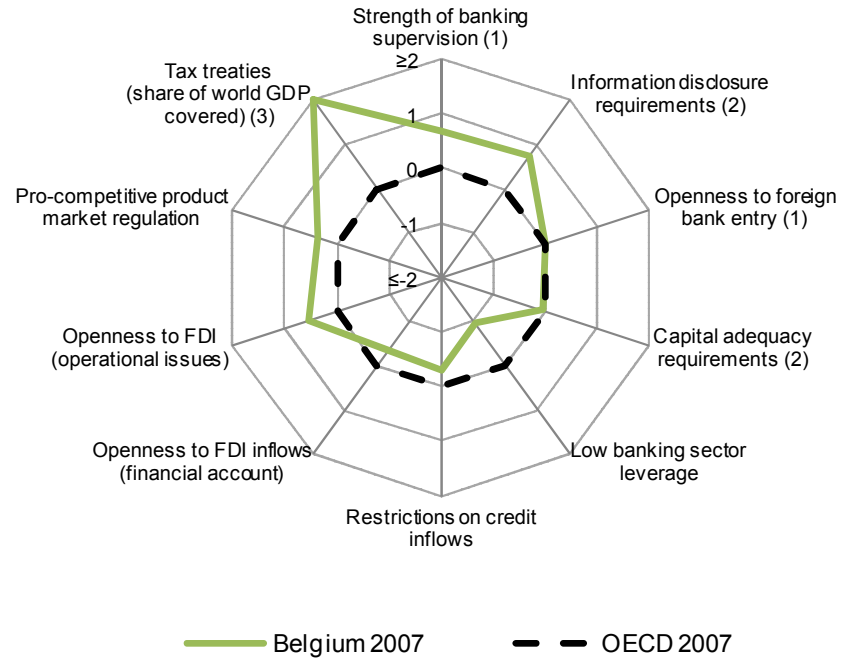

Note: For each variable, a larger value indicates a policy stance that is comparatively more conducive to financial stability. Indicators are measured in multiples of the standard deviation across countries for the variable in queation. Each variable is presented relative to the OECD average (which is normalised to zero).

(1) Last available data, 2005

(2) Last available data, 2006

(3) Last available data, 2002 


\section{BRAZIL}

\section{Financial account related risk factors to financial stability}

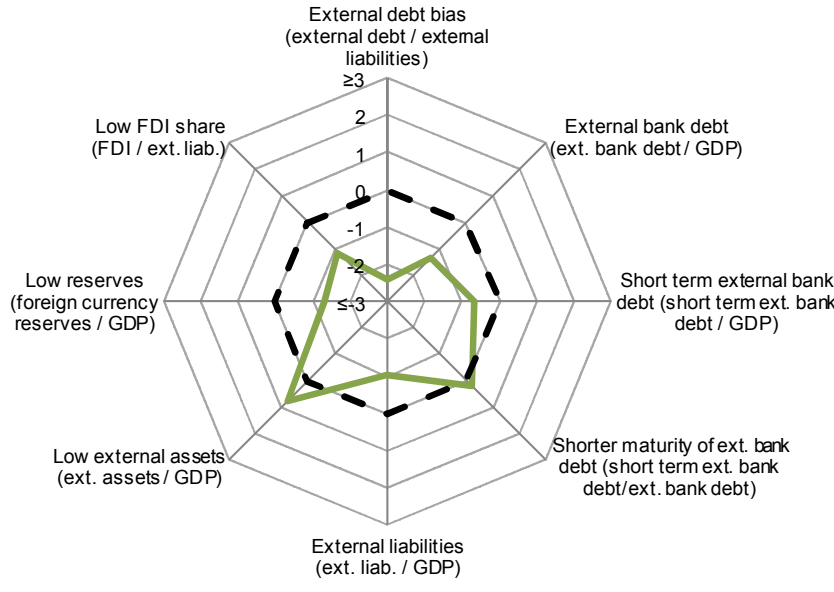

Brazil $2007 \quad-$ OECD 2007

Each variable is presented relative to the OECD median (which is normalised to zero).

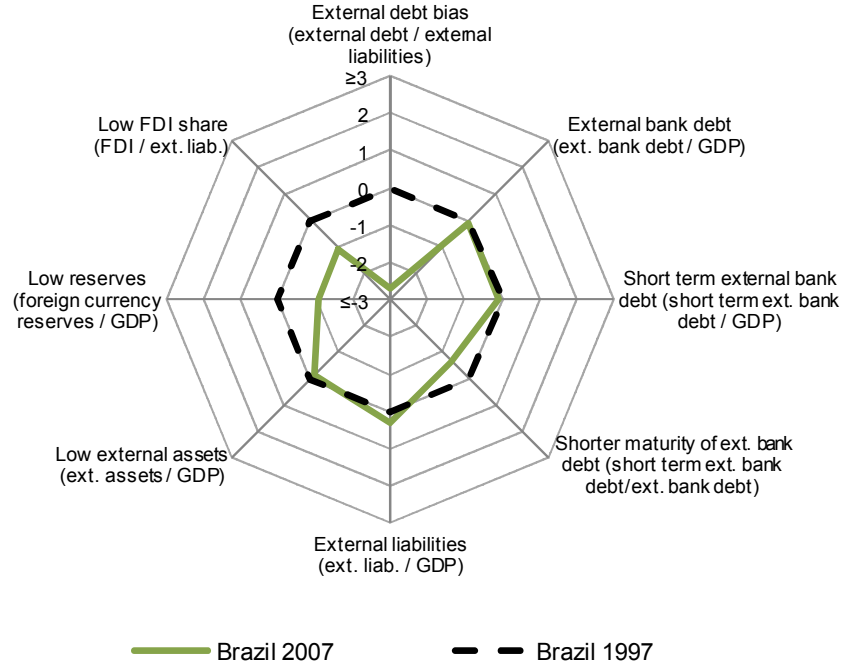

Each variable is presented in 2007 relative to the its situation in 1997 (which is normalised to zero).

Note: For each variable, a larger value indicates a riskier financial account position. Indicators are measured in multiples of the standard deviation across countries for the variable in question.

\section{Selected structural policies conducive to financial stability}

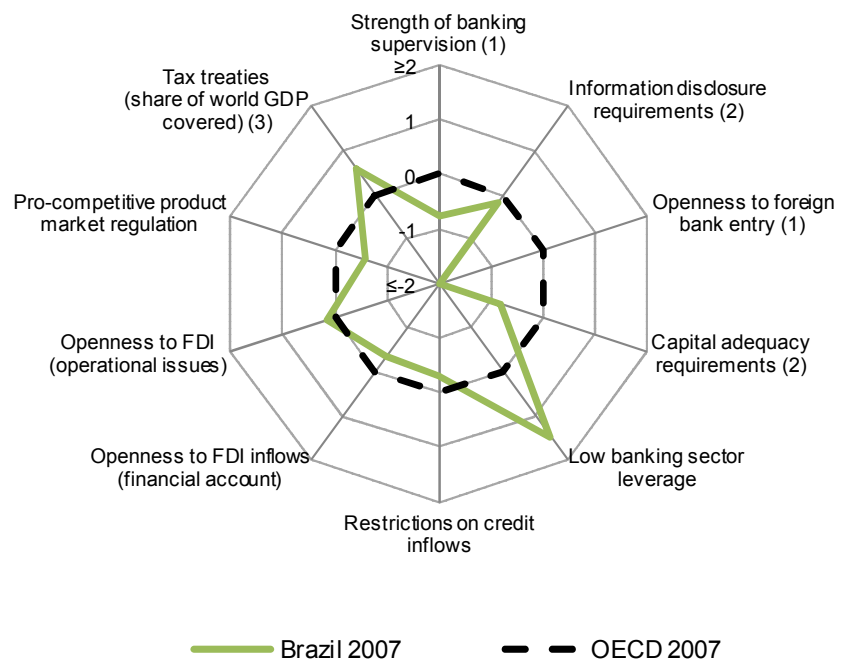

Note: For each variable, a larger value indicates a policy stance that is comparatively more conducive to financial stability. Indicators are measured in multiples of the standard deviation across countries for the variable in queation. Each variable is presented relative to the OECD average (which is normalised to zero).

(1) Last available data, 2005

(2) Last available data, 2006

(3) Last available data, 2002 


\section{CANADA}

\section{Financial account related risk factors to financial stability}

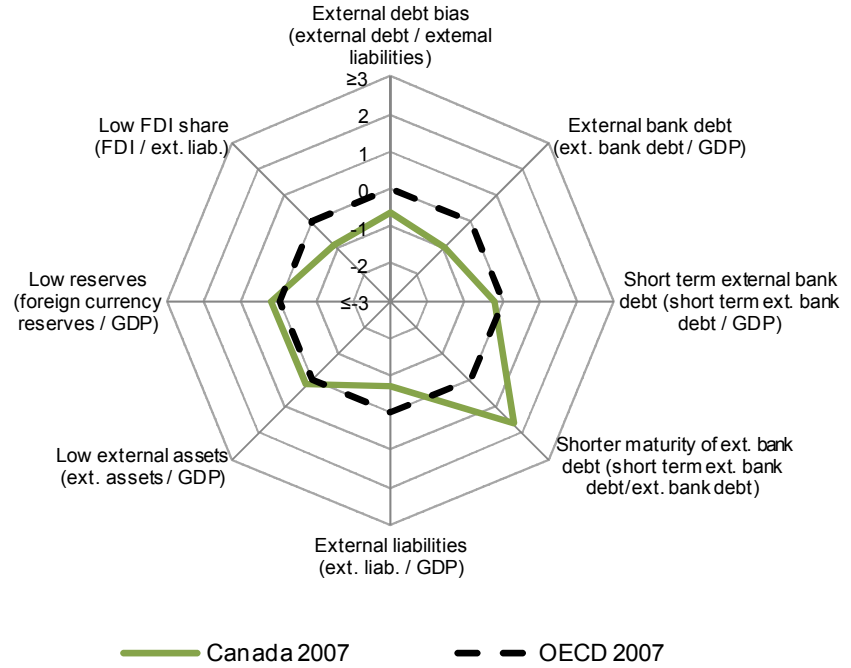

Each variable is presented relative to the OECD median (which is normalised to zero).

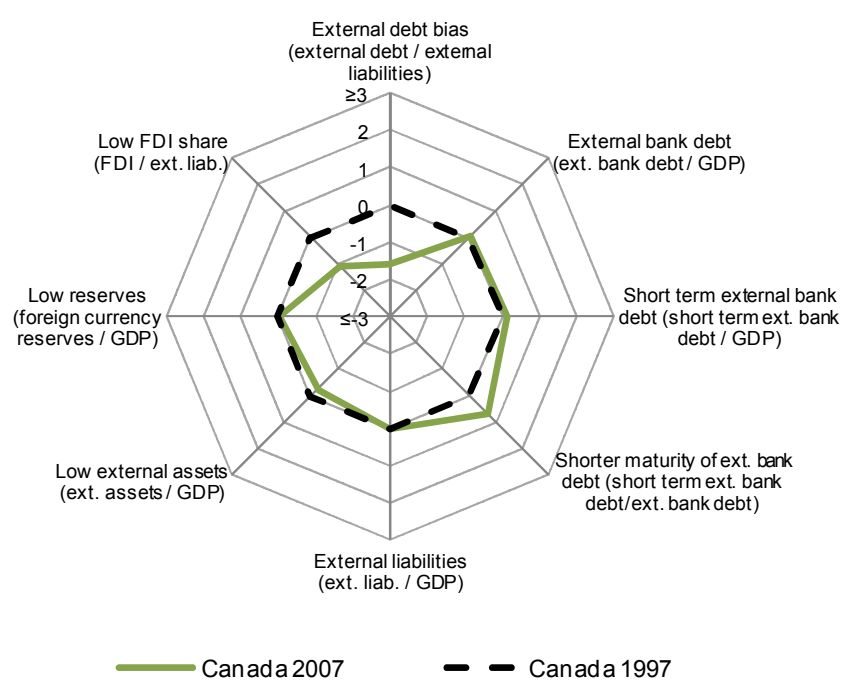

Each variable is presented in 2007 relative to the its situation in 1997 (which is normalised to zero).

Note: For each variable, a larger value indicates a riskier financial account position. Indicators are measured in multiples of the standard deviation across countries for the variable in question.

\section{Selected structural policies conducive to financial stability}

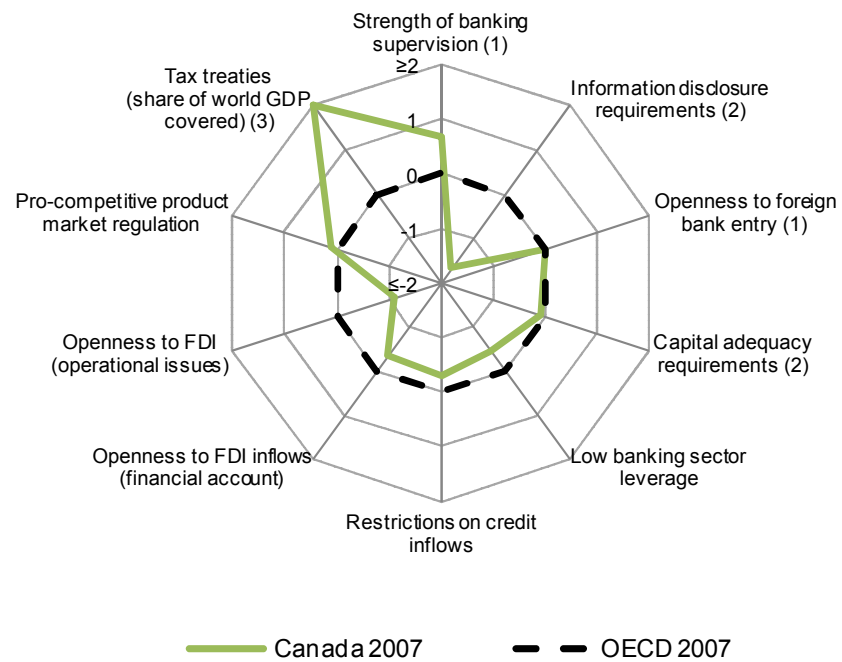

Note: For each variable, a larger value indicates a policy stance that is comparatively more conducive to financial stability. Indicators are measured in multiples of the standard deviation across countries for the variable in queation. Each variable is presented relative to the OECD average (which is normalised to zero).

(1) Last available data, 2005

(2) Last available data, 2006

(3) Last available data, 2002 


\section{CHILE}

\section{Financial account related risk factors to financial stability}

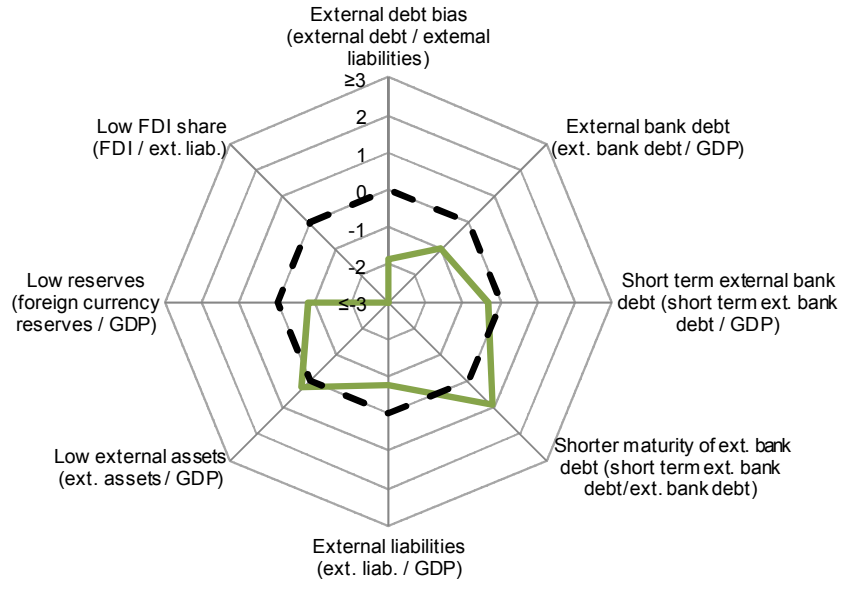

Chile $2007 \quad-$ OECD 2007

Each variable is presented relative to the OECD median (which is normalised to zero).

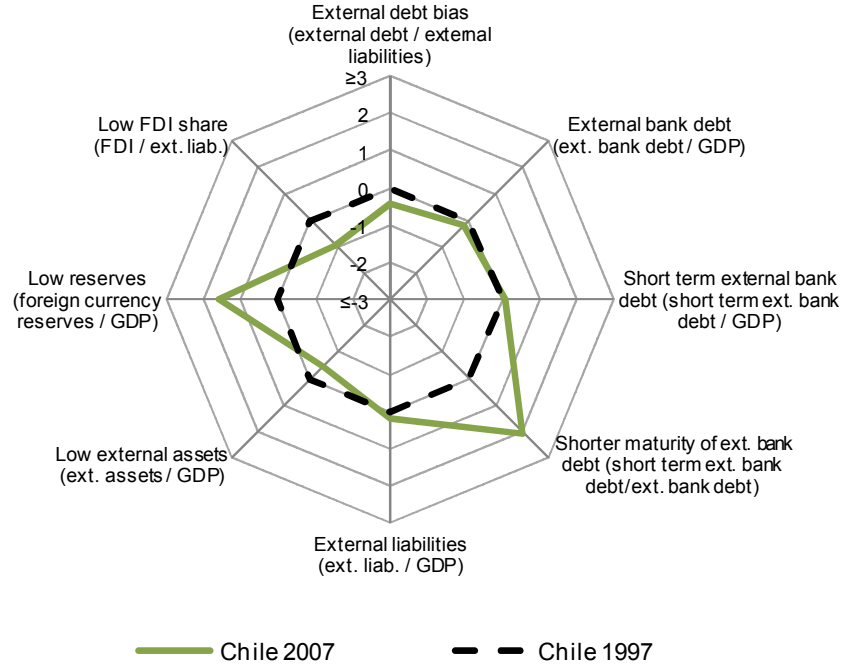

Each variable is presented in 2007 relative to the its situation in 1997 (which is normalised to zero).

Note: For each variable, a larger value indicates a riskier financial account position. Indicators are measured in multiples of the standard deviation across countries for the variable in question.

\section{Selected structural policies conducive to financial stability}

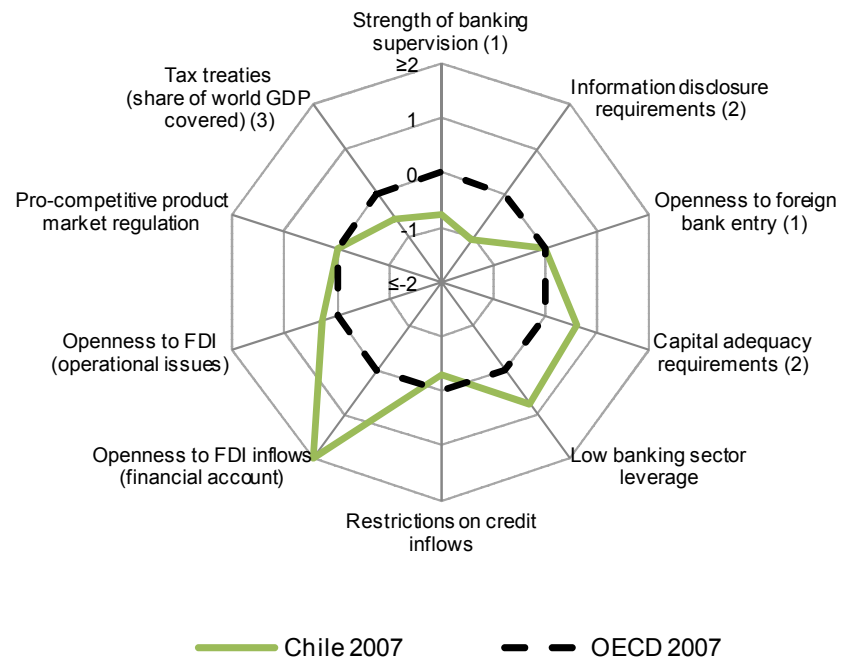

Note: For each variable, a larger value indicates a policy stance that is comparatively more conducive to financial stability. Indicators are measured in multiples of the standard deviation across countries for the variable in queation. Each variable is presented relative to the OECD average (which is normalised to zero).

(1) Last available data, 2005

(2) Last available data, 2006

(3) Last available data, 2002. 


\section{CHINA}

\section{Financial account related risk factors to financial stability}

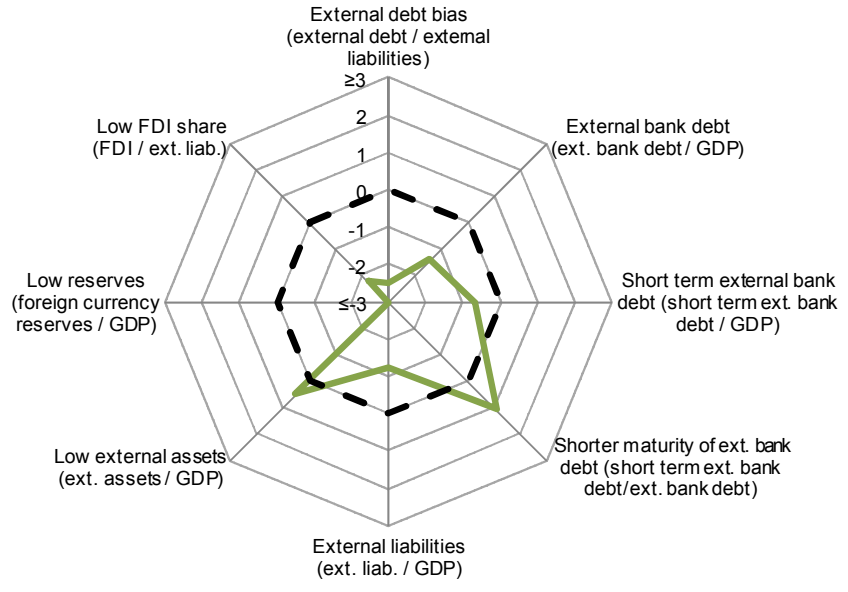

China 2007 - OECD 2007

Each variable is presented relative to the OECD median (which is normalised to zero).

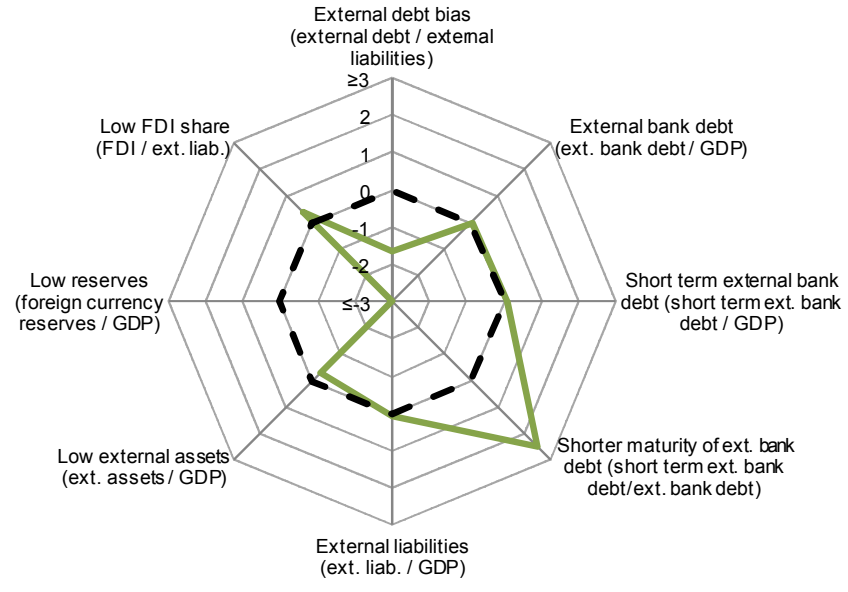

China $2007 \quad-$ China 1997

Each variable is presented in 2007 relative to the its situation in 1997 (which is normalised to zero).

Note: For each variable, a larger value indicates a riskier financial account position. Indicators are measured in multiples of the standard deviation across countries for the variable in question.

\section{Selected structural policies conducive to financial stability}
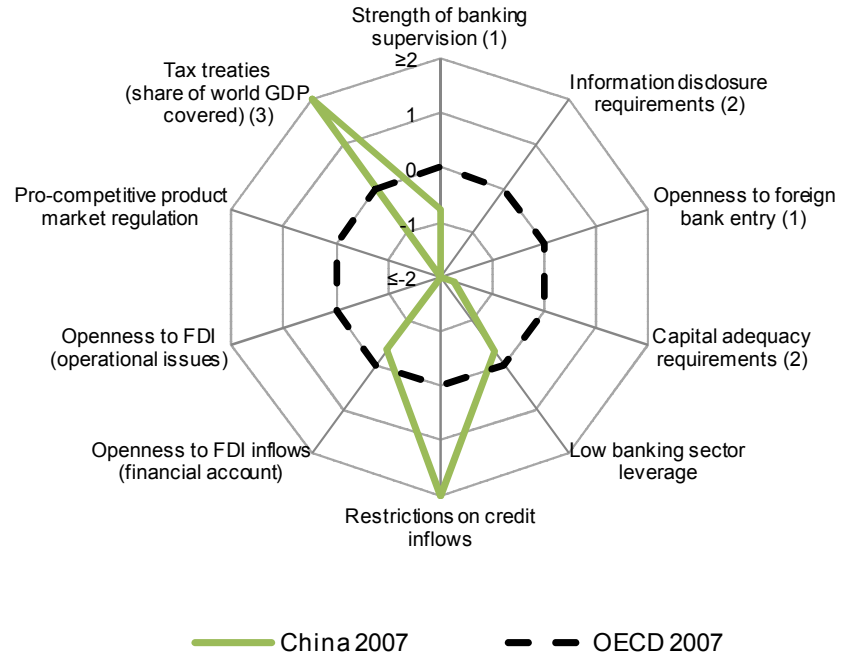

Note: For each variable, a larger value indicates a policy stance that is comparatively more conducive to financial stability. Indicators are measured in multiples of the standard deviation across countries for the variable in queation. Each variable is presented relative to the OECD average (which is normalised to zero).

(1) Last available data, 2005

(2) Last available data, 2006

(3) Last available data, 2002 


\section{CZECH REPUBLIC}

\section{Financial account related risk factors to financial stability}

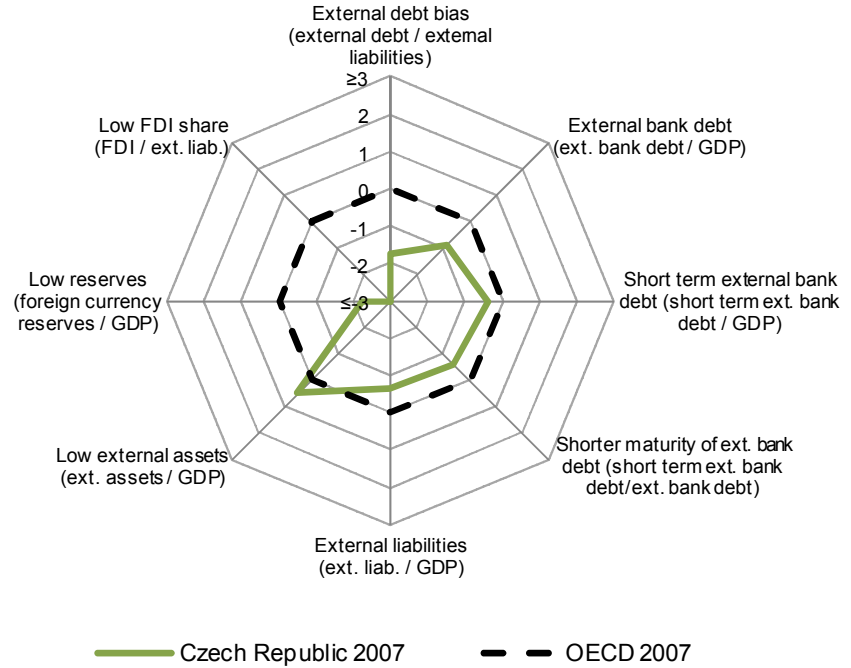

Each variable is presented relative to the OECD median (which is normalised to zero).

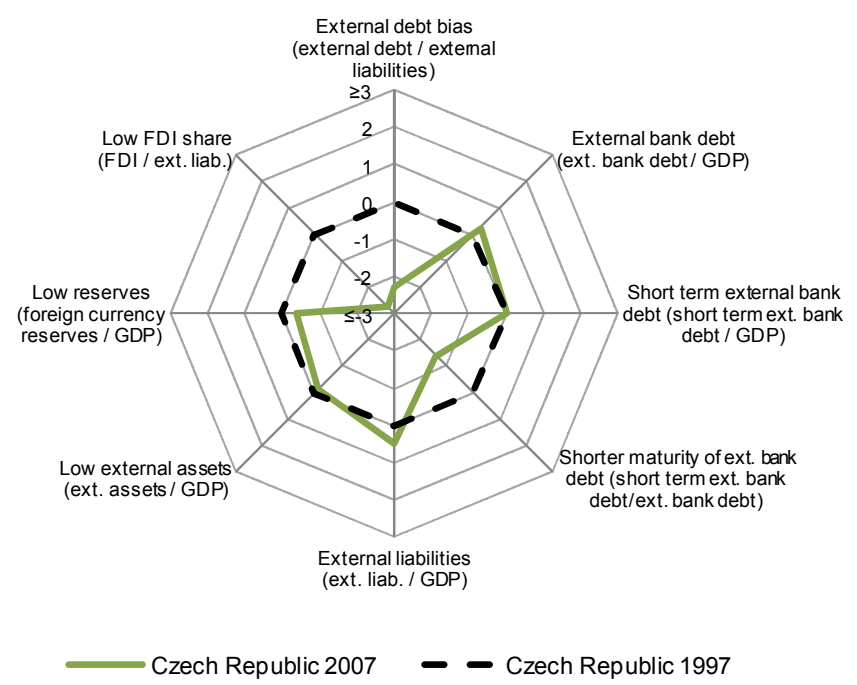

Each variable is presented in 2007 relative to the its situation in 1997 (which is normalised to zero).

Note: For each variable, a larger value indicates a riskier financial account position. Indicators are measured in multiples of the standard deviation across countries for the variable in question.

\section{Selected structural policies conducive to financial stability}

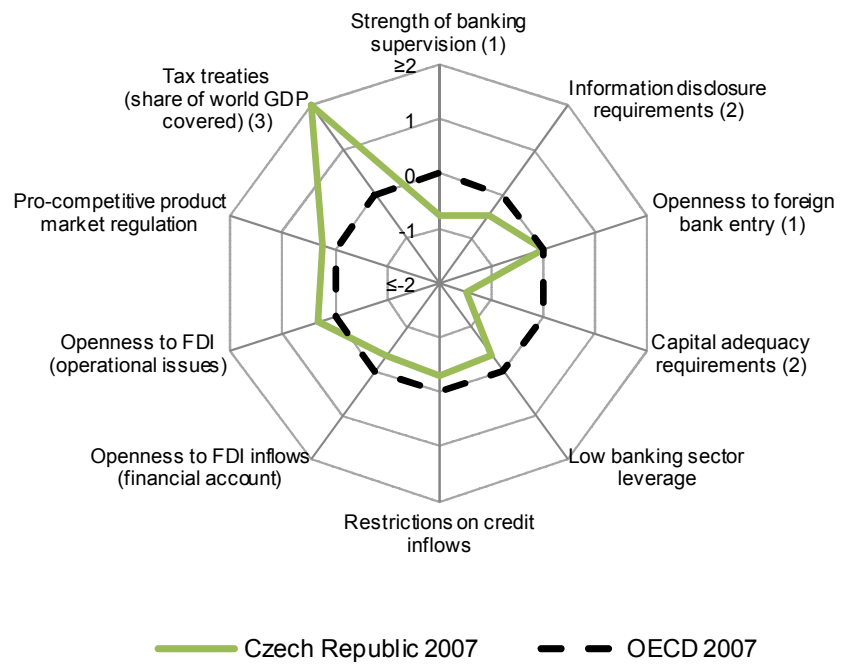

Note: For each variable, a larger value indicates a policy stance that is comparatively more conducive to financial stability. Indicators are measured in multiples of the standard deviation across countries for the variable in queation. Each variable is presented relative to the OECD average (which is normalised to zero).

(1) Last available data, 2005

(2) Last available data, 2006

(3) Last available data, 2002 


\section{DENMARK}

\section{Financial account related risk factors to financial stability}

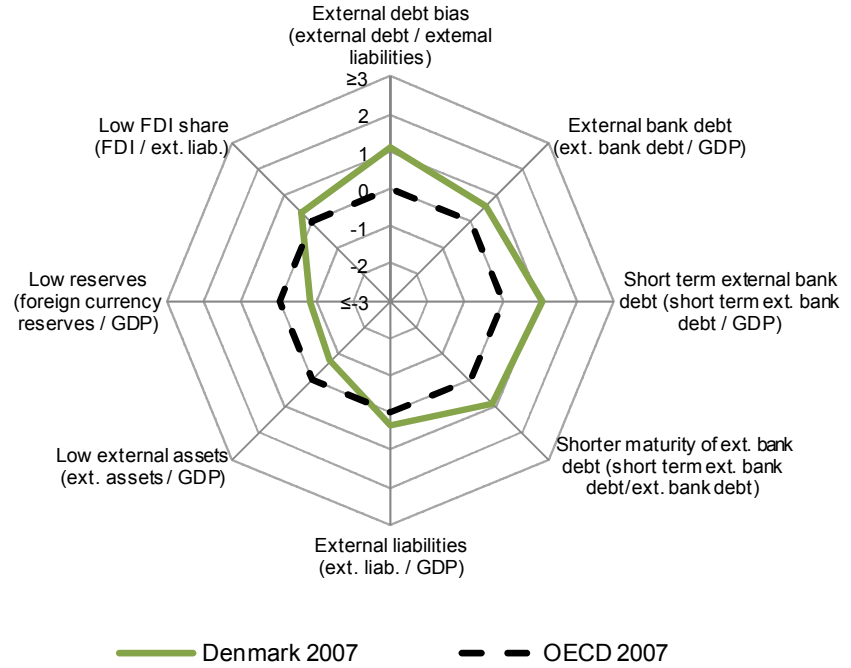

Each variable is presented relative to the OECD median (which is normalised to zero).

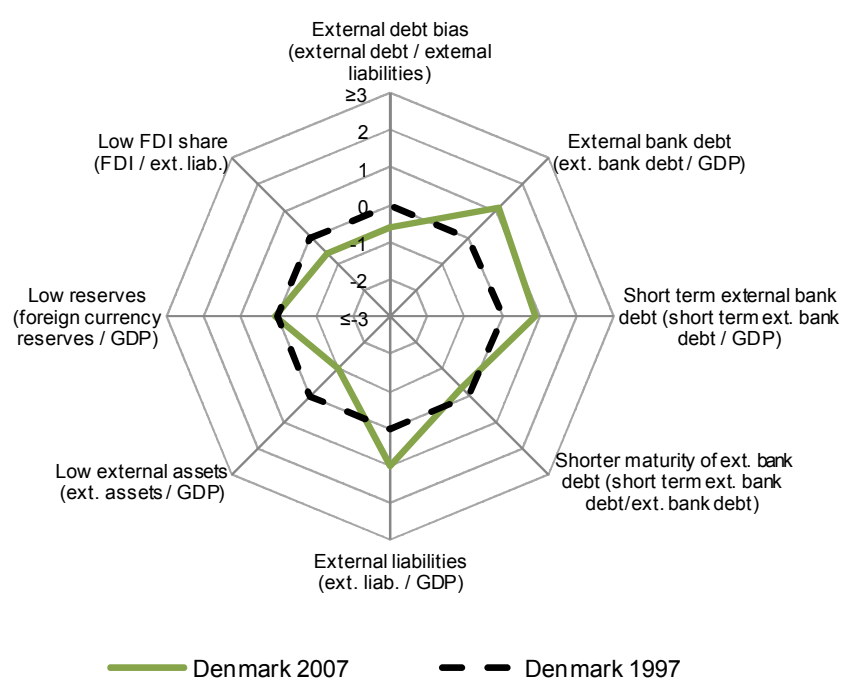

Each variable is presented in 2007 relative to the its situation in 1997 (which is normalised to zero).

Note: For each variable, a larger value indicates a riskier financial account position. Indicators are measured in multiples of the standard deviation across countries for the variable in question.

\section{Selected structural policies conducive to financial stability}

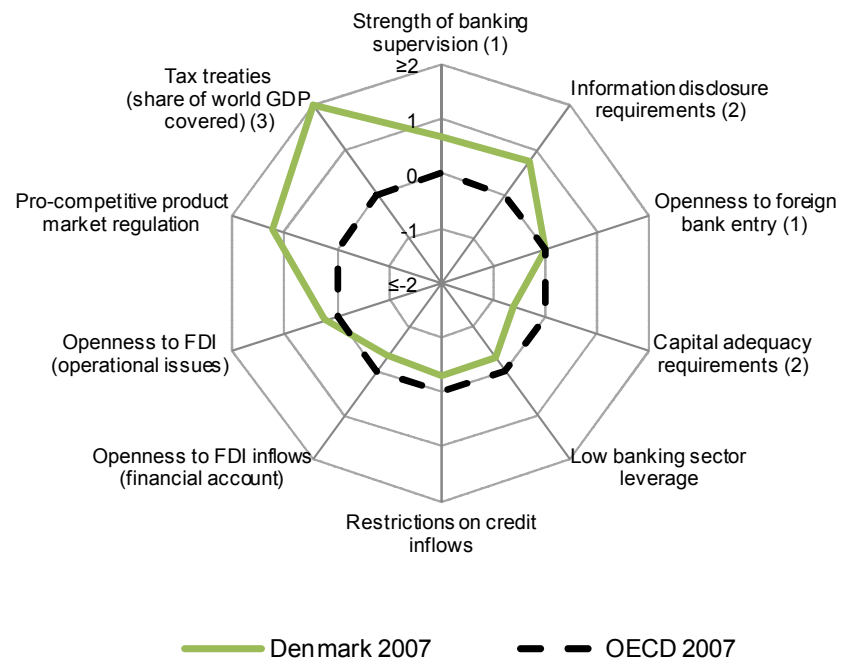

Note: For each variable, a larger value indicates a policy stance that is comparatively more conducive to financial stability. Indicators are measured in multiples of the standard deviation across countries for the variable in queation. Each variable is presented relative to the OECD average (which is normalised to zero).

(1) Last available data, 2005

(2) Last available data, 2006

(3) Last available data, 2002 


\section{ESTONIA}

\section{Financial account related risk factors to financial stability}

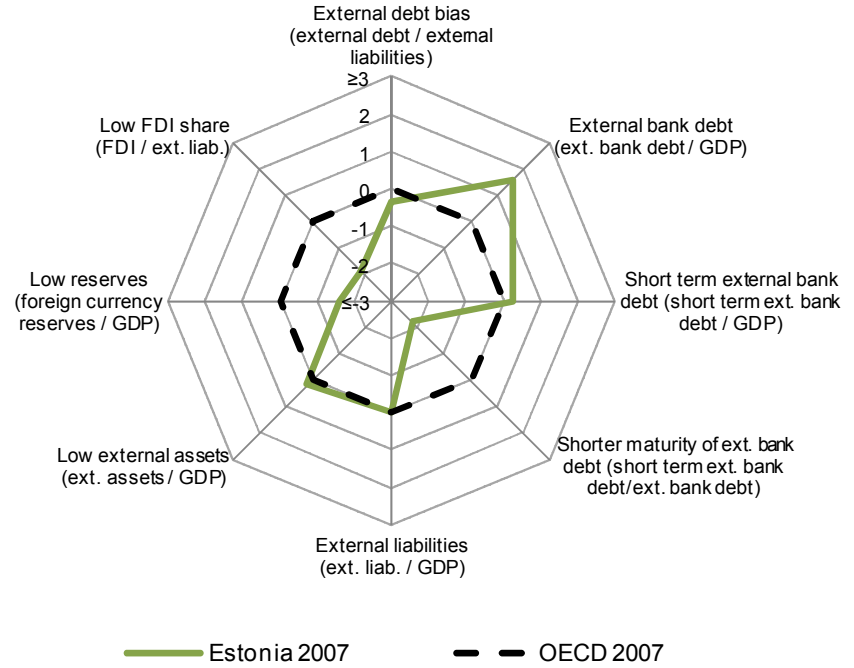

Each variable is presented relative to the OECD median (which is normalised to zero).

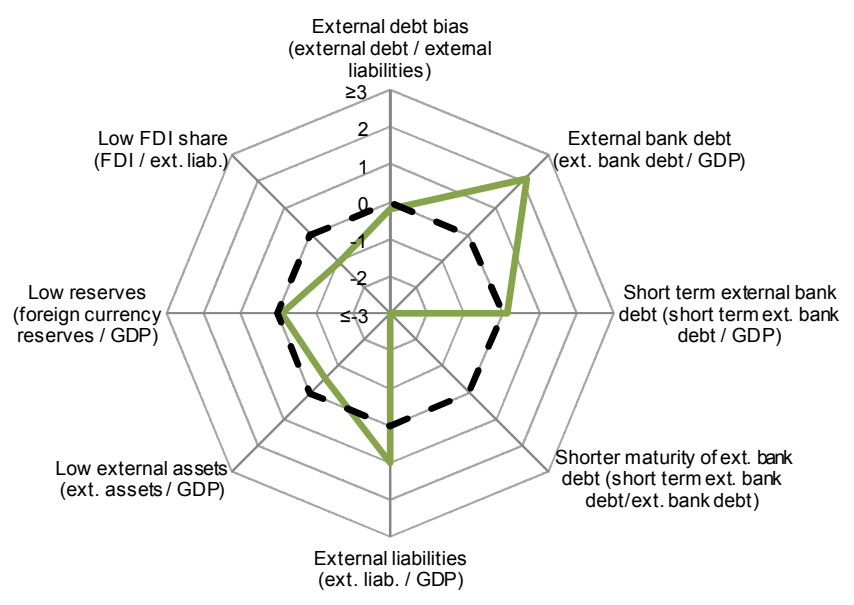

Each variable is presented in 2007 relative to the its situation in 1997 (which is normalised to zero).

Note: For each variable, a larger value indicates a riskier financial account position. Indicators are measured in multiples of the standard deviation across countries for the variable in question.

\section{Selected structural policies conducive to financial stability}

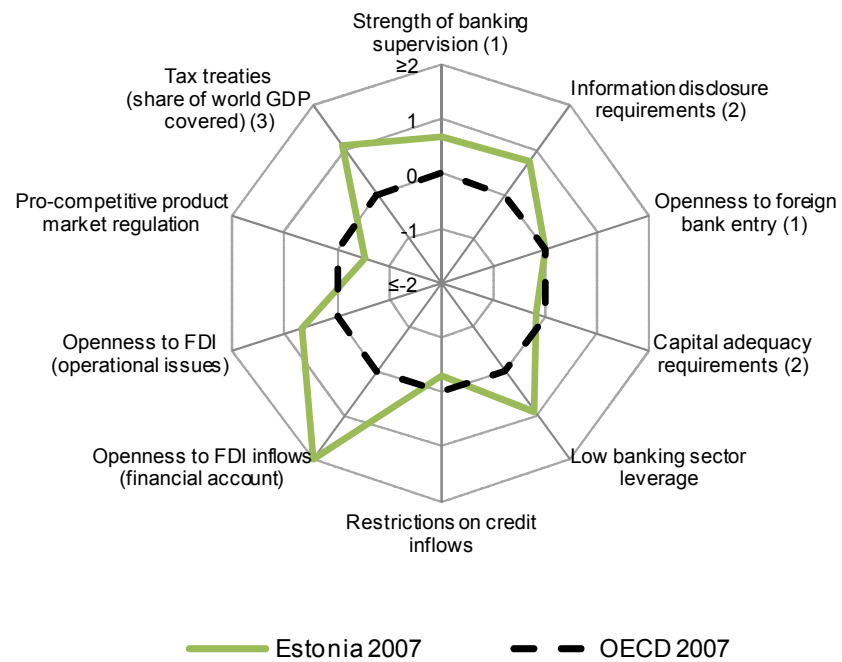

Note: For each variable, a larger value indicates a policy stance that is comparatively more conducive to financial stability. Indicators are measured in multiples of the standard deviation across countries for the variable in queation. Each variable is presented relative to the OECD average (which is normalised to zero).
(1) Last available data, 2005
(2) Last available data, 2006
(3) Last available data, 2002 


\section{FINLAND}

\section{Financial account related risk factors to financial stability}

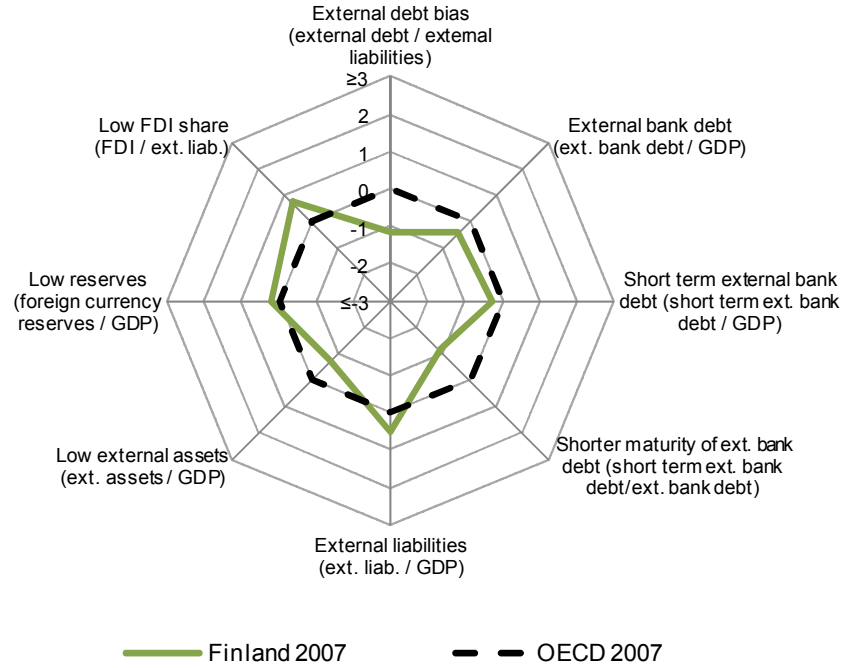

Each variable is presented relative to the OECD median (which is normalised to zero).

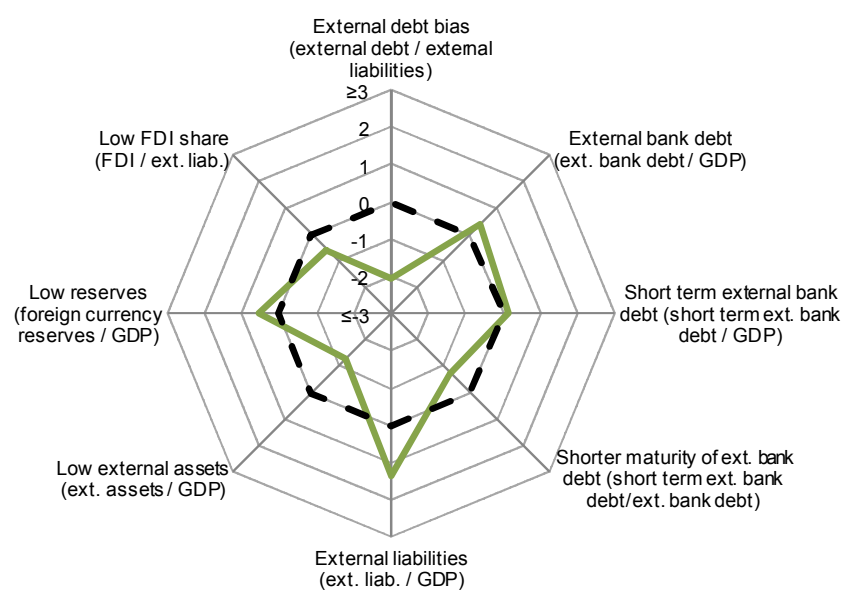

Each variable is presented in 2007 relative to the its situation in 1997 (which is normalised to zero).

Note: For each variable, a larger value indicates a riskier financial account position. Indicators are measured in multiples of the standard deviation across countries for the variable in question.

\section{Selected structural policies conducive to financial stability}

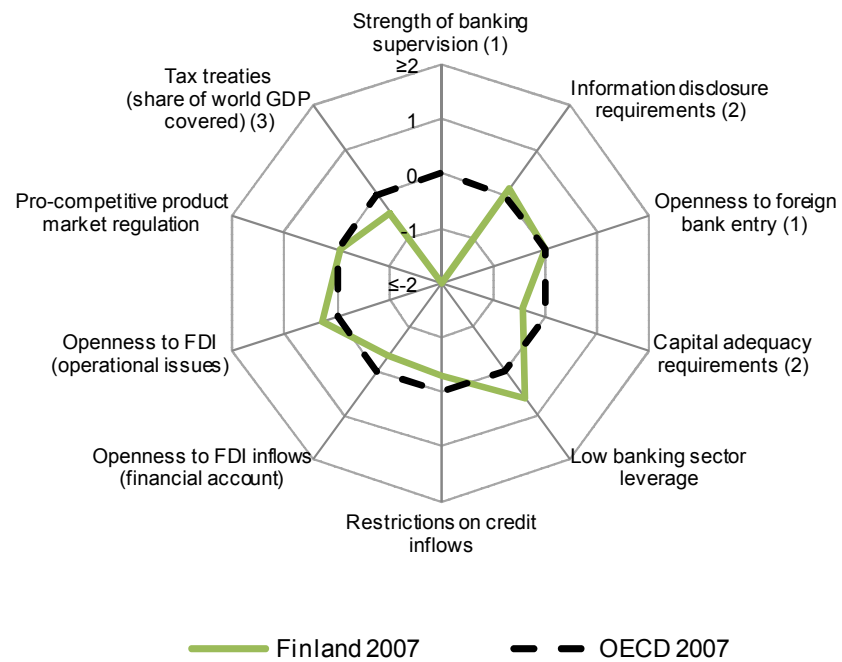

Note: For each variable, a larger value indicates a policy stance that is comparatively more conducive to financial stability. Indicators are measured in multiples of the standard deviation across countries for the variable in queation. Each variable is presented relative to the OECD average (which is normalised to zero).

(1) Last available data, 2005

(2) Last available data, 2006

(3) Last available data, 2002. 


\section{FRANCE}

\section{Financial account related risk factors to financial stability}

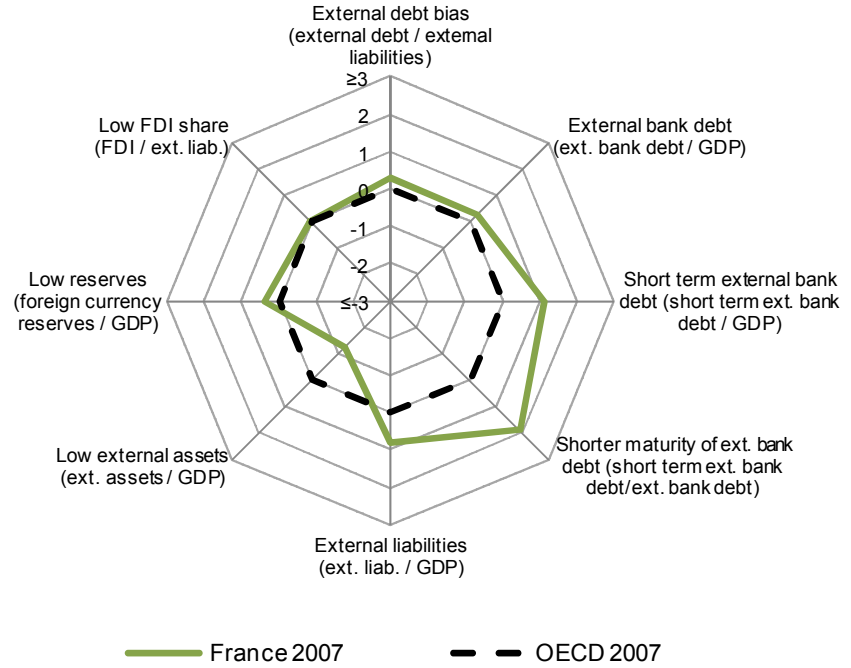

Each variable is presented relative to the OECD median (which is normalised to zero).

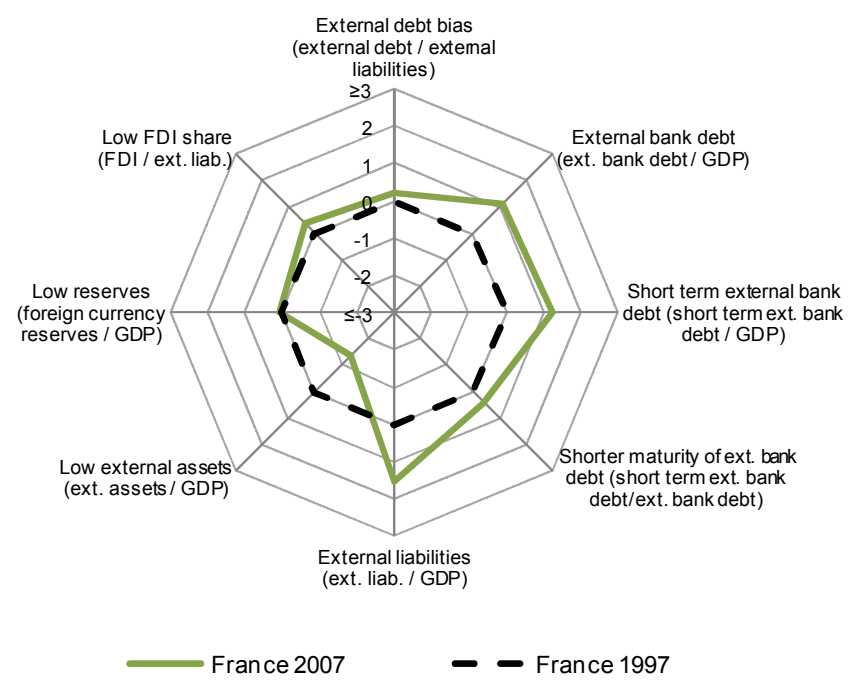

Each variable is presented in 2007 relative to the its situation in 1997 (which is normalised to zero).

Note: For each variable, a larger value indicates a riskier financial account position. Indicators are measured in multiples of the standard deviation across countries for the variable in question.

\section{Selected structural policies conducive to financial stability}
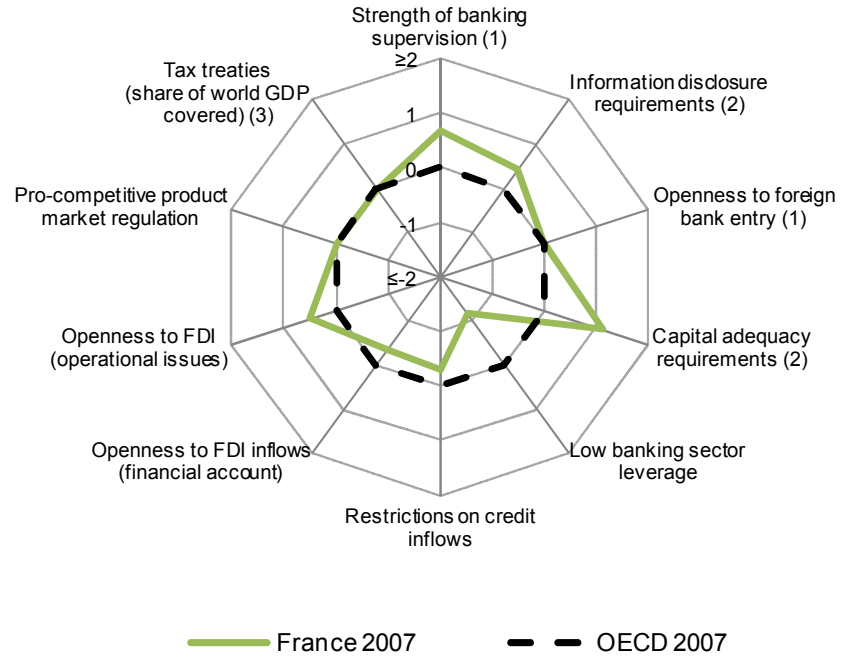

Note: For each variable, a larger value indicates a policy stance that is comparatively more conducive to financial stability. Indicators are measured in multiples of the standard deviation across countries for the variable in queation. Each variable is presented relative to the OECD average (which is normalised to zero).

(1) Last available data, 2005

(2) Last available data, 2006

(3) Last available data, 2002 


\section{GERMANY}

\section{Financial account related risk factors to financial stability}

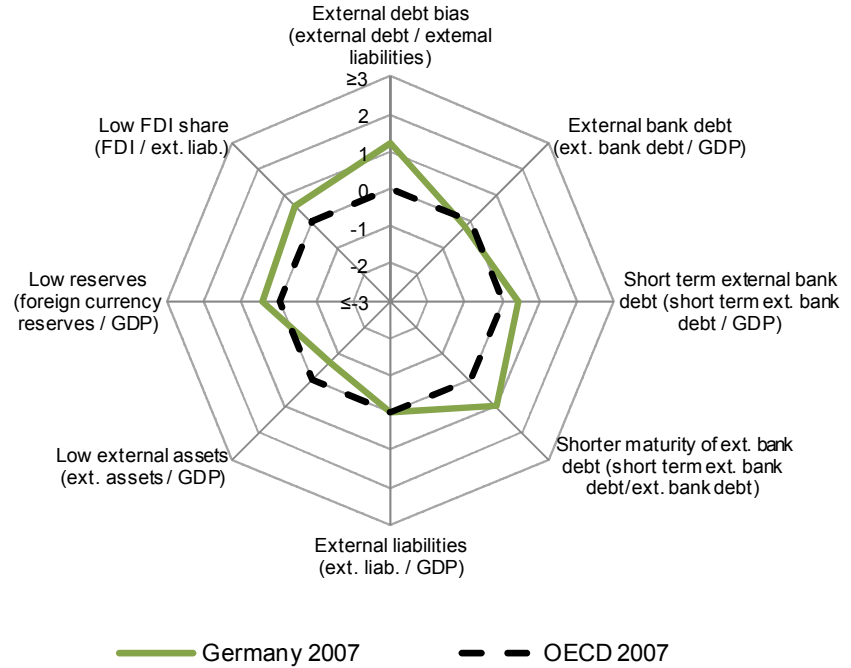

Each variable is presented relative to the OECD median (which is normalised to zero).

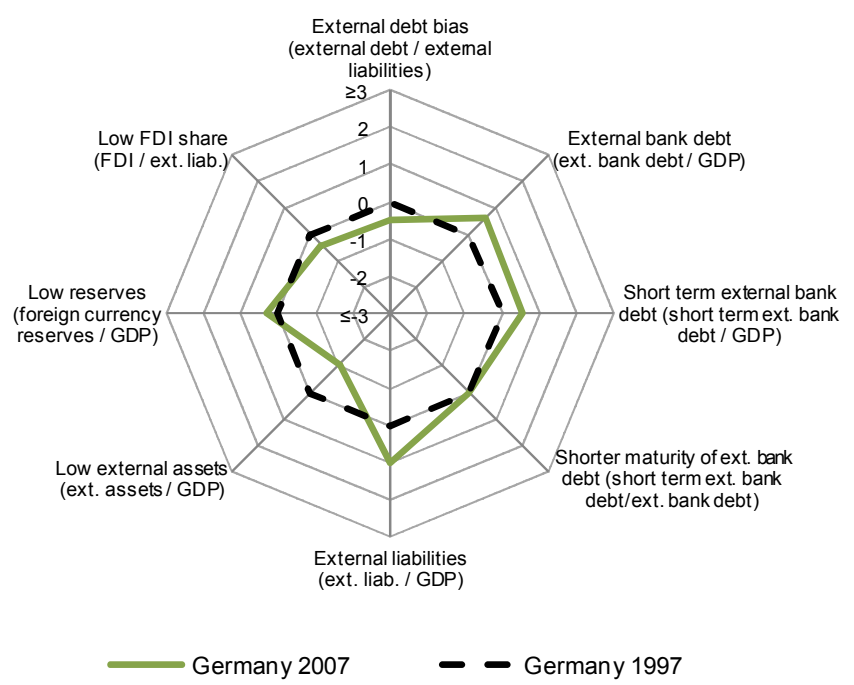

Each variable is presented in 2007 relative to the its situation in 1997 (which is normalised to zero).

Note: For each variable, a larger value indicates a riskier financial account position. Indicators are measured in multiples of the standard deviation across countries for the variable in question.

\section{Selected structural policies conducive to financial stability}

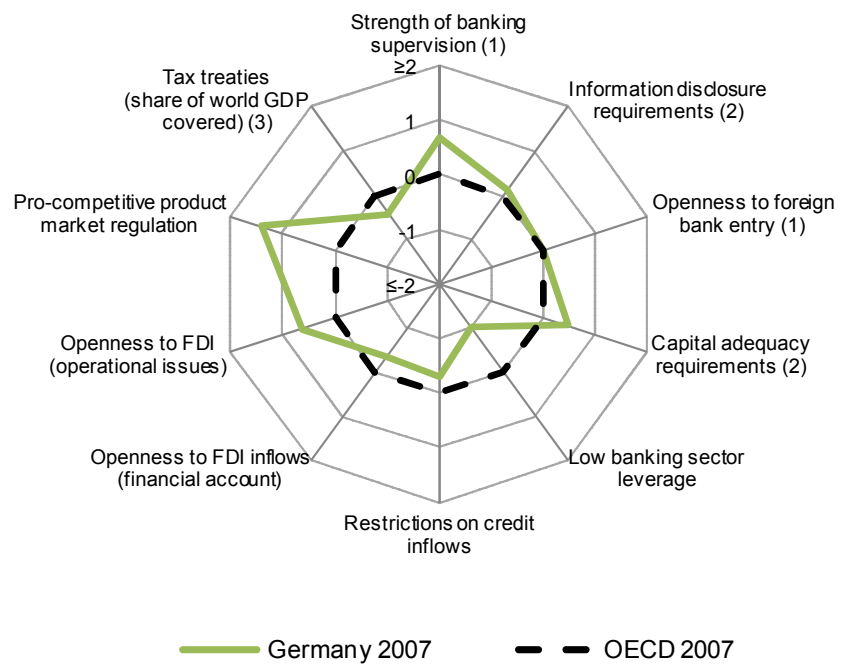

Note: For each variable, a larger value indicates a policy stance that is comparatively more conducive to financial stability. Indicators are measured in multiples of the standard deviation across countries for the variable in queation. Each variable is presented relative to the OECD average (which is normalised to zero).

(1) Last available data, 2005

(2) Last available data, 2006

(3) Last available data, 2002. 


\section{GREECE}

\section{Financial account related risk factors to financial stability}

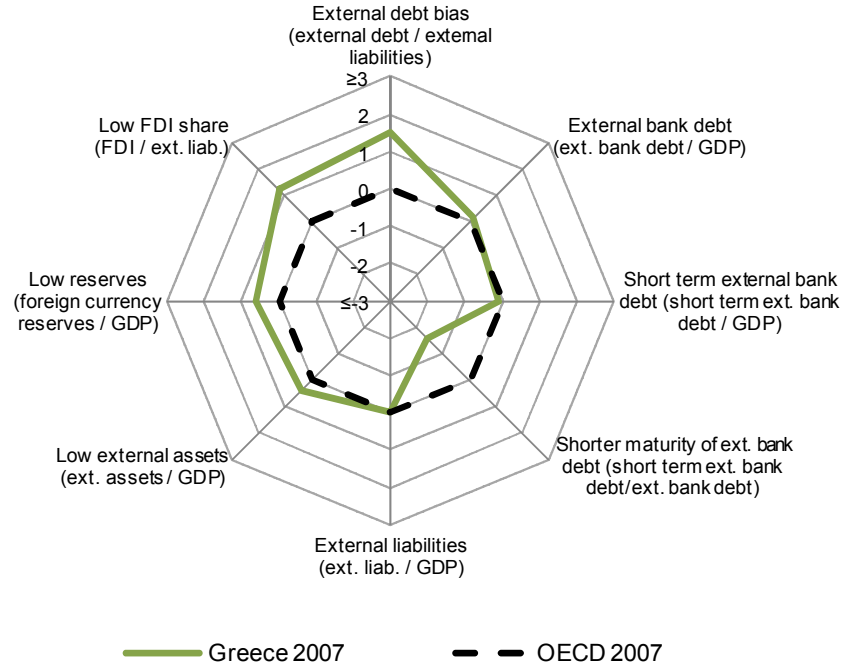

Each variable is presented relative to the OECD median (which is normalised to zero).

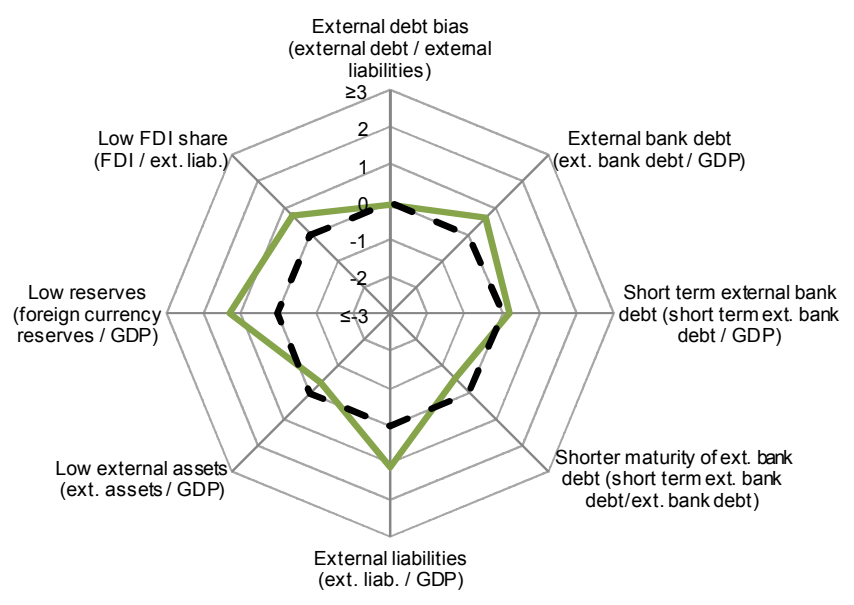

Each variable is presented in 2007 relative to the its situation in 1997 (which is normalised to zero).

Note: For each variable, a larger value indicates a riskier financial account position. Indicators are measured in multiples of the standard deviation across countries for the variable in question.

\section{Selected structural policies conducive to financial stability}

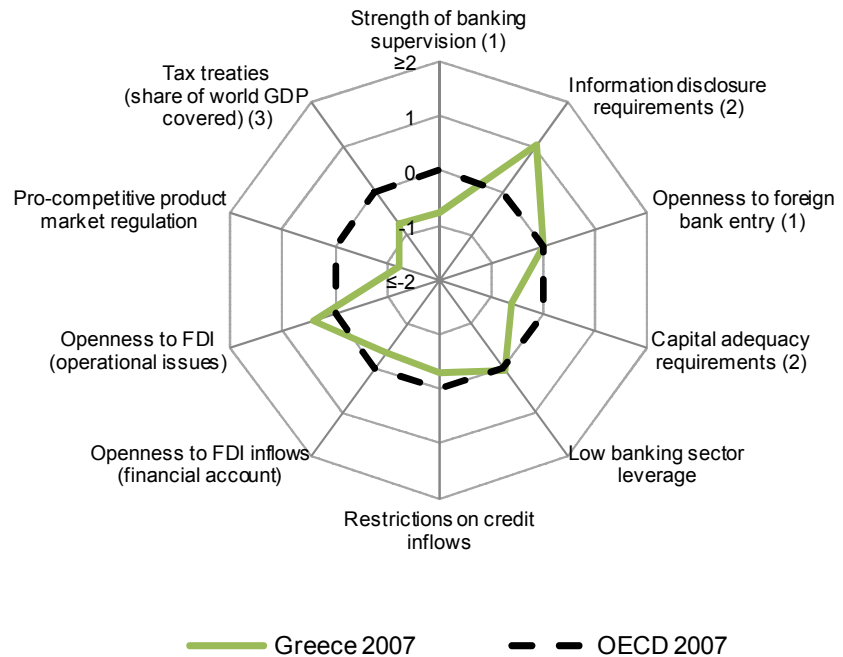

Note: For each variable, a larger value indicates a policy stance that is comparatively more conducive to financial stability. Indicators are measured in multiples of the standard deviation across countries for the variable in queation. Each variable is presented relative to the OECD average (which is normalised to zero).

(1) Last available data, 2005

(2) Last available data, 2006

(3) Last available data, 2002 


\section{HUNGARY}

\section{Financial account related risk factors to financial stability}

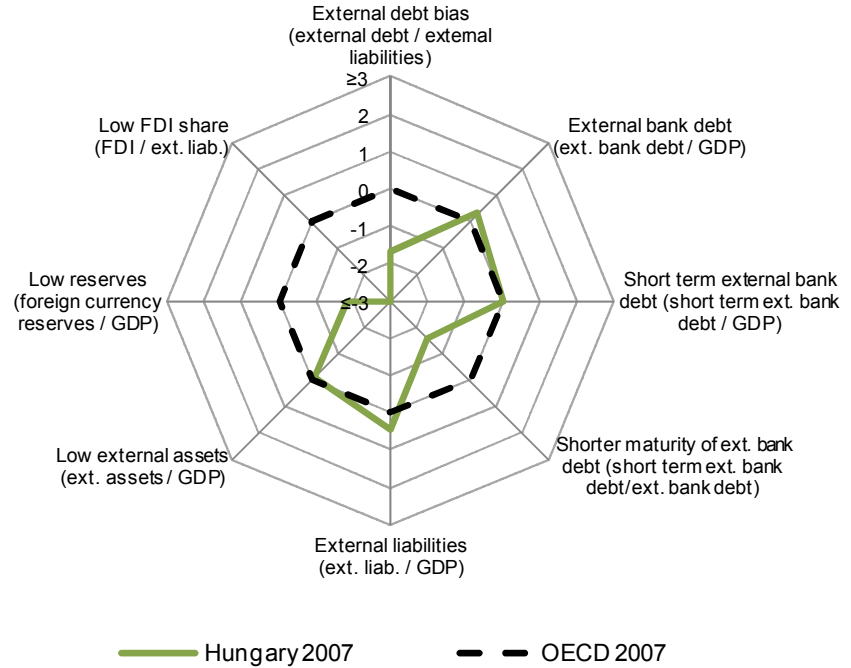

Each variable is presented relative to the OECD median (which is normalised to zero).

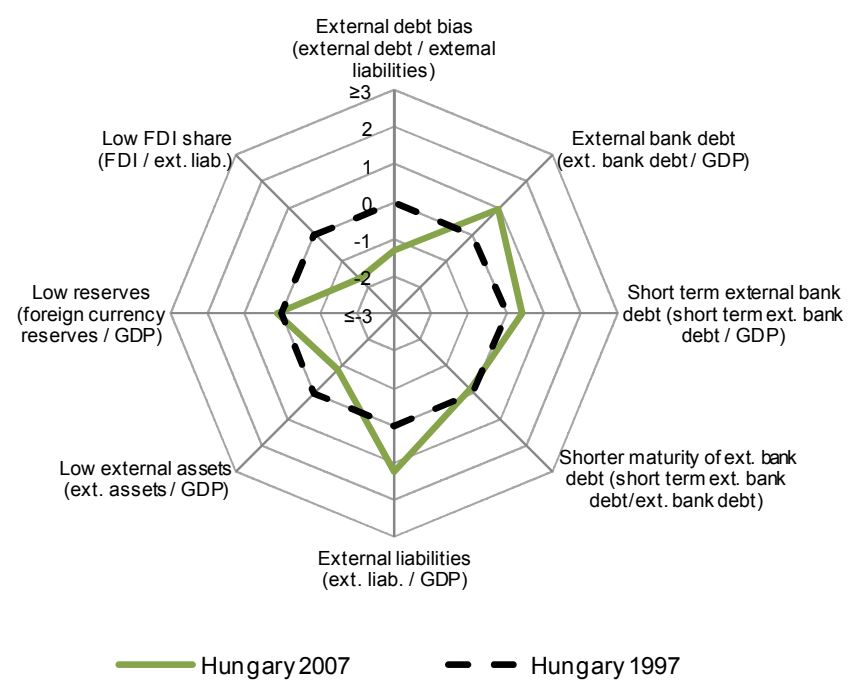

Each variable is presented in 2007 relative to the its situation in 1997 (which is normalised to zero).

Note: For each variable, a larger value indicates a riskier financial account position. Indicators are measured in multiples of the standard deviation across countries for the variable in question.

\section{Selected structural policies conducive to financial stability}

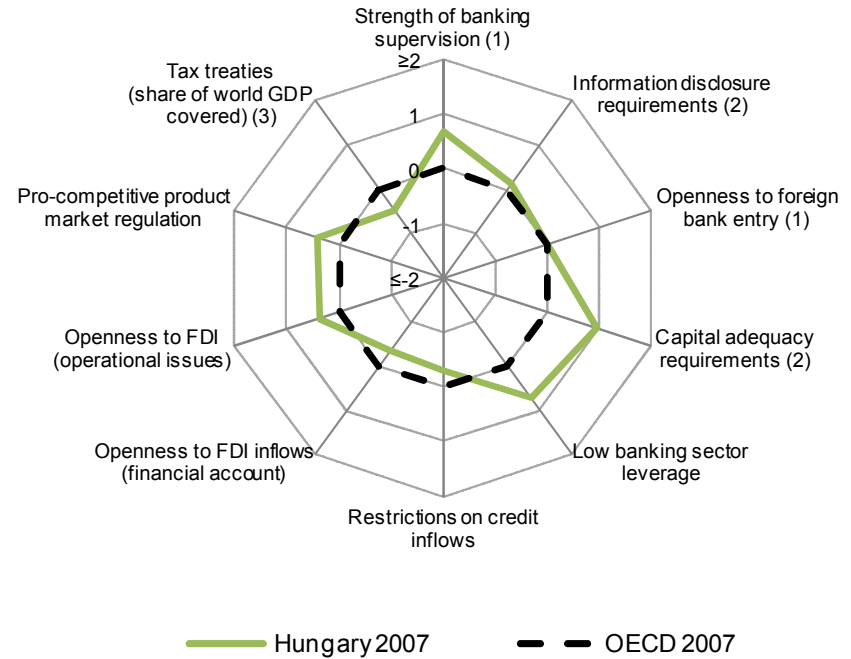

Note: For each variable, a larger value indicates a policy stance that is comparatively more conducive to financial stability. Indicators are measured in multiples of the standard deviation across countries for the variable in queation. Each variable is presented relative to the OECD average (which is normalised to zero).

(1) Last available data, 2005

(2) Last available data, 2006

(3) Last available data, 2002 


\section{ICELAND}

\section{Financial account related risk factors to financial stability}

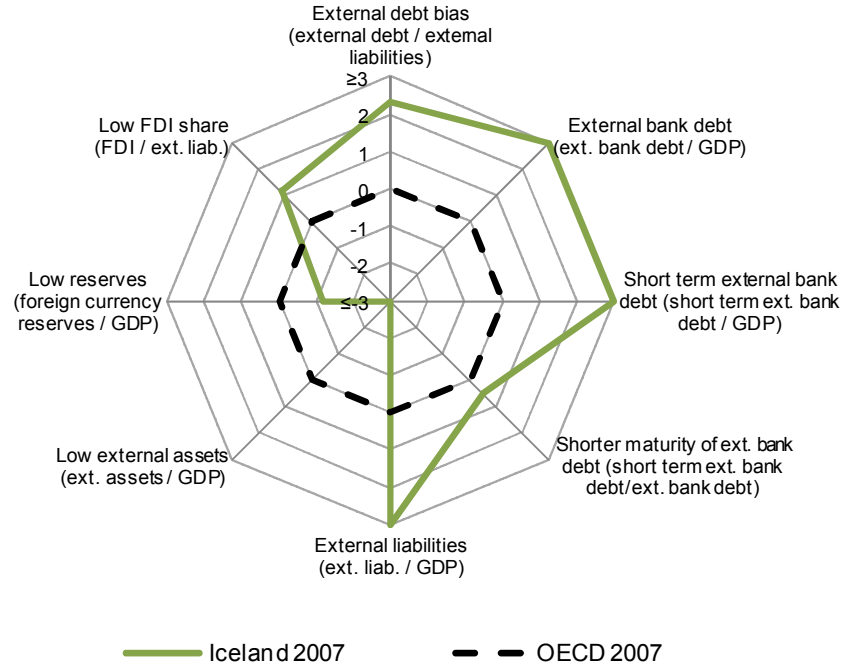

Each variable is presented relative to the OECD median (which is normalised to zero).

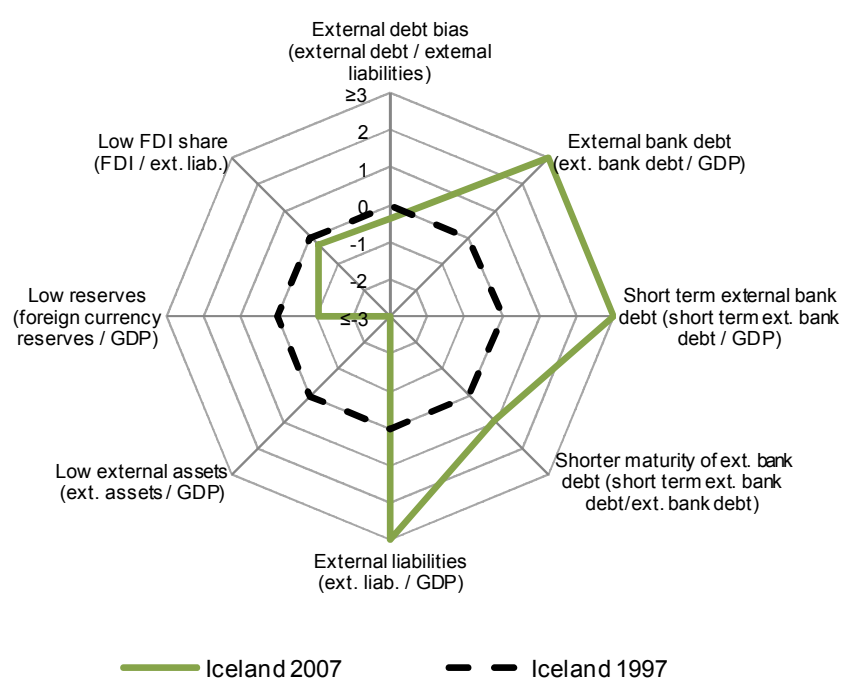

Each variable is presented in 2007 relative to the its situation in 1997 (which is normalised to zero).

Note: For each variable, a larger value indicates a riskier financial account position. Indicators are measured in multiples of the standard deviation across countries for the variable in question.

\section{Selected structural policies conducive to financial stability}

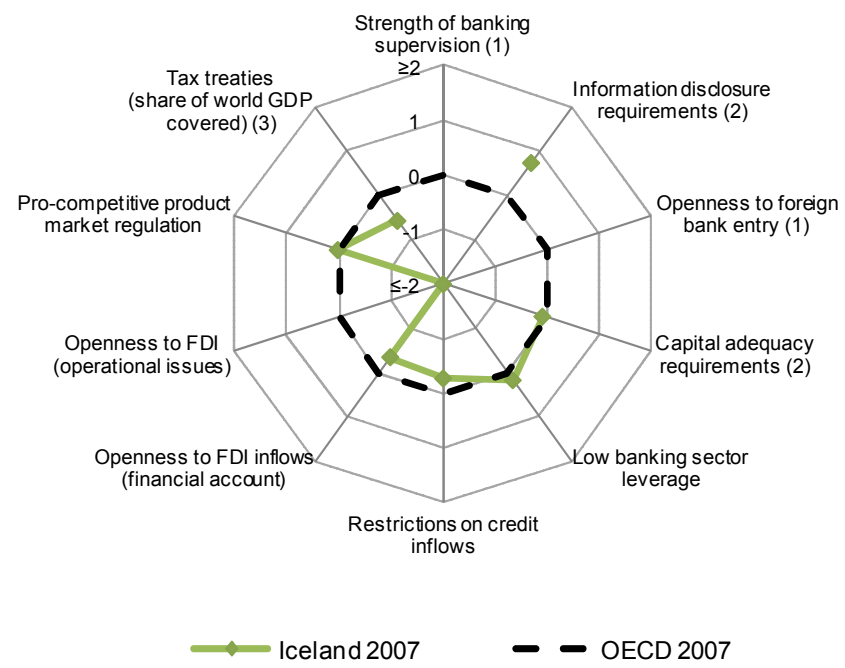

Note: For each variable, a larger value indicates a policy stance that is comparatively more conducive to financial stability. Indicators are measured in multiples of the standard deviation across countries for the variable in queation. Each variable is presented relative to the OECD average (which is normalised to zero).

(1) No data available for the country.

(2) Last available data, 2006.

(3) Last available data, 2002 


\section{INDIA}

\section{Financial account related risk factors to financial stability}

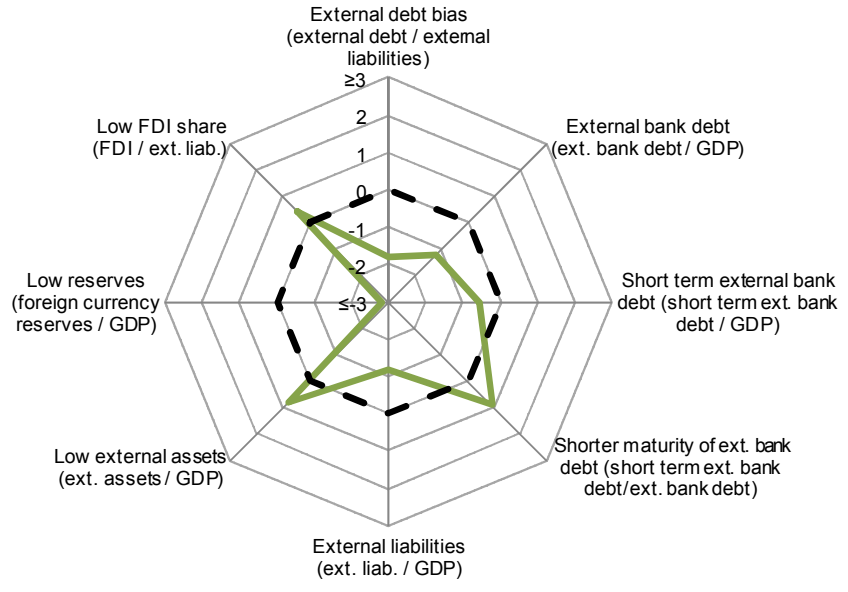

India $2007 \quad-$ OECD 2007

Each variable is presented relative to the OECD median (which is normalised to zero).

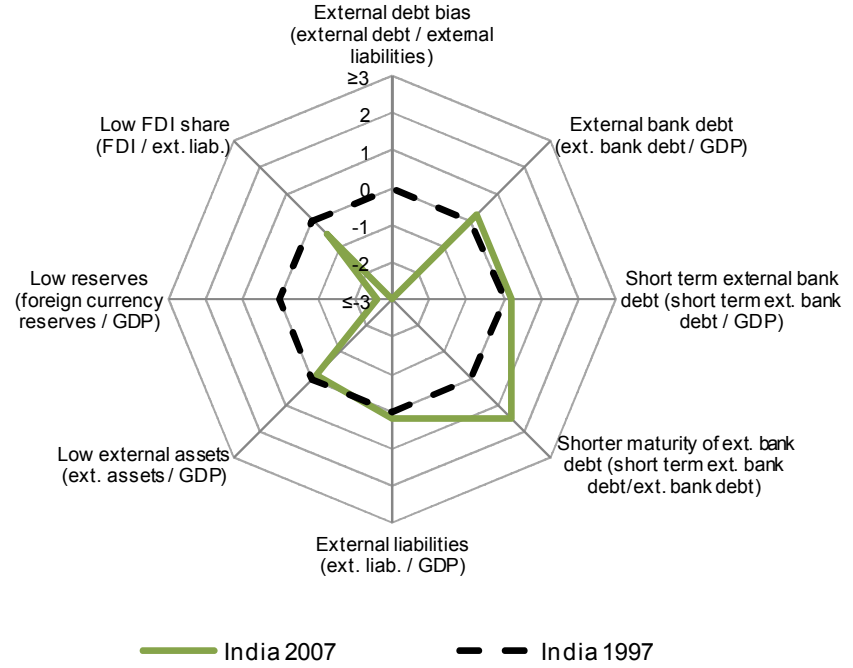

Each variable is presented in 2007 relative to the its situation in 1997 (which is normalised to zero).

Note: For each variable, a larger value indicates a riskier financial account position. Indicators are measured in multiples of the standard deviation across countries for the variable in question.

\section{Selected structural policies conducive to financial stability}

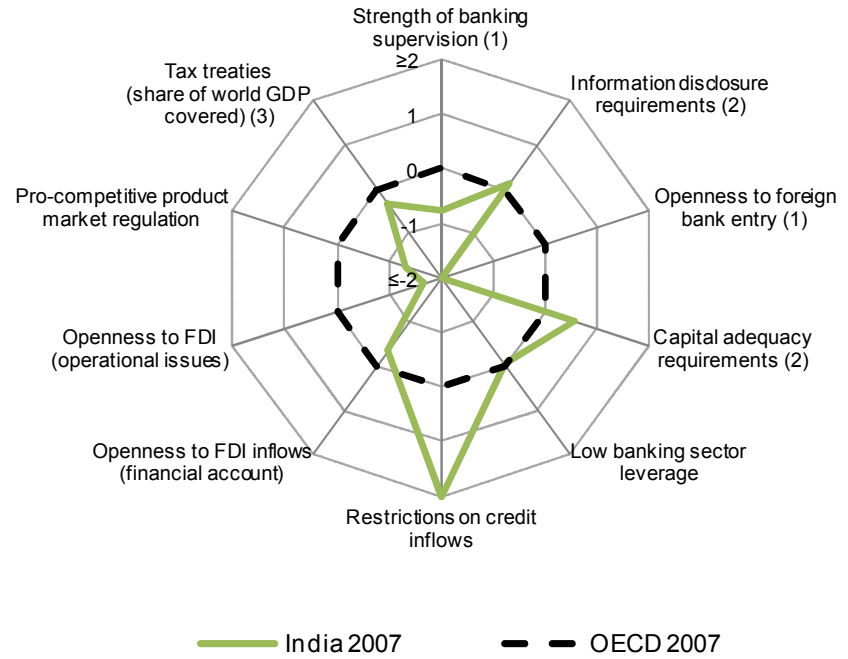

Note: For each variable, a larger value indicates a policy stance that is comparatively more conducive to financial stability. Indicators are measured in multiples of the standard deviation across countries for the variable in queation. Each variable is presented relative to the OECD average (which is normalised to zero).

(1) Last available data, 2005

(2) Last available data, 2006

(3) Last available data, 2002 


\section{INDONESIA}

\section{Financial account related risk factors to financial stability}

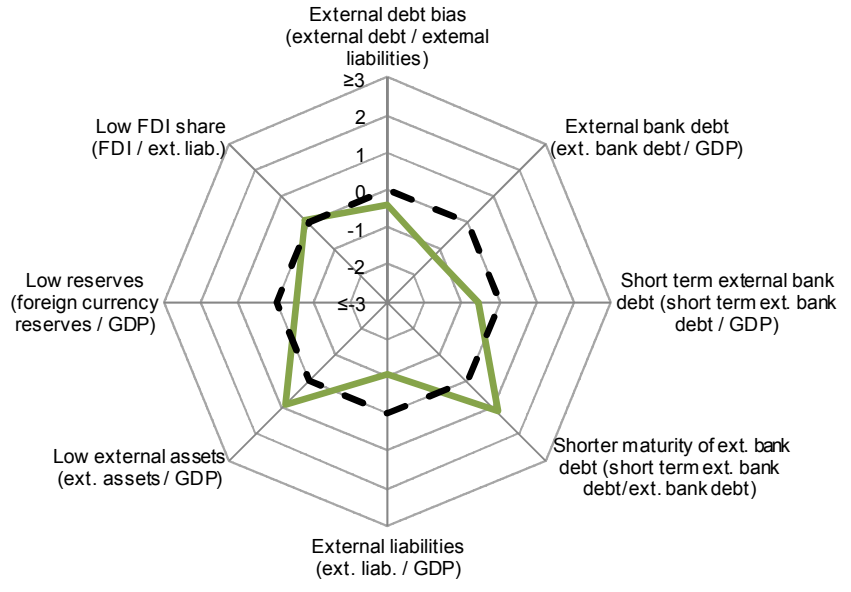

Indonesia $2007 \quad-$ OECD 2007

Each variable is presented relative to the OECD median (which is normalised to zero).

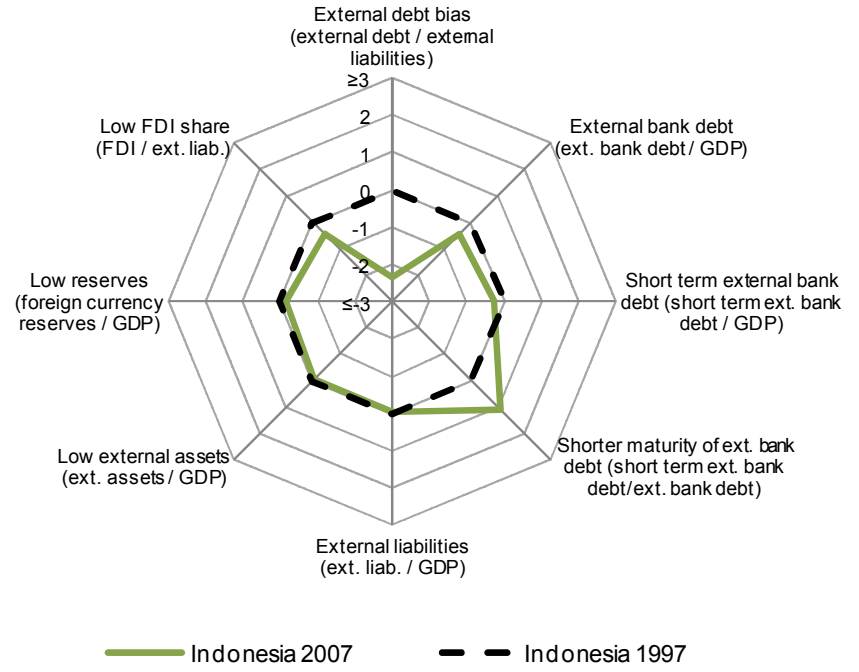

Each variable is presented in 2007 relative to the its situation in 1997 (which is normalised to zero).

Note: For each variable, a larger value indicates a riskier financial account position. Indicators are measured in multiples of the standard deviation across countries for the variable in question.

\section{Selected structural policies conducive to financial stability}

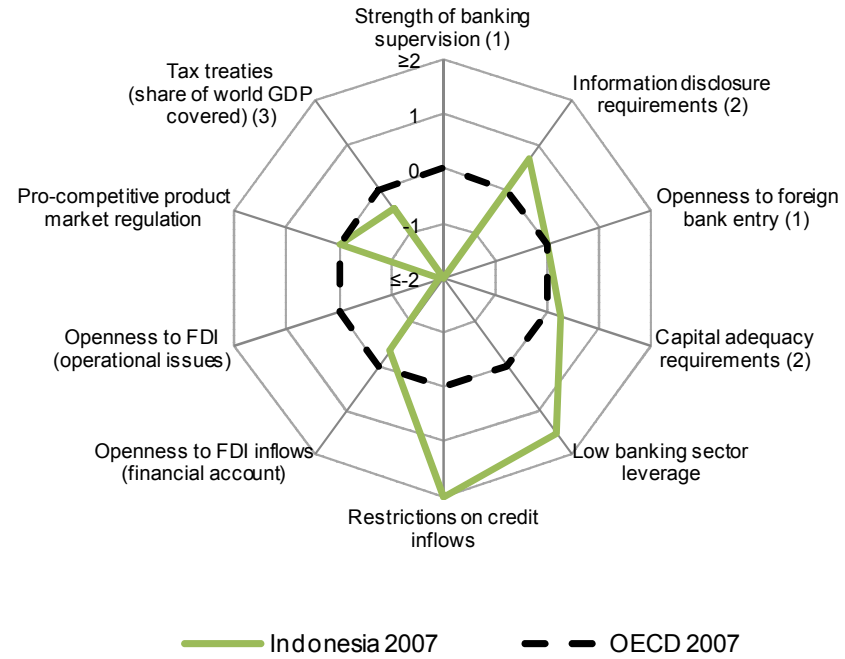

Note: For each variable, a larger value indicates a policy stance that is comparatively more conducive to financial stability. Indicators are measured in multiples of the standard deviation across countries for the variable in queation. Each variable is presented relative to the OECD average (which is normalised to zero).

(1) Last available data, 2005

(2) Last available data, 2006

(3) Last available data, 2002 


\section{IRELAND}

\section{Financial account related risk factors to financial stability}

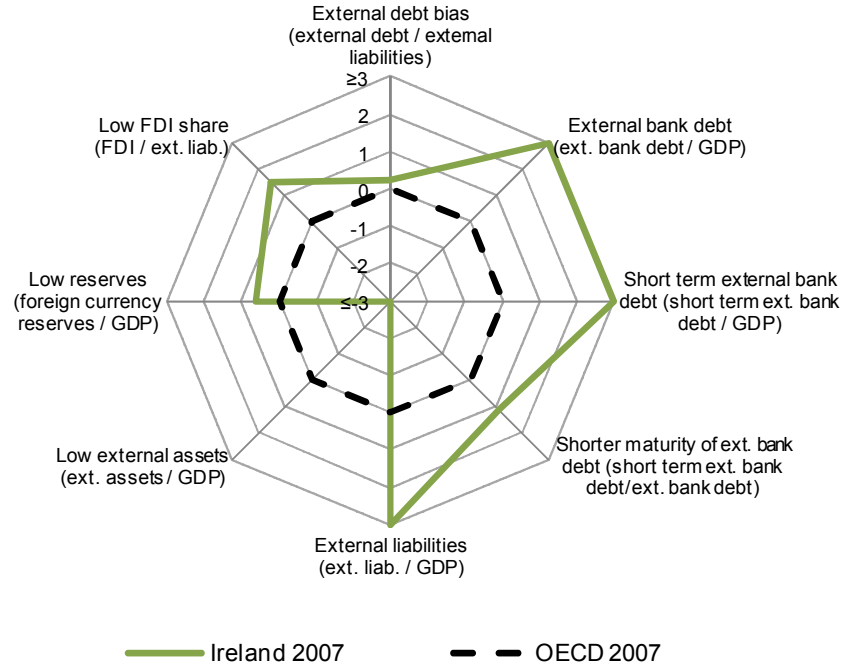

Each variable is presented relative to the OECD median (which is normalised to zero).

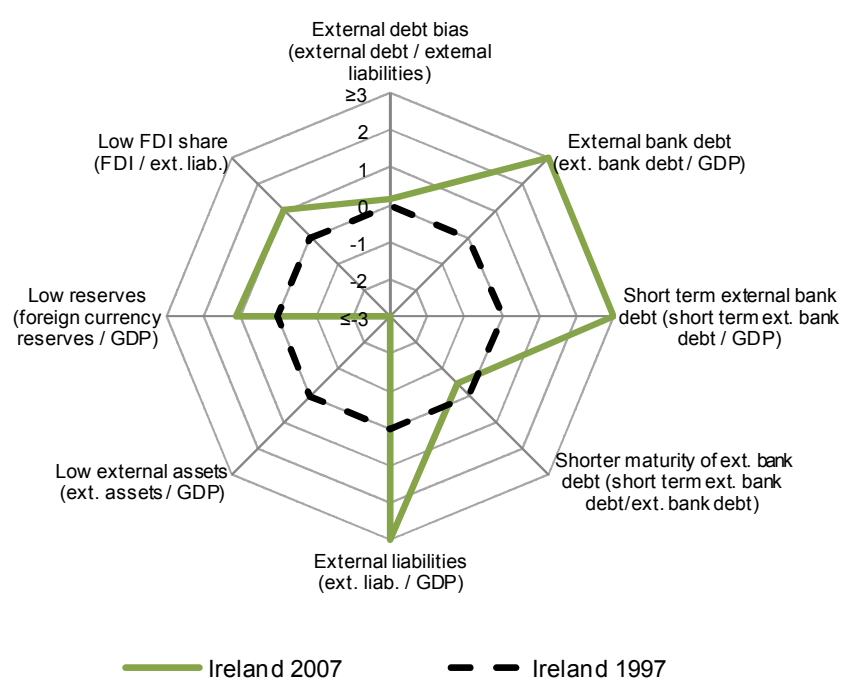

Each variable is presented in 2007 relative to the its situation in 1997 (which is normalised to zero).

Note: For each variable, a larger value indicates a riskier financial account position. Indicators are measured in multiples of the standard deviation across countries for the variable in question.

\section{Selected structural policies conducive to financial stability}

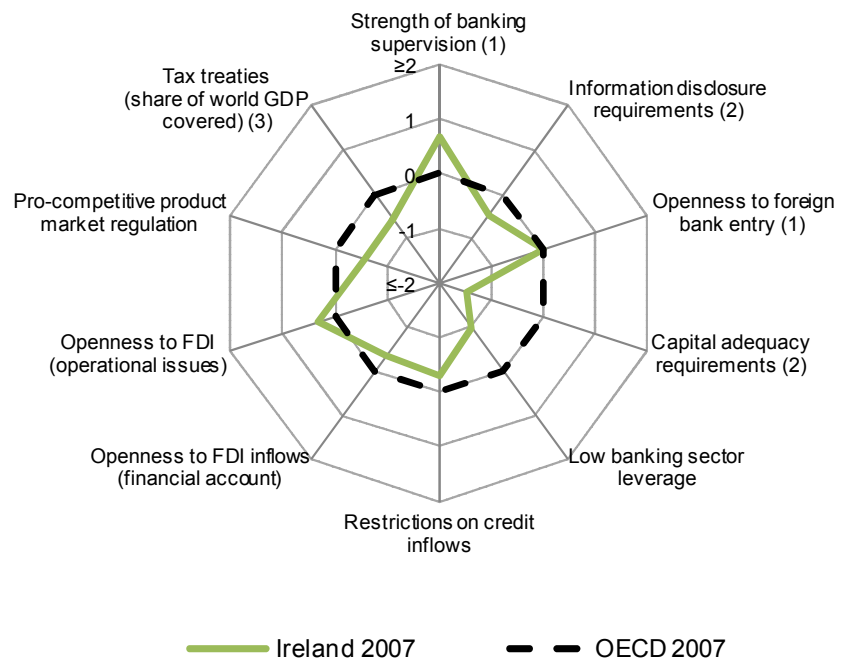

Note: For each variable, a larger value indicates a policy stance that is comparatively more conducive to financial stability. Indicators are measured in multiples of the standard deviation across countries for the variable in queation. Each variable is presented relative to the OECD average (which is normalised to zero).
(1) Last available data, 2005 .
(2) Last available data, 2006
(3) Last available data, 2002 


\section{ISRAEL}

\section{Financial account related risk factors to financial stability}

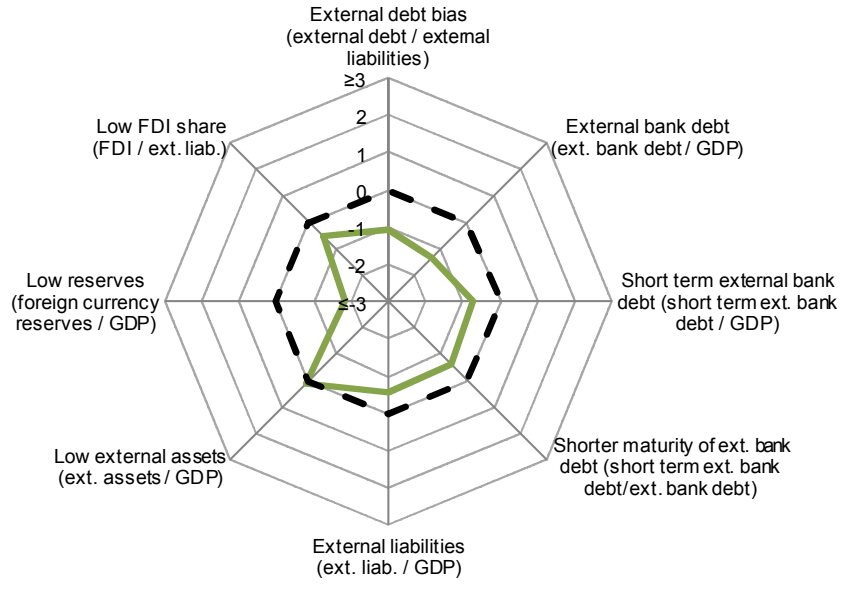

Israel $2007 \quad$ - OECD 2007

Each variable is presented relative to the OECD median (which is normalised to zero).

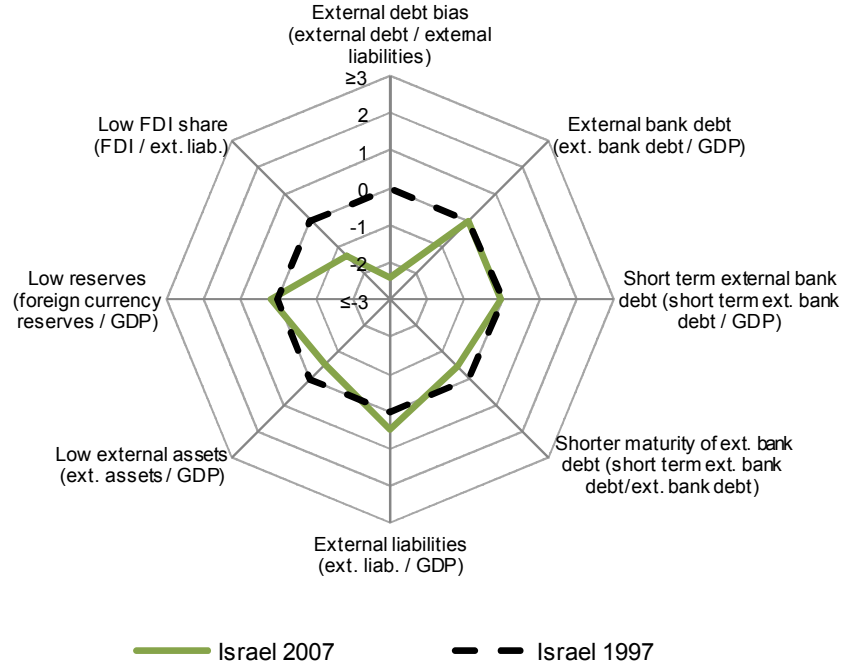

Each variable is presented in 2007 relative to the its situation in 1997 (which is normalised to zero).

Note: For each variable, a larger value indicates a riskier financial account position. Indicators are measured in multiples of the standard deviation across countries for the variable in question.

\section{Selected structural policies conducive to financial stability}

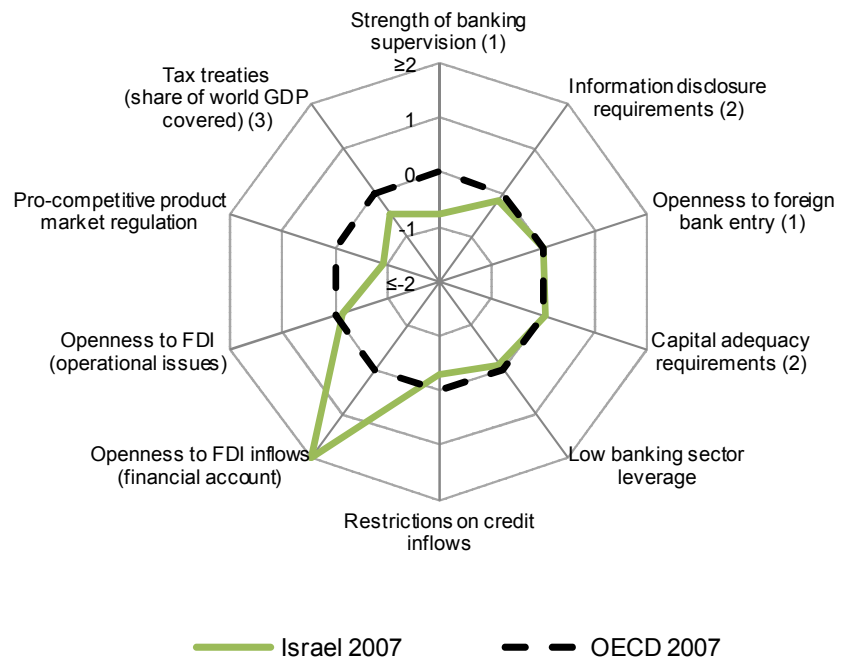

Note: For each variable, a larger value indicates a policy stance that is comparatively more conducive to financial stability. Indicators are measured in multiples of the standard deviation across countries for the variable in queation. Each variable is presented relative to the OECD average (which is normalised to zero).

(1) Last available data, 2005

(2) Last available data, 2006

(3) Last available data, 2002 


\section{ITALY}

\section{Financial account related risk factors to financial stability}

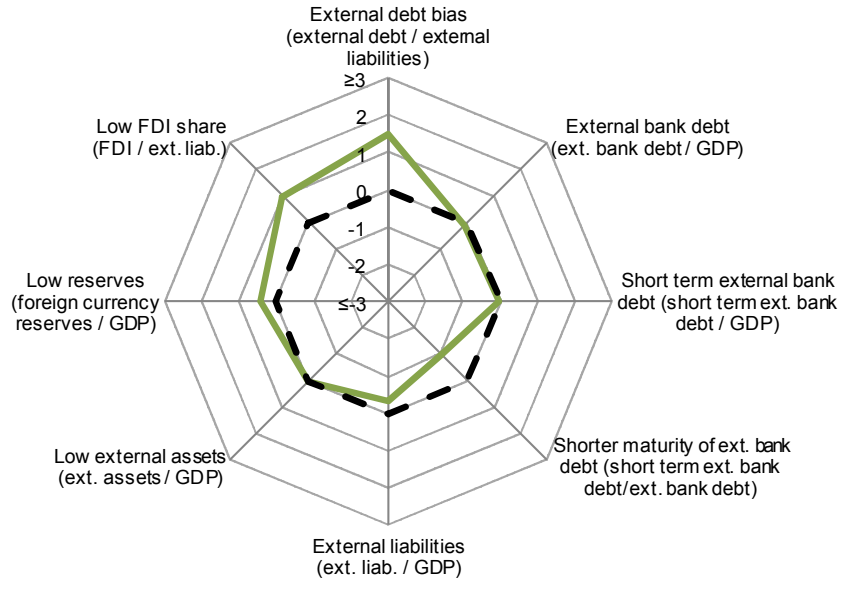

Italy $2007 \quad$ - O OECD 2007

Each variable is presented relative to the OECD median (which is normalised to zero).

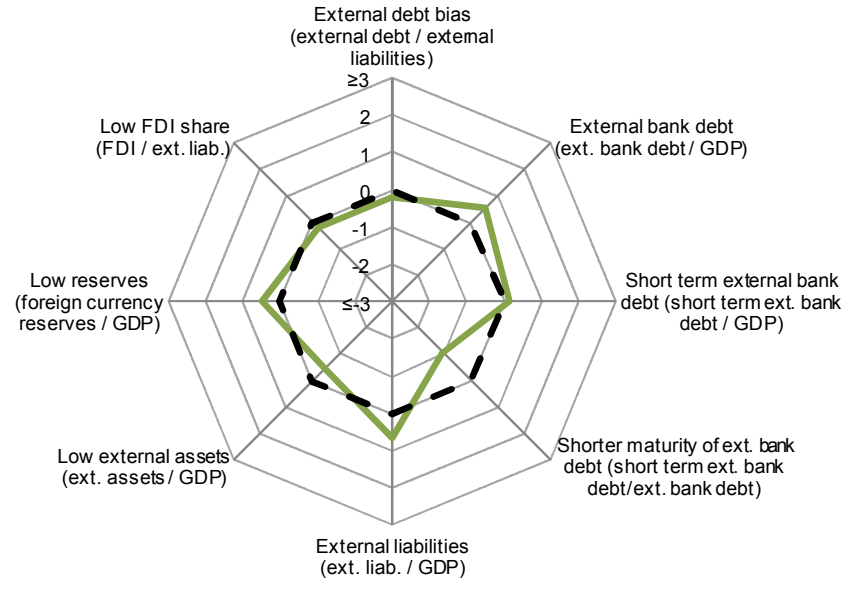

Each variable is presented in 2007 relative to the its situation in 1997 (which is normalised to zero).

Note: For each variable, a larger value indicates a riskier financial account position. Indicators are measured in multiples of the standard deviation across countries for the variable in question.

\section{Selected structural policies conducive to financial stability}

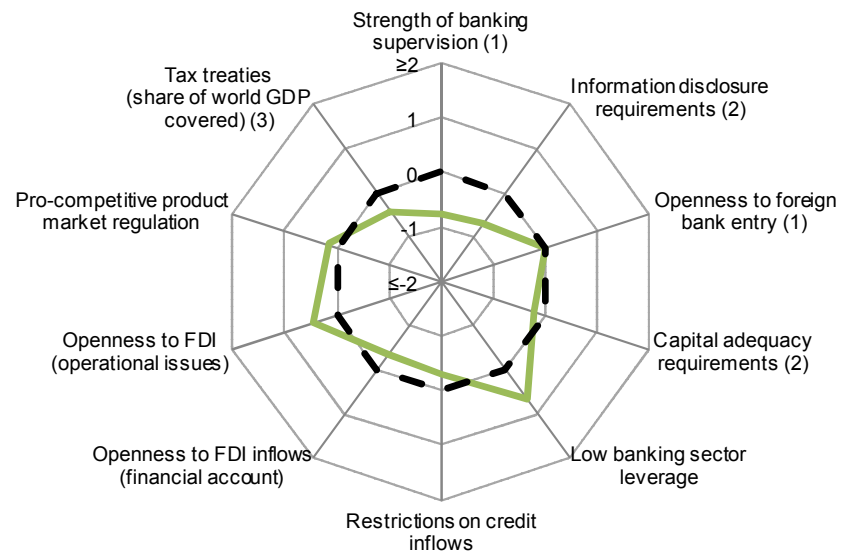

Italy 2007

Note: For each variable, a larger value indicates a policy stance that is comparatively more conducive to financial stability. Indicators are measured in multiples of the standard deviation across countries for the variable in queation. Each variable is presented relative to the OECD average (which is normalised to zero).

(1) Last available data, 2005

(2) Last available data, 2006

(3) Last available data, 2002. 


\section{JAPAN}

\section{Financial account related risk factors to financial stability}

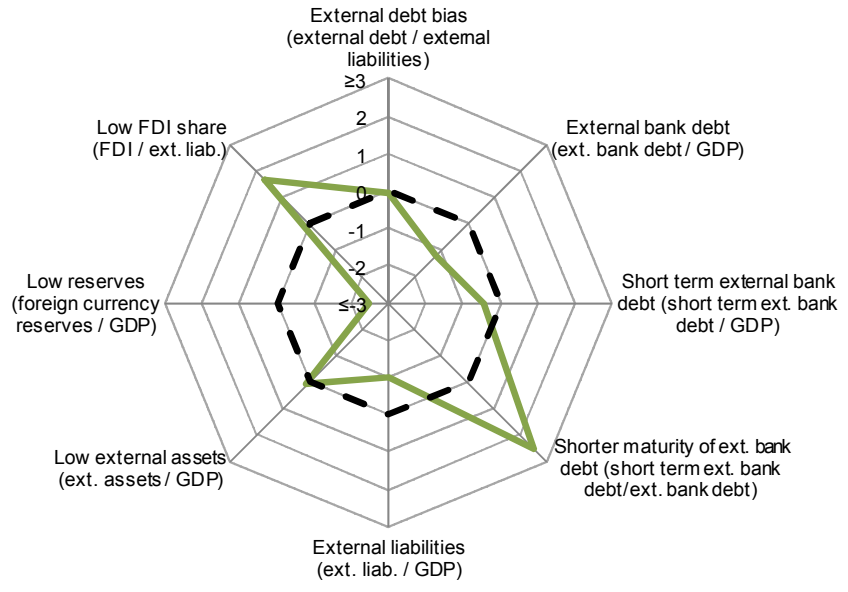

- Japan $2007 \quad$ - O OECD 2007

Each variable is presented relative to the OECD median (which is normalised to zero).

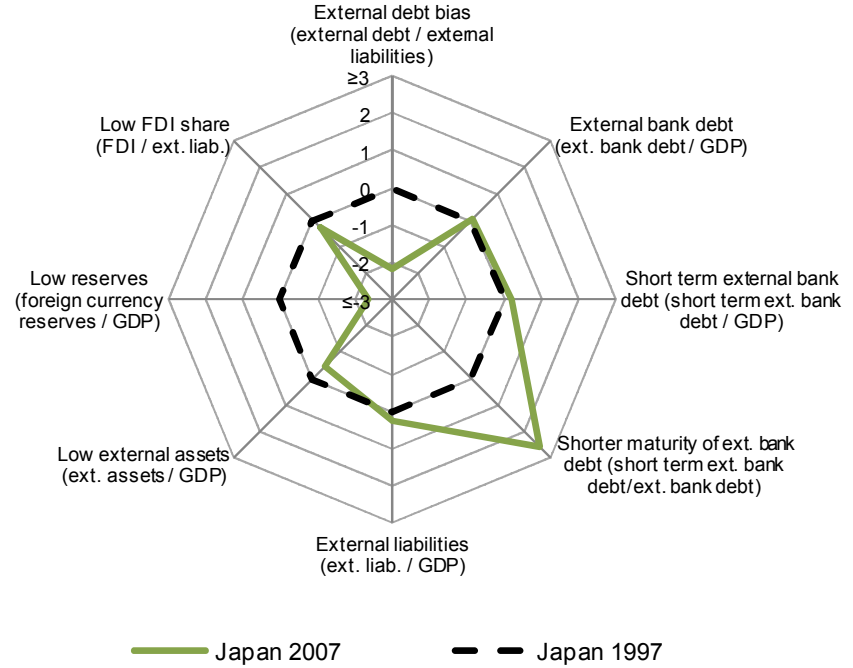

Each variable is presented in 2007 relative to the its situation in 1997 (which is normalised to zero).

Note: For each variable, a larger value indicates a riskier financial account position. Indicators are measured in multiples of the standard deviation across countries for the variable in question.

\section{Selected structural policies conducive to financial stability}
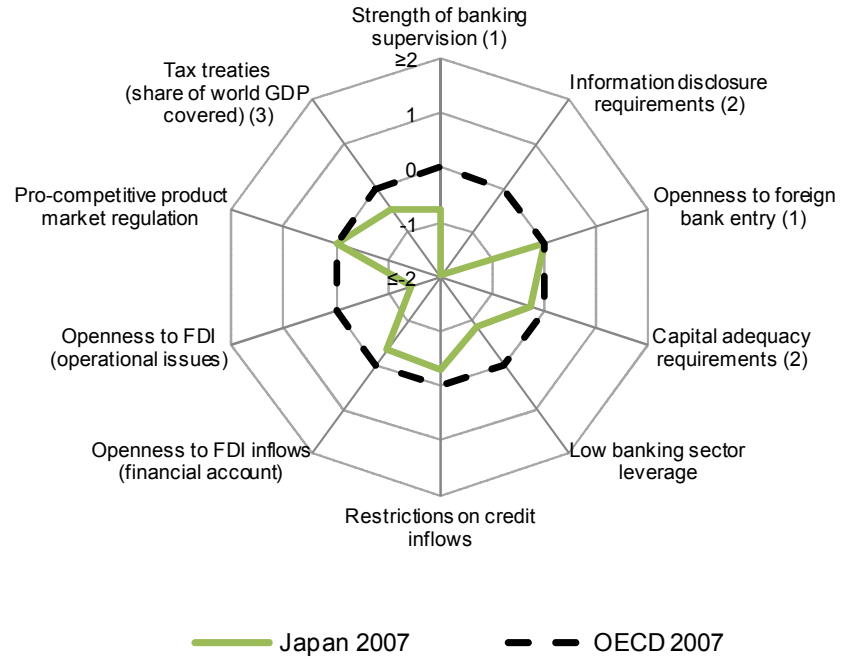

Note: For each variable, a larger value indicates a policy stance that is comparatively more conducive to financial stability. Indicators are measured in multiples of the standard deviation across countries for the variable in queation. Each variable is presented relative to the OECD average (which is normalised to zero).

(1) Last available data, 2005

(2) Last available data, 2006

(3) Last available data, 2002 


\section{KOREA}

\section{Financial account related risk factors to financial stability}

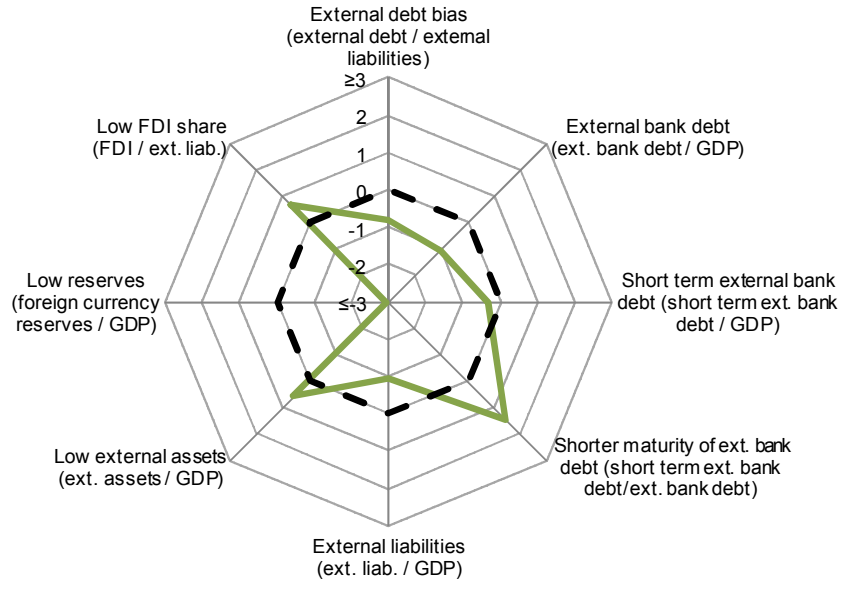

Korea $2007 \quad-\quad$ OECD 2007

Each variable is presented relative to the OECD median (which is normalised to zero).

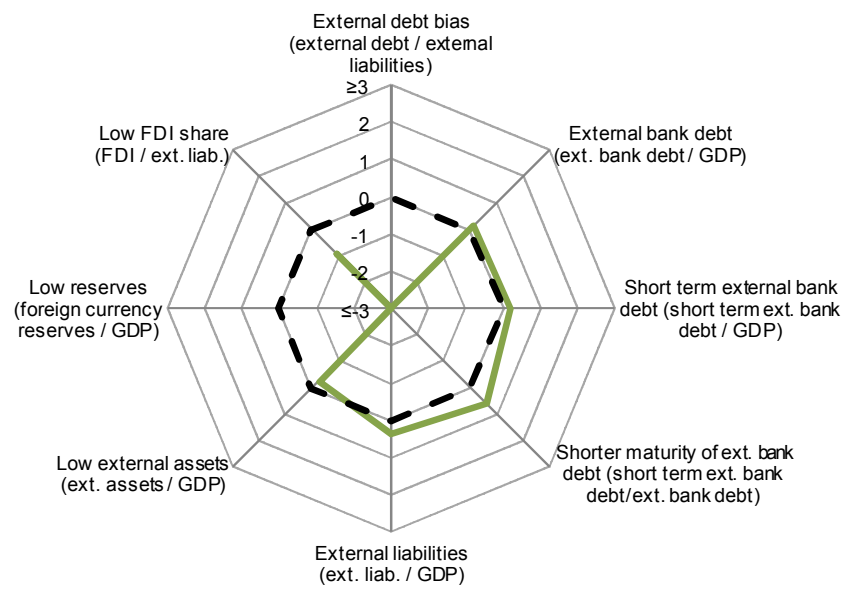

Each variable is presented in 2007 relative to the its situation in 1997 (which is normalised to zero).

Note: For each variable, a larger value indicates a riskier financial account position. Indicators are measured in multiples of the standard deviation across countries for the variable in question.

\section{Selected structural policies conducive to financial stability}

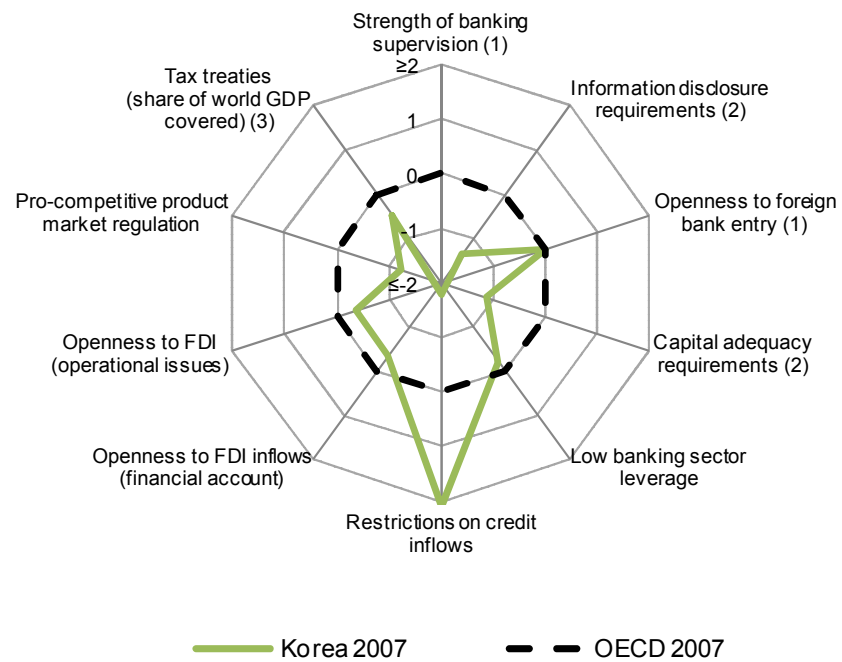

Note: For each variable, a larger value indicates a policy stance that is comparatively more conducive to financial stability. Indicators are measured in multiples of the standard deviation across countries for the variable in queation. Each variable is presented relative to the OECD average (which is normalised to zero).

(1) Last available data, 2005

(2) Last available data, 2006

(3) Last available data, 2002 


\section{LUXEMBOURG}

\section{Financial account related risk factors to financial stability}

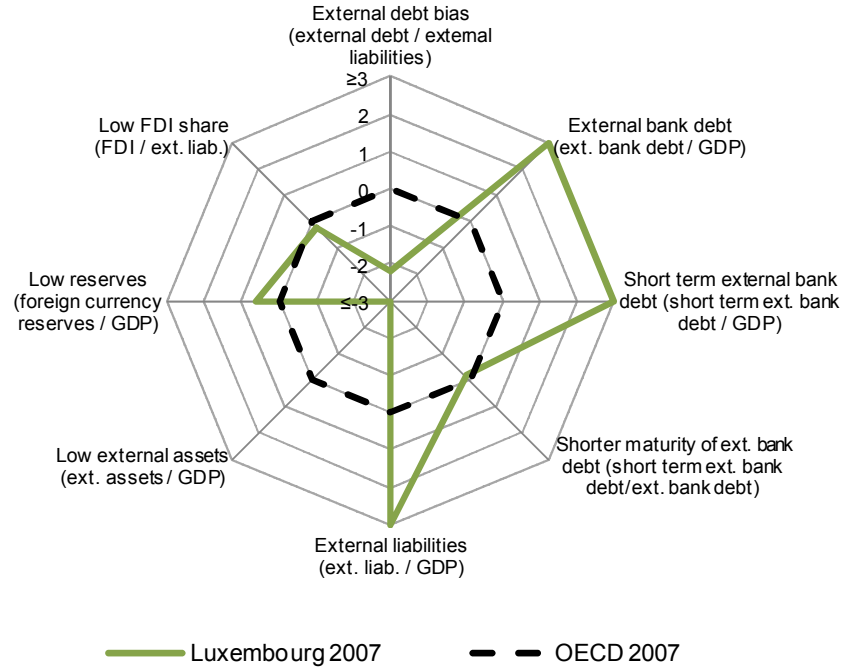

Each variable is presented relative to the OECD median (which is normalised to zero).

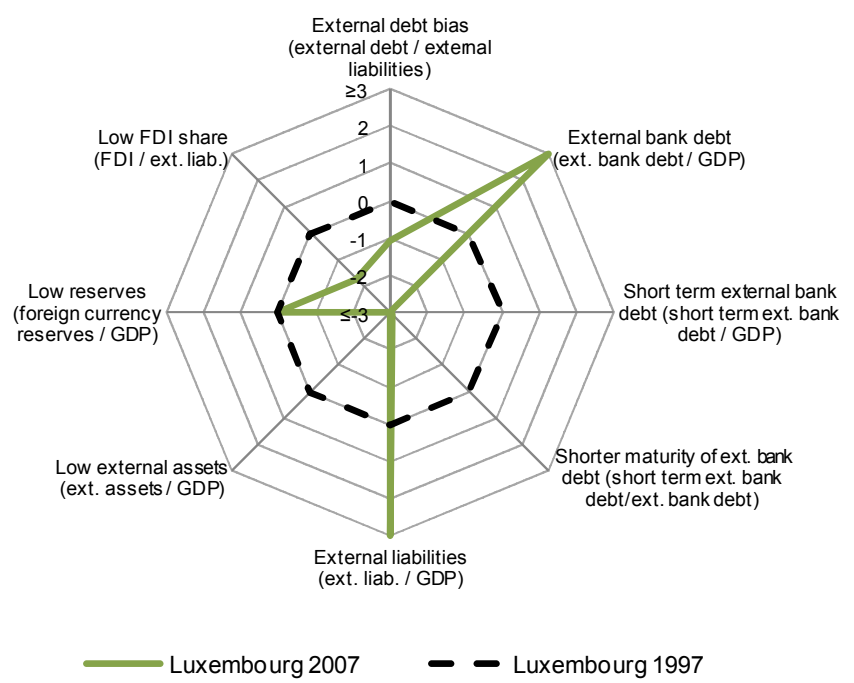

Each variable is presented in 2007 relative to the its situation in 1997 (which is normalised to zero).

Note: For each variable, a larger value indicates a riskier financial account position. Indicators are measured in multiples of the standard deviation across countries for the variable in question.

\section{Selected structural policies conducive to financial stability}

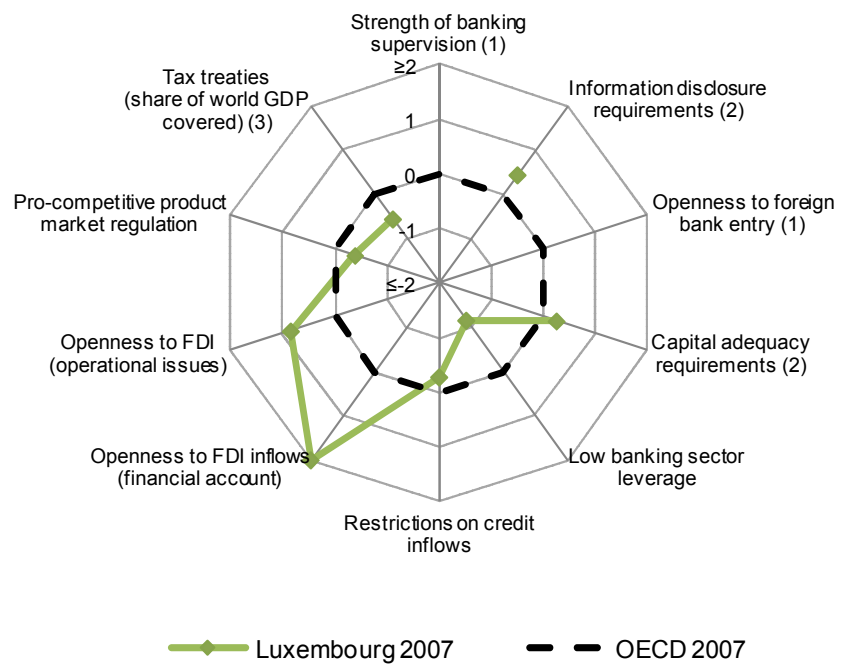

Note: For each variable, a larger value indicates a policy stance that is comparatively more conducive to financial stability. Indicators are measured in multiples of the standard deviation across countries for the variable in queation. Each variable is presented relative to the OECD average (which is normalised to zero).

(1) No data available for the country.

(2) Last available data, 2006.

(3) Last available data, 2002 


\section{MEXICO}

\section{Financial account related risk factors to financial stability}

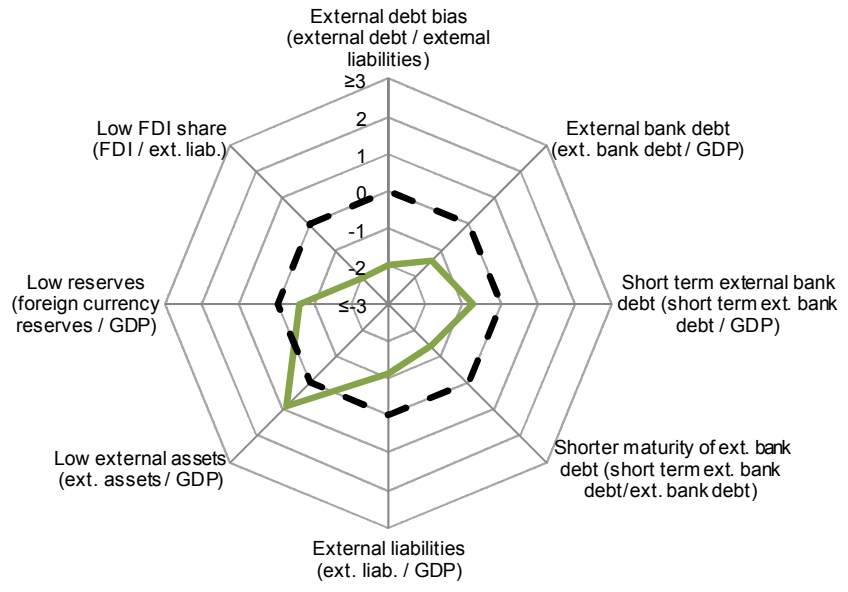

Mexico $2007 \quad$ - OECD 2007

Each variable is presented relative to the OECD median (which is normalised to zero).

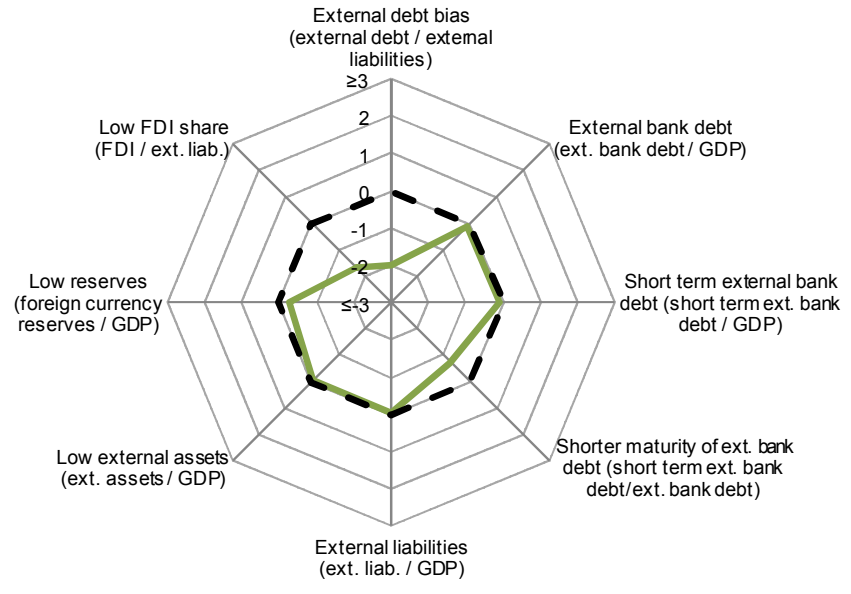

Each variable is presented in 2007 relative to the its situation in 1997 (which is normalised to zero).

Note: For each variable, a larger value indicates a riskier financial account position. Indicators are measured in multiples of the standard deviation across countries for the variable in question.

\section{Selected structural policies conducive to financial stability}

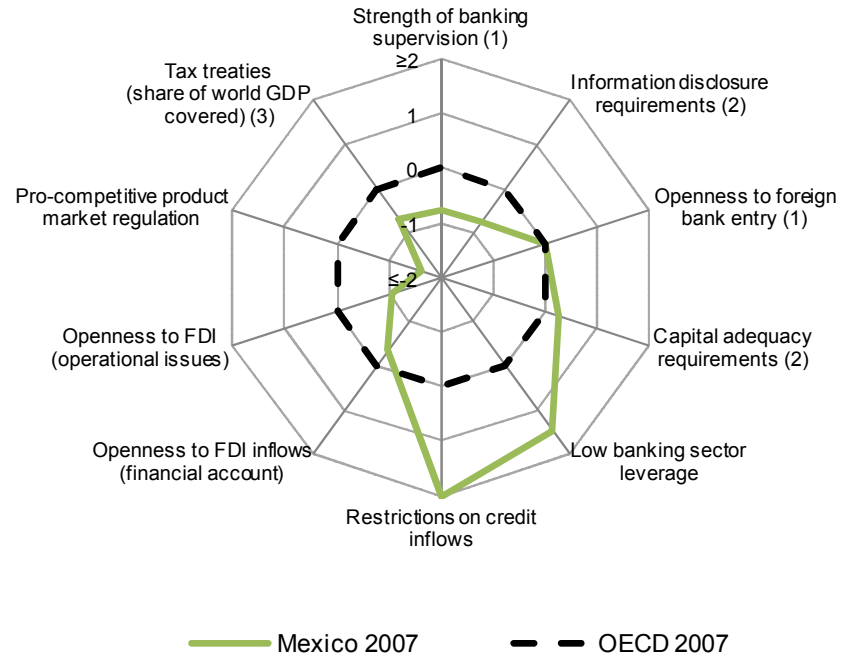

Note: For each variable, a larger value indicates a policy stance that is comparatively more conducive to financial stability. Indicators are measured in multiples of the standard deviation across countries for the variable in queation. Each variable is presented relative to the OECD average (which is normalised to zero).

(1) Last available data, 2005

(2) Last available data, 2006

(3) Last available data, 2002 


\section{NETHERLANDS}

\section{Financial account related risk factors to financial stability}

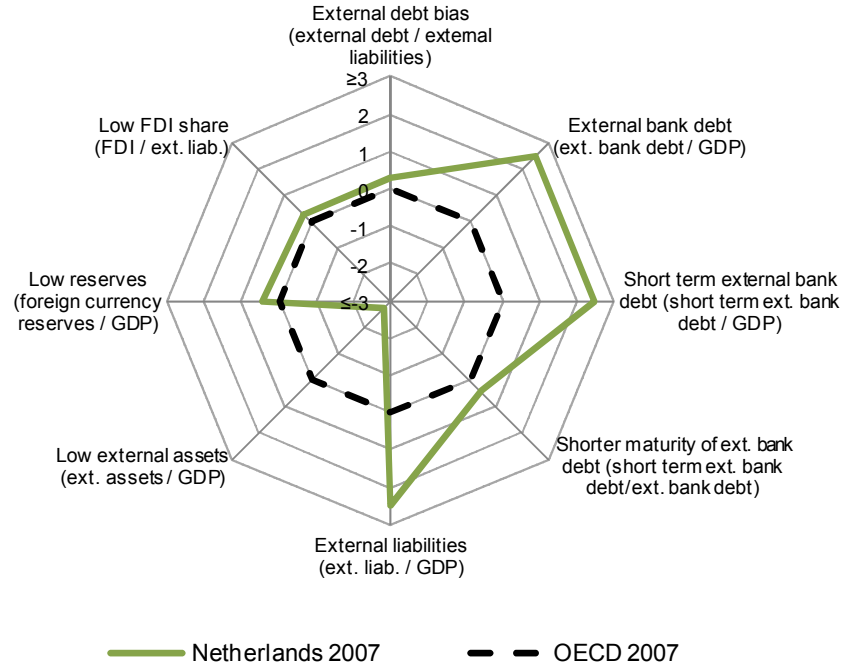

Each variable is presented relative to the OECD median (which is normalised to zero).

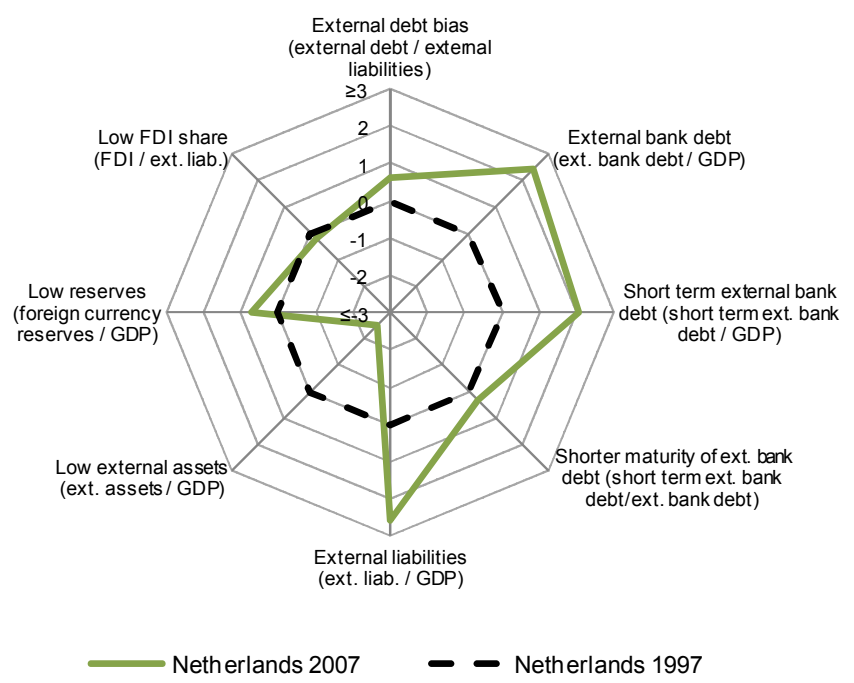

Each variable is presented in 2007 relative to the its situation in 1997 (which is normalised to zero).

Note: For each variable, a larger value indicates a riskier financial account position. Indicators are measured in multiples of the standard deviation across countries for the variable in question.

\section{Selected structural policies conducive to financial stability}

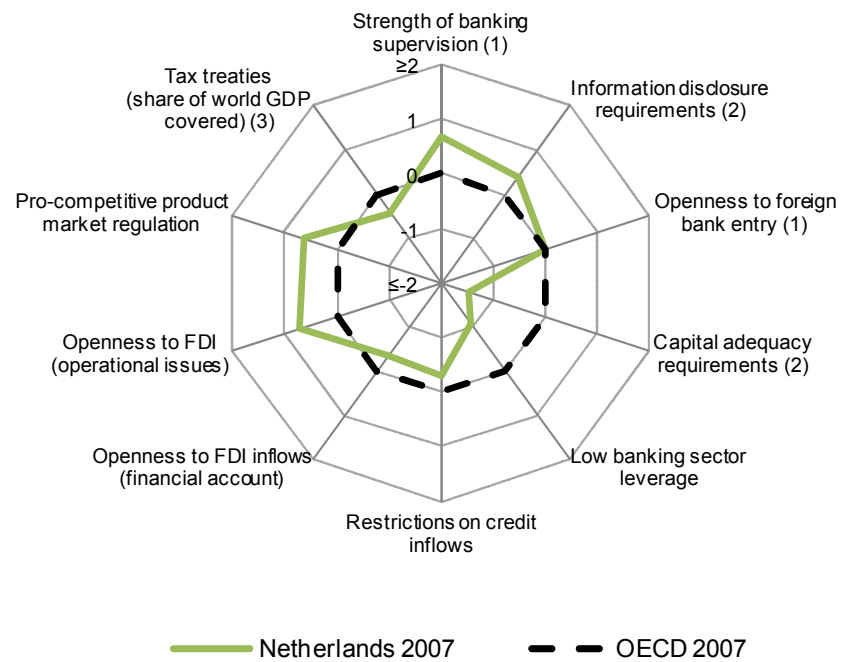

Note: For each variable, a larger value indicates a policy stance that is comparatively more conducive to financial stability. Indicators are measured in multiples of the standard deviation across countries for the variable in queation. Each variable is presented relative to the OECD average (which is normalised to zero).
(1) Last available data, 2005
(2) Last available data, 2006
(3) Last available data, 2002 


\section{NEW ZEALAND}

\section{Financial account related risk factors to financial stability}

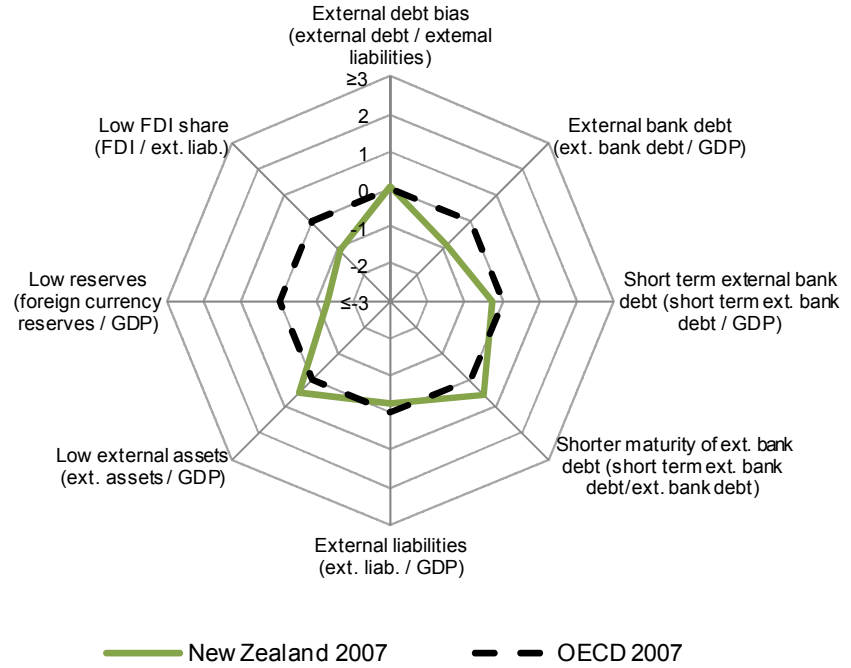

Each variable is presented relative to the OECD median (which is normalised to zero).

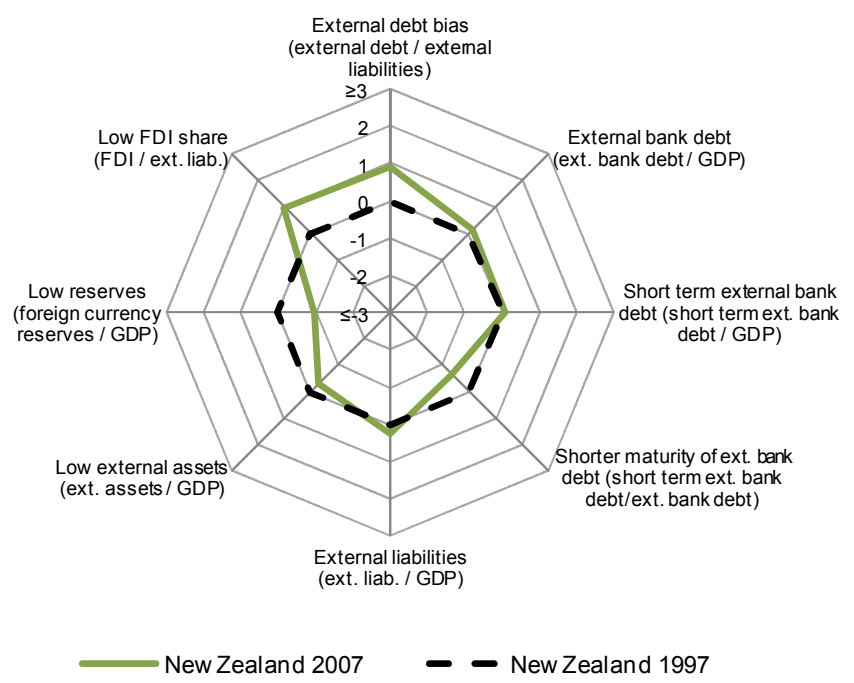

Each variable is presented in 2007 relative to the its situation in 1997 (which is normalised to zero).

Note: For each variable, a larger value indicates a riskier financial account position. Indicators are measured in multiples of the standard deviation across countries for the variable in question.

\section{Selected structural policies conducive to financial stability}

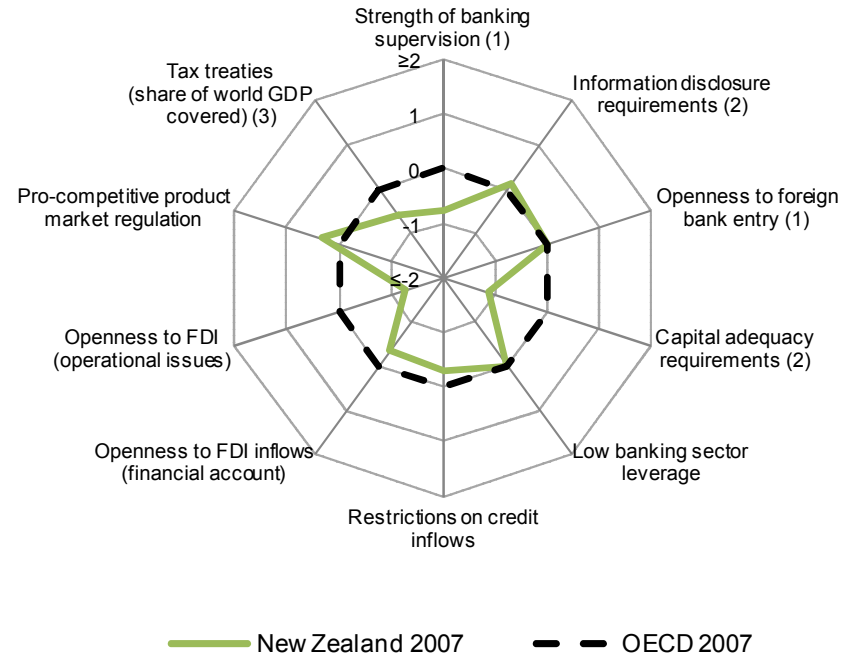

Note: For each variable, a larger value indicates a policy stance that is comparatively more conducive to financial stability. Indicators are measured in multiples of the standard deviation across countries for the variable in queation. Each variable is presented relative to the OECD average (which is normalised to zero).

(1) Last available data, 2005

(2) Last available data, 2006

(3) Last available data, 2002 


\section{NORWAY}

\section{Financial account related risk factors to financial stability}

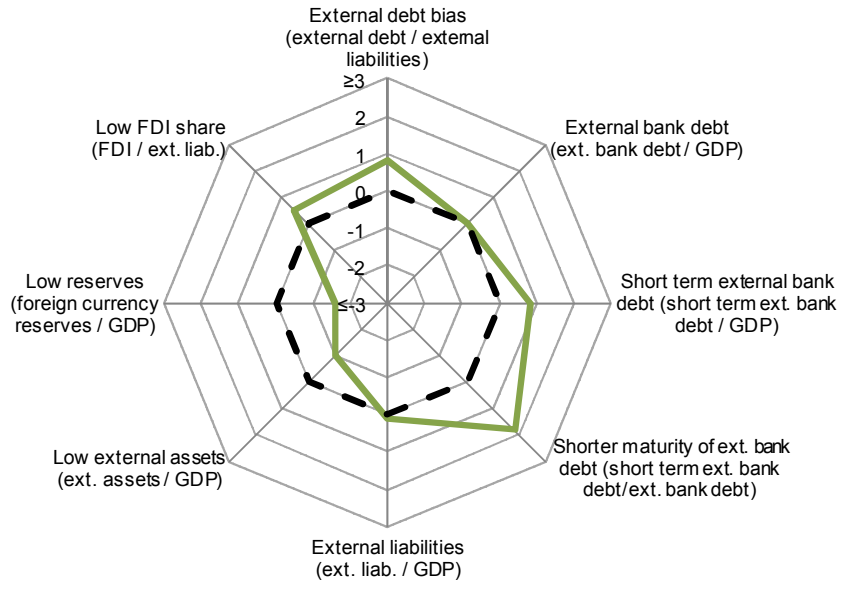

Norway $2007 \quad-$ OECD 2007

Each variable is presented relative to the OECD median (which is normalised to zero).

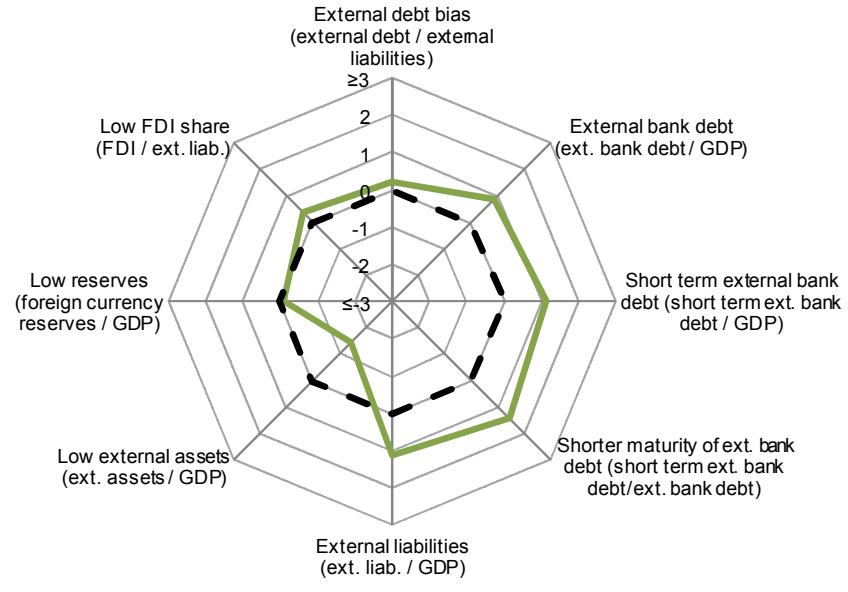

Norway $2007 \quad-$ Norway 1997

Each variable is presented in 2007 relative to the its situation in 1997 (which is normalised to zero).

Note: For each variable, a larger value indicates a riskier financial account position. Indicators are measured in multiples of the standard deviation across countries for the variable in question.

\section{Selected structural policies conducive to financial stability}

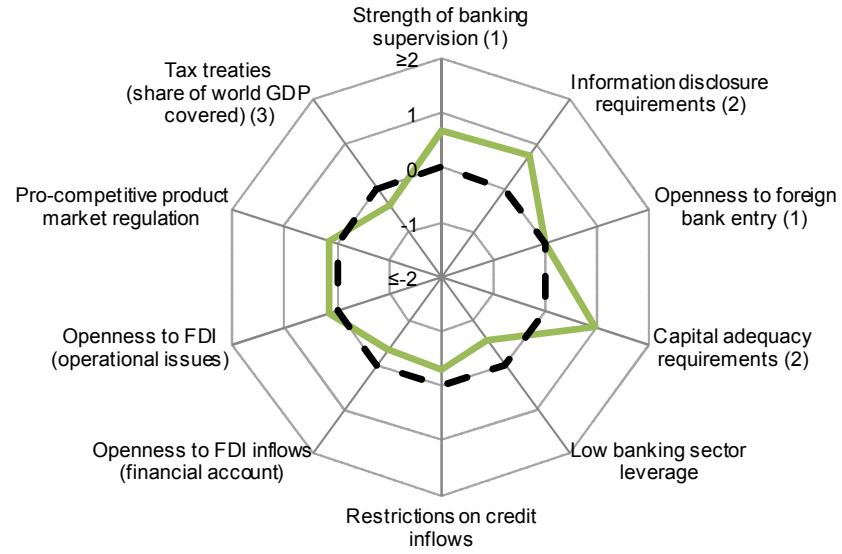

Norway $2007 \quad-\quad$ OECD 2007

Note: For each variable, a larger value indicates a policy stance that is comparatively more conducive to financial stability. Indicators are measured in multiples of the standard deviation across countries for the variable in queation. Each variable is presented relative to the OECD average (which is normalised to zero).

(1) Last available data, 2005

(2) Last available data, 2006

(3) Last available data, 2002 


\section{POLAND}

\section{Financial account related risk factors to financial stability}

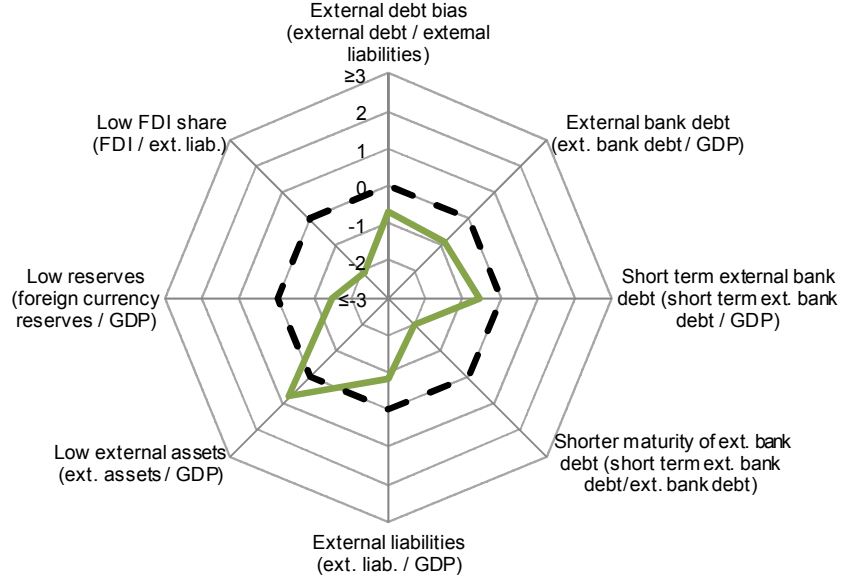

Poland $2007 \quad$ - OECD 2007

Each variable is presented relative to the OECD median (which is normalised to zero).

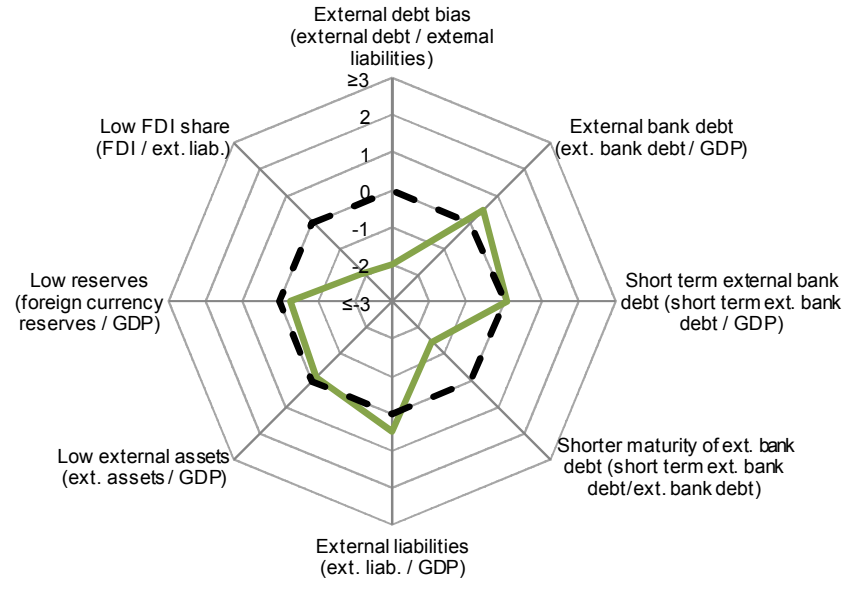

Each variable is presented in 2007 relative to the its situation in 1997 (which is normalised to zero).

Note: For each variable, a larger value indicates a riskier financial account position. Indicators are measured in multiples of the standard deviation across countries for the variable in question.

\section{Selected structural policies conducive to financial stability}

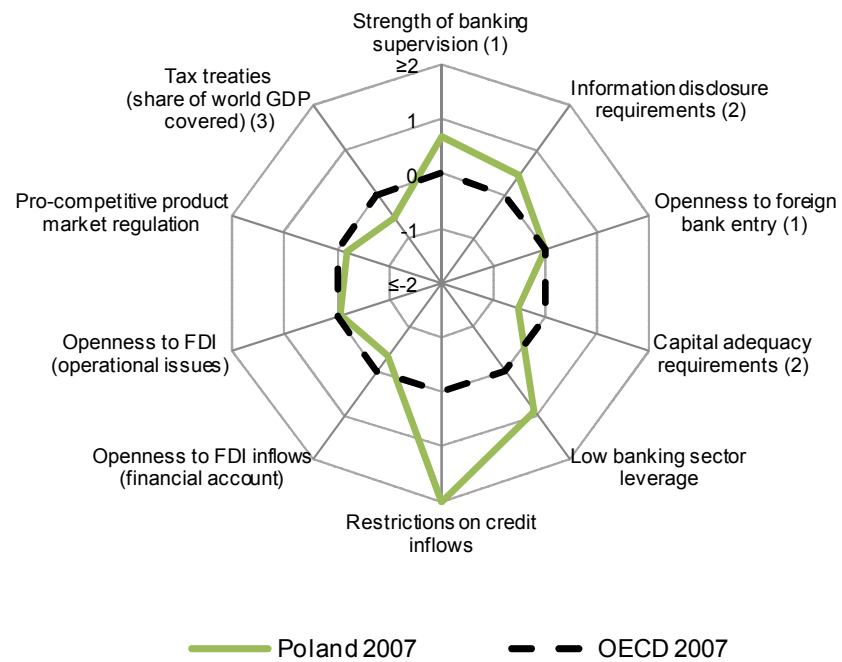

Note: For each variable, a larger value indicates a policy stance that is comparatively more conducive to financial stability. Indicators are measured in multiples of the standard deviation across countries for the variable in queation. Each variable is presented relative to the OECD average (which is normalised to zero).

(1) Last available data, 2005

(2) Last available data, 2006

(3) Last available data, 2002 


\section{PORTUGAL}

\section{Financial account related risk factors to financial stability}

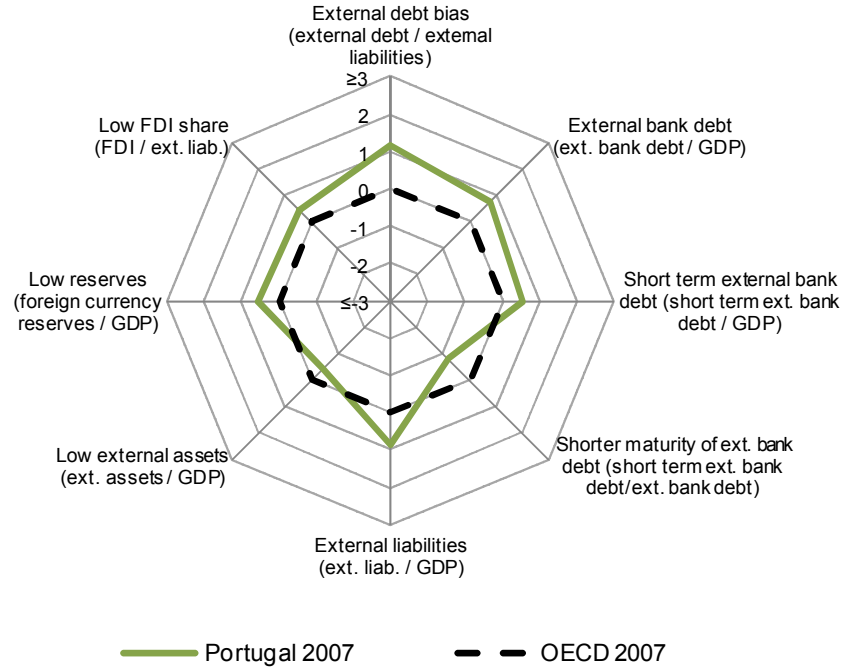

Each variable is presented relative to the OECD median (which is normalised to zero).

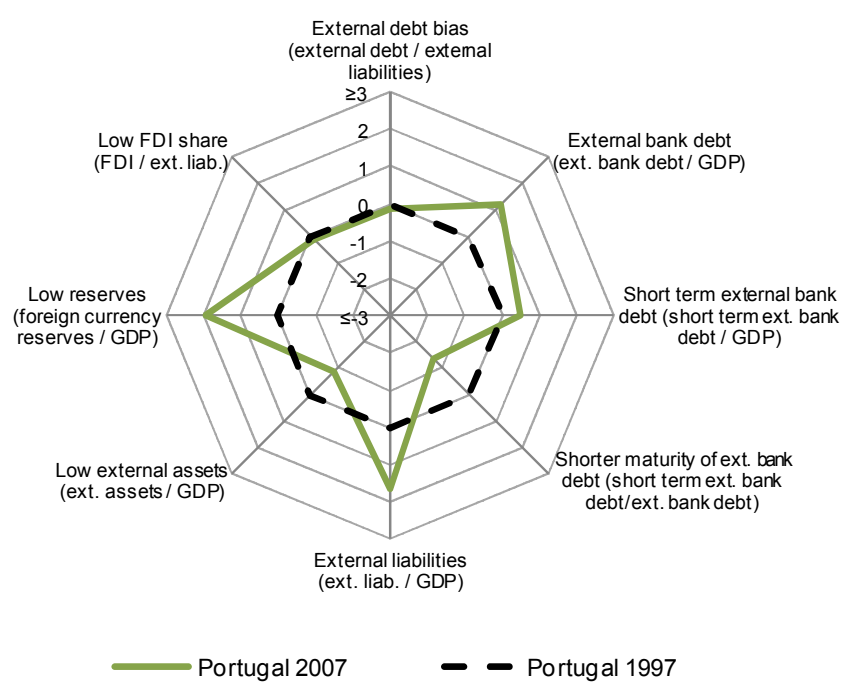

Each variable is presented in 2007 relative to the its situation in 1997 (which is normalised to zero).

Note: For each variable, a larger value indicates a riskier financial account position. Indicators are measured in multiples of the standard deviation across countries for the variable in question.

\section{Selected structural policies conducive to financial stability}

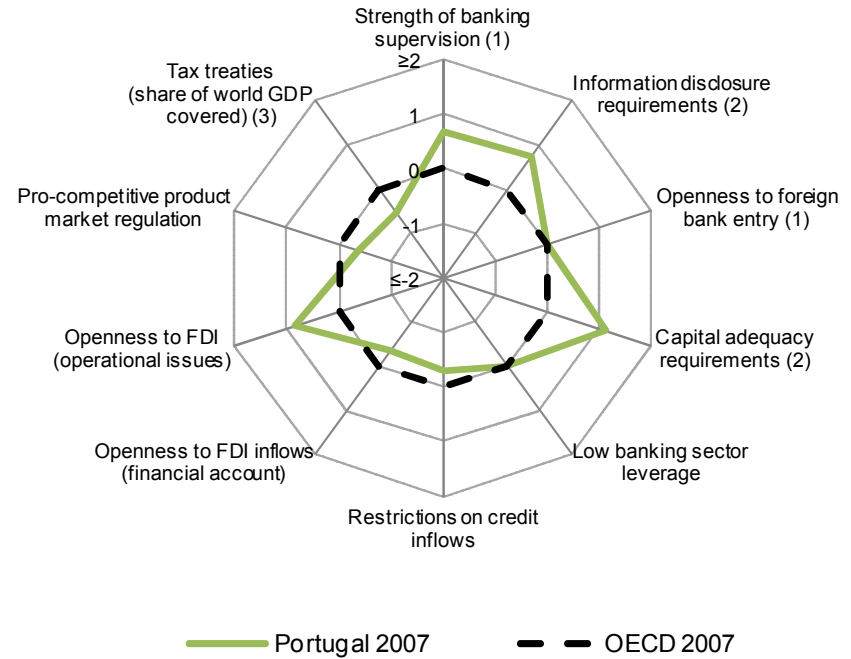

Note: For each variable, a larger value indicates a policy stance that is comparatively more conducive to financial stability. Indicators are measured in multiples of the standard deviation across countries for the variable in queation. Each variable is presented relative to the OECD average (which is normalised to zero).

(1) Last available data, 2005

(2) Last available data, 2006

(3) Last available data, 2002 


\section{RUSSIAN FEDERATION}

\section{Financial account related risk factors to financial stability}

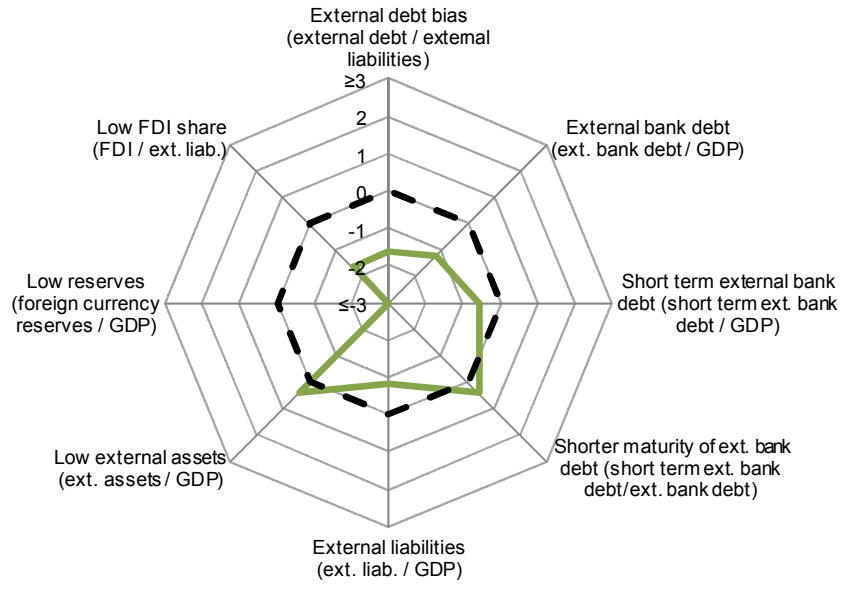

Russia $2007 \quad-$ OECD 2007

Each variable is presented relative to the OECD median (which is normalised to zero).

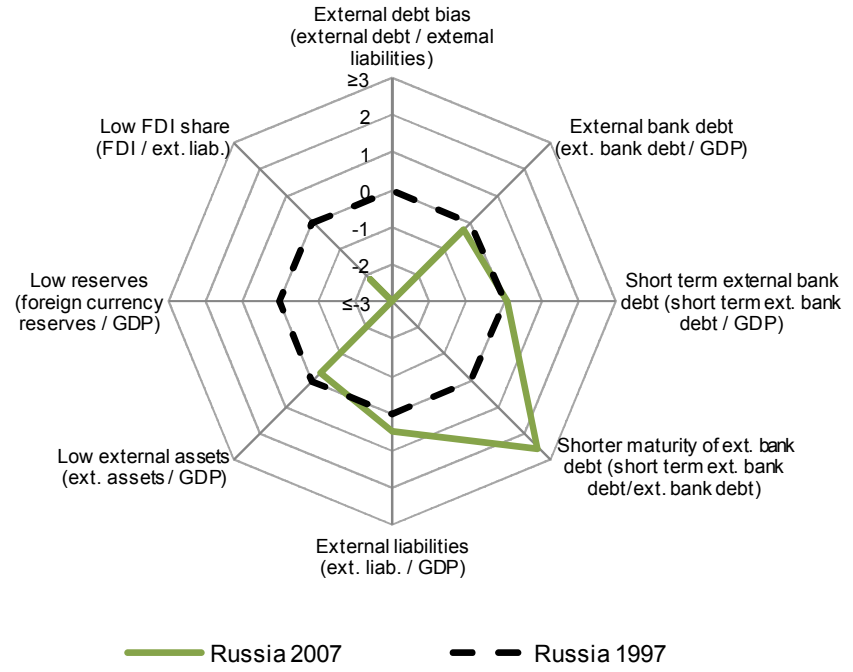

Each variable is presented in 2007 relative to the its situation in 1997 (which is normalised to zero).

Note: For each variable, a larger value indicates a riskier financial account position. Indicators are measured in multiples of the standard deviation across countries for the variable in question.

\section{Selected structural policies conducive to financial stability}
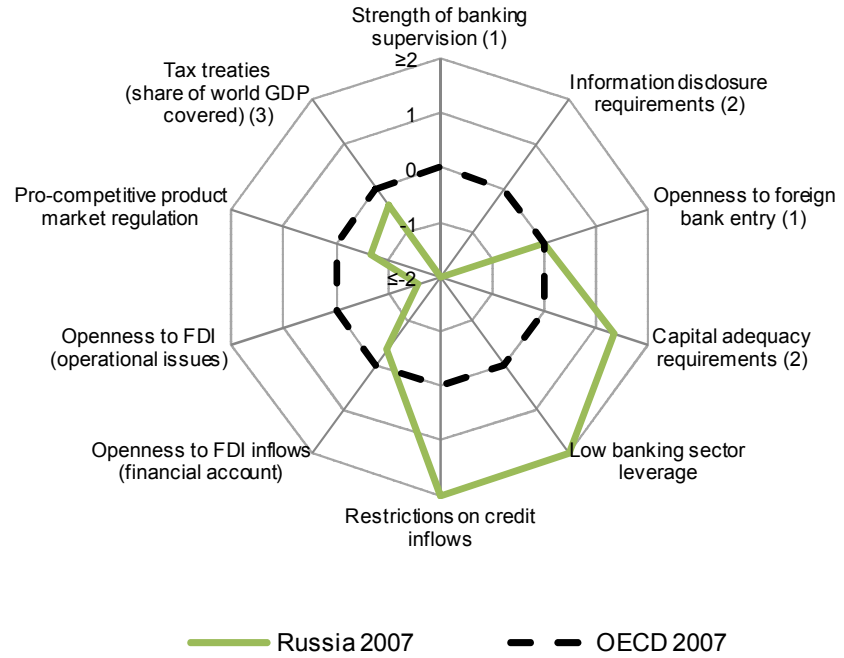

Note: For each variable, a larger value indicates a policy stance that is comparatively more conducive to financial stability. Indicators are measured in multiples of the standard deviation across countries for the variable in queation. Each variable is presented relative to the OECD average (which is normalised to zero).

(1) Last available data, 2005

(2) Last available data, 2006

(3) Last available data, 2002 


\section{SLOVAK REPUBLIC}

\section{Financial account related risk factors to financial stability}

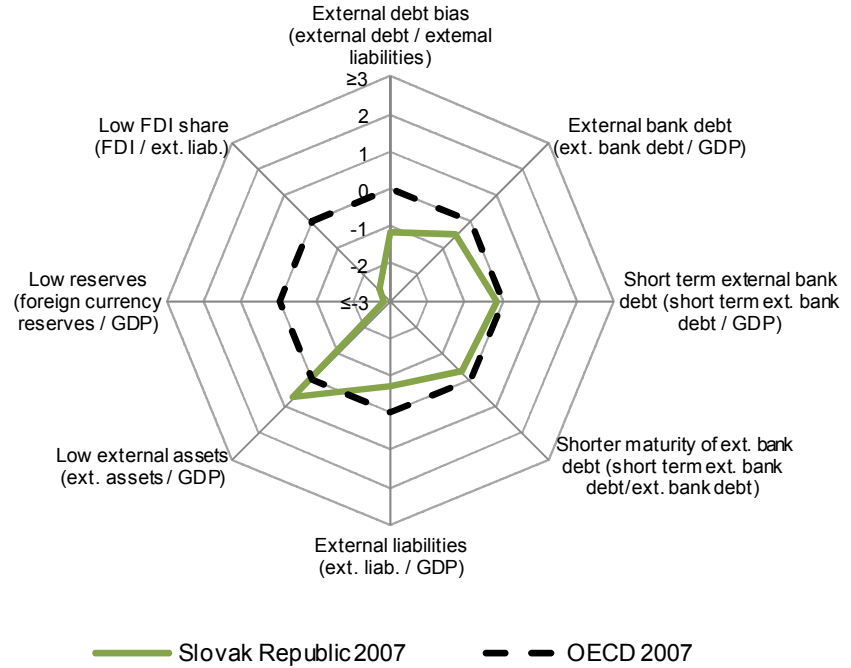

Each variable is presented relative to the OECD median (which is normalised to zero).

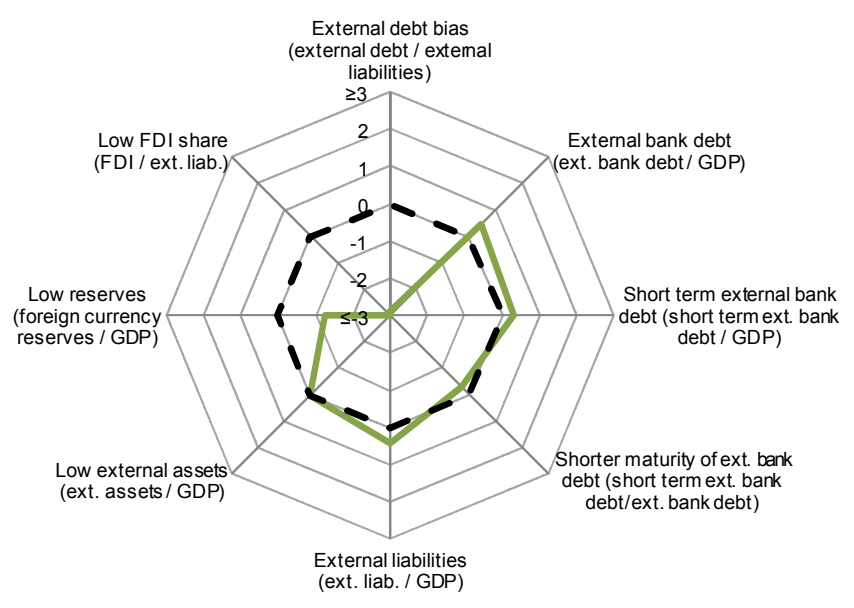

Each variable is presented in 2007 relative to the its situation in 1997 (which is normalised to zero).

Note: For each variable, a larger value indicates a riskier financial account position. Indicators are measured in multiples of the standard deviation across countries for the variable in question.

\section{Selected structural policies conducive to financial stability}

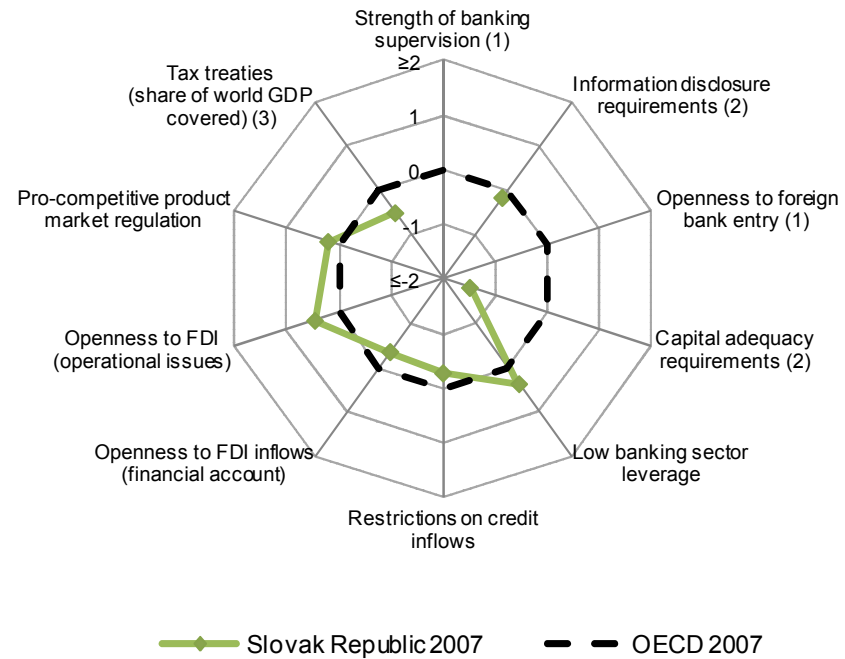

Note: For each variable, a larger value indicates a policy stance that is comparatively more conducive to financial stability. Indicators are measured in multiples of the standard deviation across countries for the variable in queation. Each variable is presented relative to the OECD average (which is normalised to zero).

(1) No data available for the country.

(2) Last available data, 2006

(3) Last available data, 2002 


\section{SLOVENIA}

\section{Financial account related risk factors to financial stability}

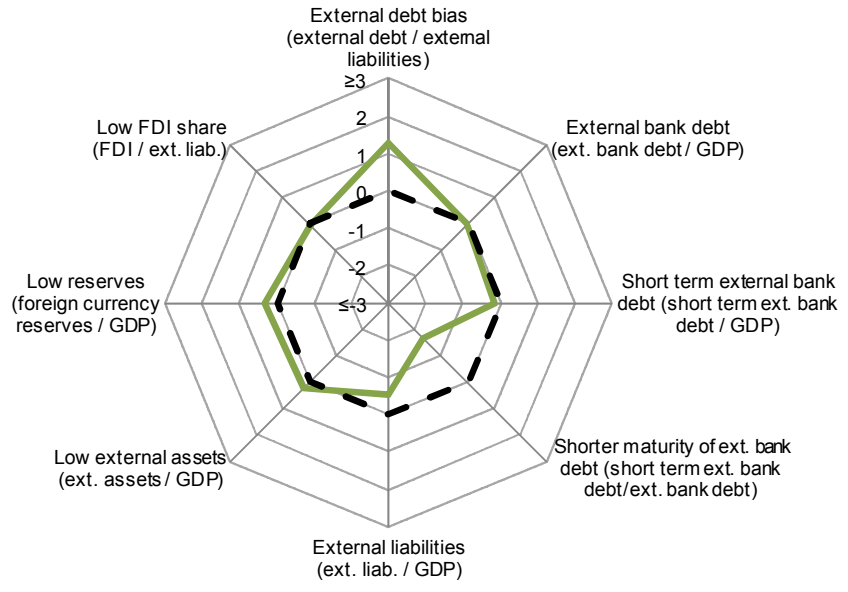

- Slovenia $2007 \quad$ - OECD 2007

Each variable is presented relative to the OECD median (which is normalised to zero).

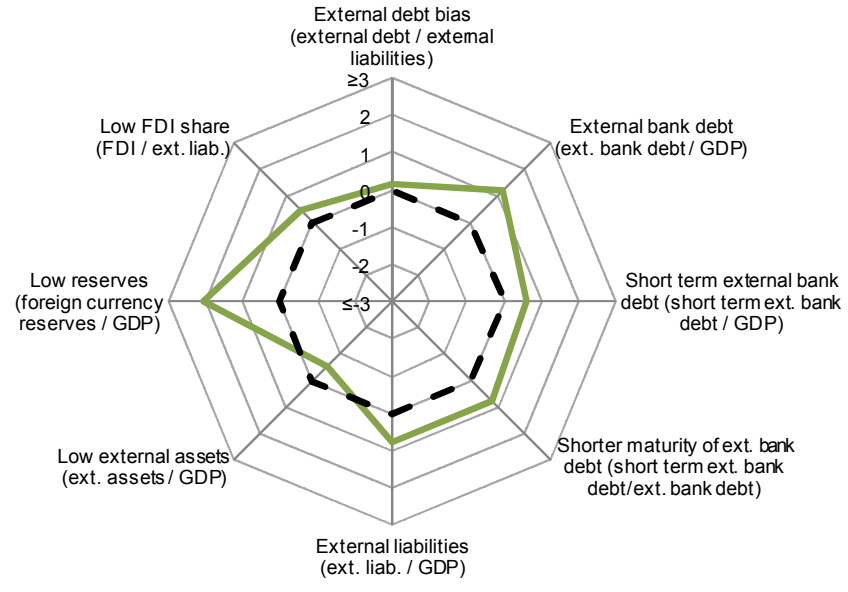

Slovenia $2007 \quad-$ Slovenia 1997

Each variable is presented in 2007 relative to the its situation in 1997 (which is normalised to zero).

Note: For each variable, a larger value indicates a riskier financial account position. Indicators are measured in multiples of the standard deviation across countries for the variable in question.

\section{Selected structural policies conducive to financial stability}

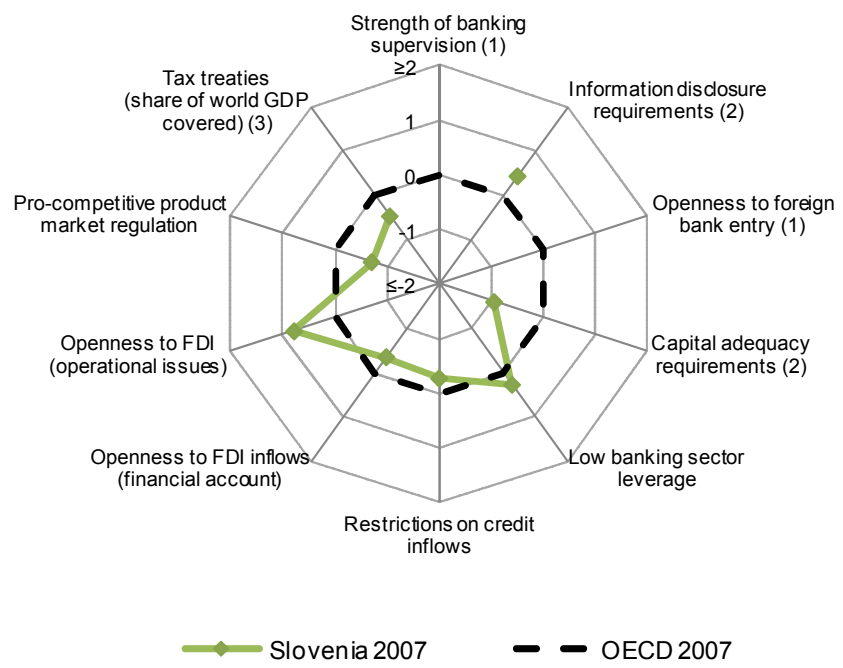

Note: For each variable, a larger value indicates a policy stance that is comparatively more conducive to financial stability. Indicators are measured in multiples of the standard deviation across countries for the variable in queation. Each variable is presented relative to the OECD average (which is normalised to zero).

(1) No data available for the country.

(2) Last available data, 2006.

(3) Last available data, 2002 


\section{SOUTH AFRICA}

\section{Financial account related risk factors to financial stability}

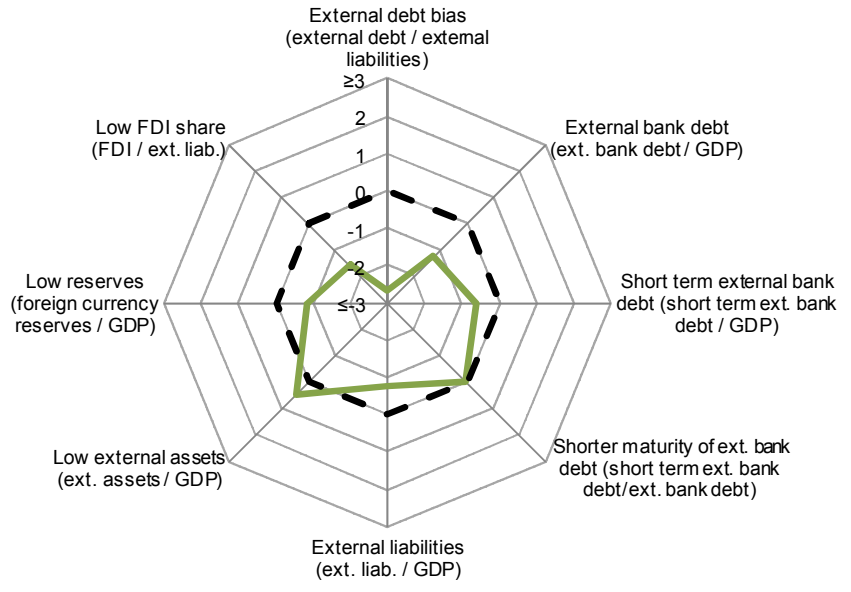

South Africa $2007 \quad$ - OECD 2007

Each variable is presented relative to the OECD median (which is normalised to zero).

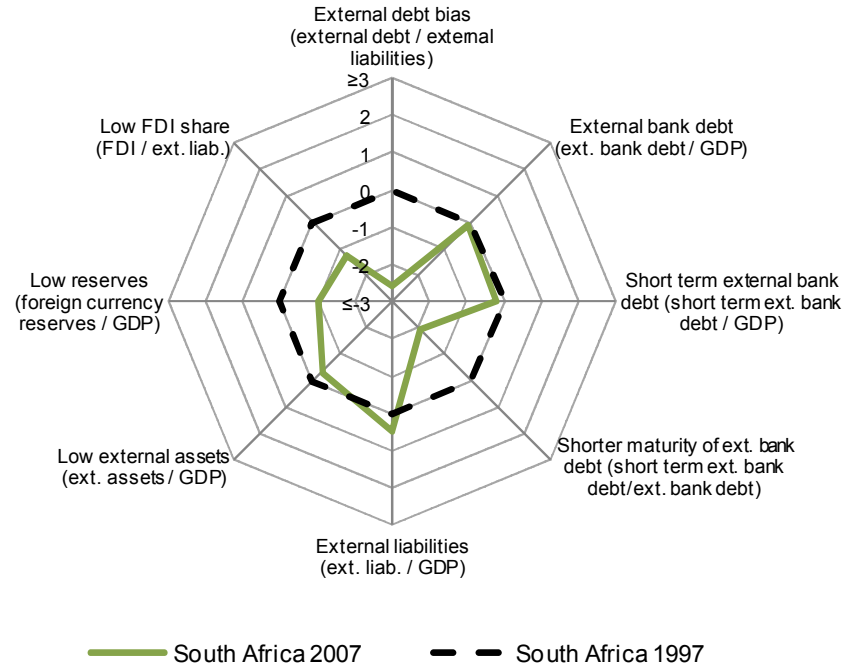

Each variable is presented in 2007 relative to the its situation in 1997 (which is normalised to zero).

Note: For each variable, a larger value indicates a riskier financial account position. Indicators are measured in multiples of the standard deviation across countries for the variable in question.

\section{Selected structural policies conducive to financial stability}

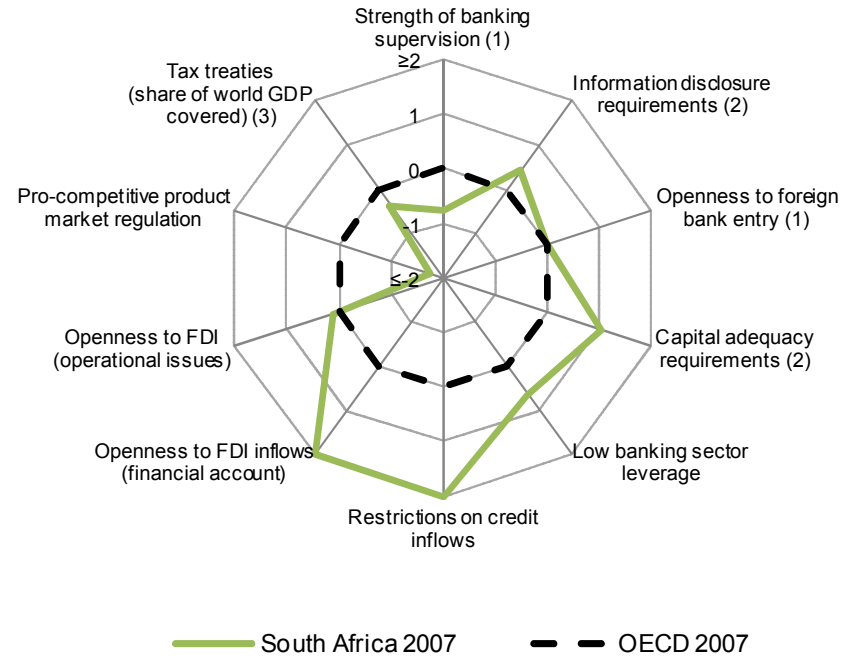

Note: For each variable, a larger value indicates a policy stance that is comparatively more conducive to financial stability. Indicators are measured in multiples of the standard deviation across countries for the variable in queation. Each variable is presented relative to the OECD average (which is normalised to zero).

(1) Last available data, 2005

(2) Last available data, 2006

(3) Last available data, 2002 


\section{SPAIN}

\section{Financial account related risk factors to financial stability}

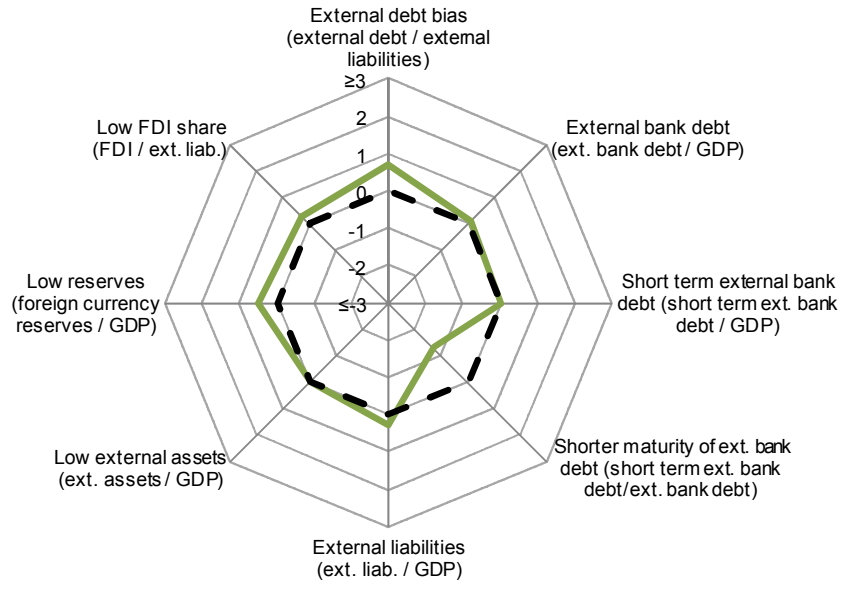

$\longrightarrow$ Spain $2007 \quad-$ OECD 2007

Each variable is presented relative to the OECD median (which is normalised to zero).

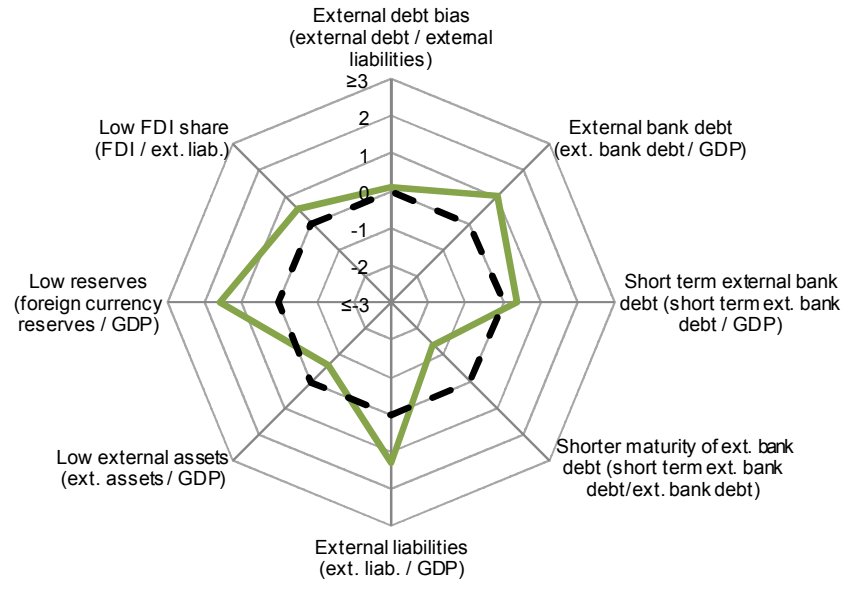

Each variable is presented in 2007 relative to the its situation in 1997 (which is normalised to zero).

Note: For each variable, a larger value indicates a riskier financial account position. Indicators are measured in multiples of the standard deviation across countries for the variable in question.

\section{Selected structural policies conducive to financial stability}

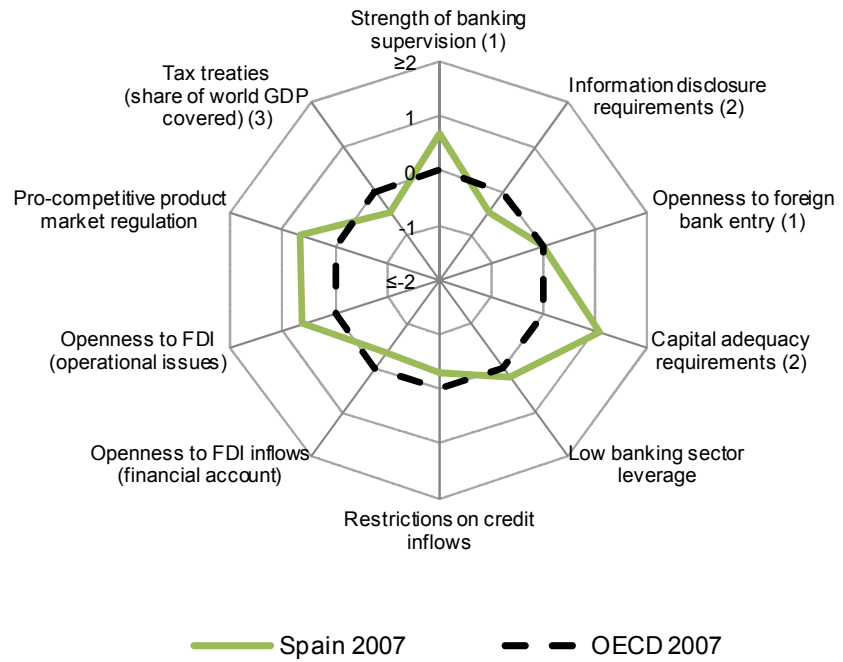

Note: For each variable, a larger value indicates a policy stance that is comparatively more conducive to financial stability. Indicators are measured in multiples of the standard deviation across countries for the variable in queation. Each variable is presented relative to the OECD average (which is normalised to zero).

(1) Last available data, 2005

(2) Last available data, 2006

(3) Last available data, 2002 


\section{SWEDEN}

\section{Financial account related risk factors to financial stability}

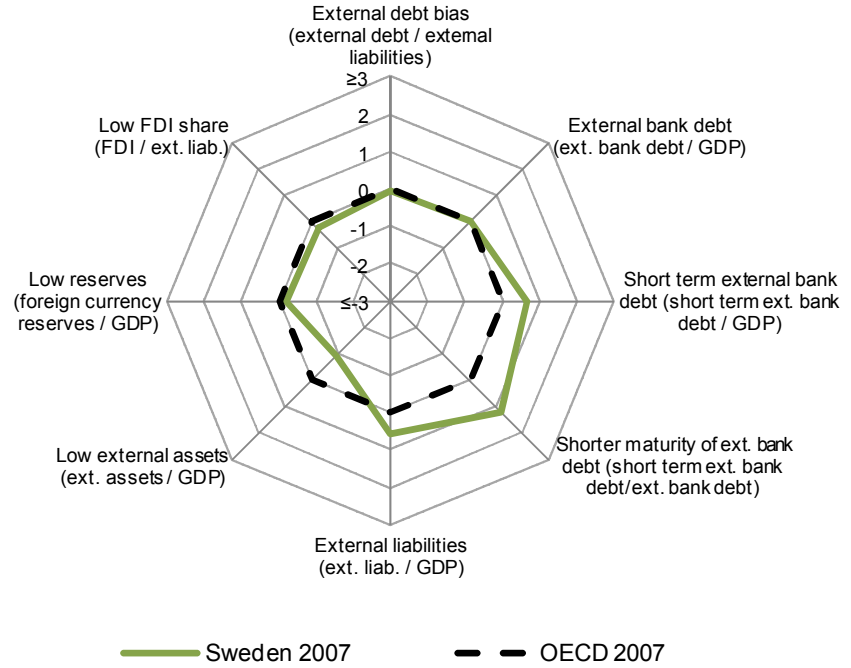

Each variable is presented relative to the OECD median (which is normalised to zero).

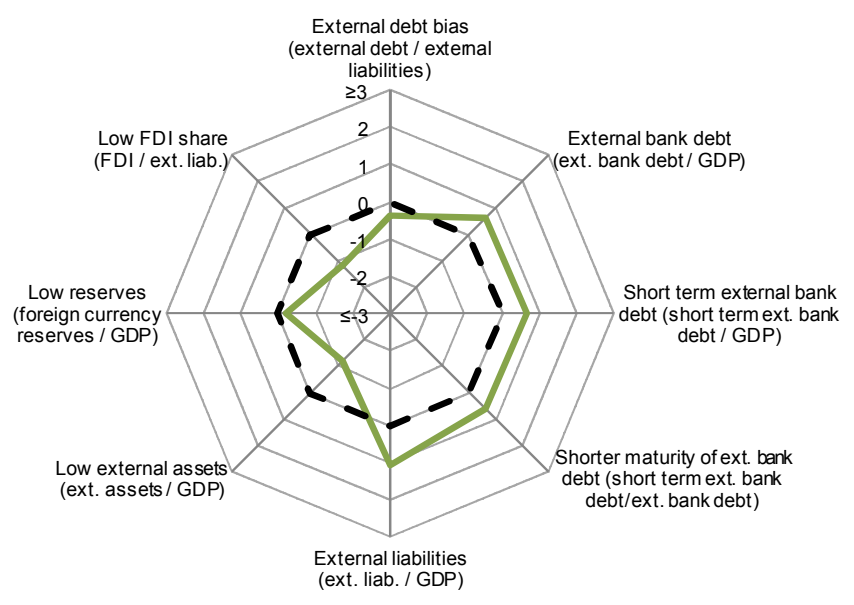

Each variable is presented in 2007 relative to the its situation in 1997 (which is normalised to zero).

Note: For each variable, a larger value indicates a riskier financial account position. Indicators are measured in multiples of the standard deviation across countries for the variable in question.

\section{Selected structural policies conducive to financial stability}

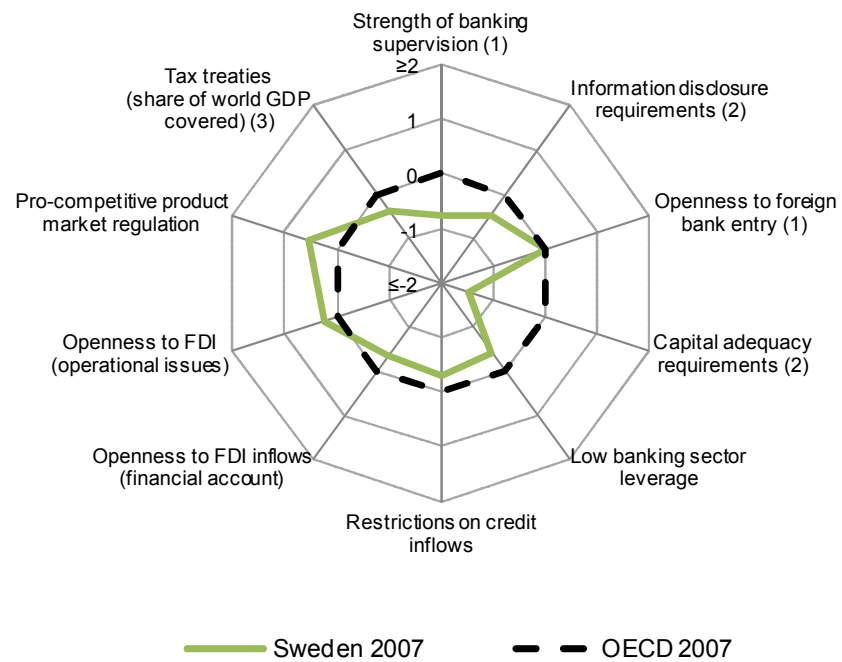

Note: For each variable, a larger value indicates a policy stance that is comparatively more conducive to financial stability. Indicators are measured in multiples of the standard deviation across countries for the variable in queation. Each variable is presented relative to the OECD average (which is normalised to zero).

(1) Last available data, 2005

(2) Last available data, 2006

(3) Last available data, 2002 


\section{SWITZERLAND}

\section{Financial account related risk factors to financial stability}

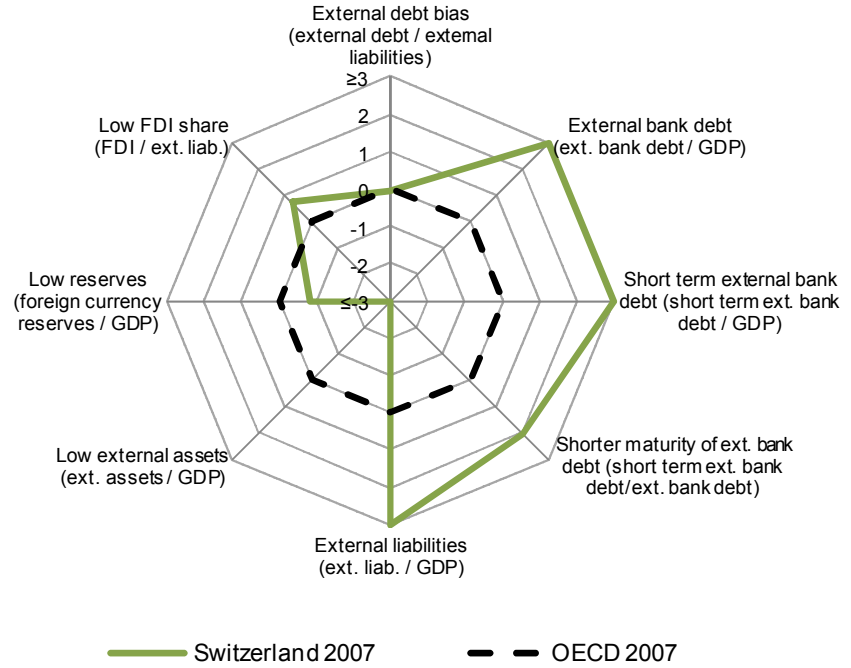

Each variable is presented relative to the OECD median (which is normalised to zero).

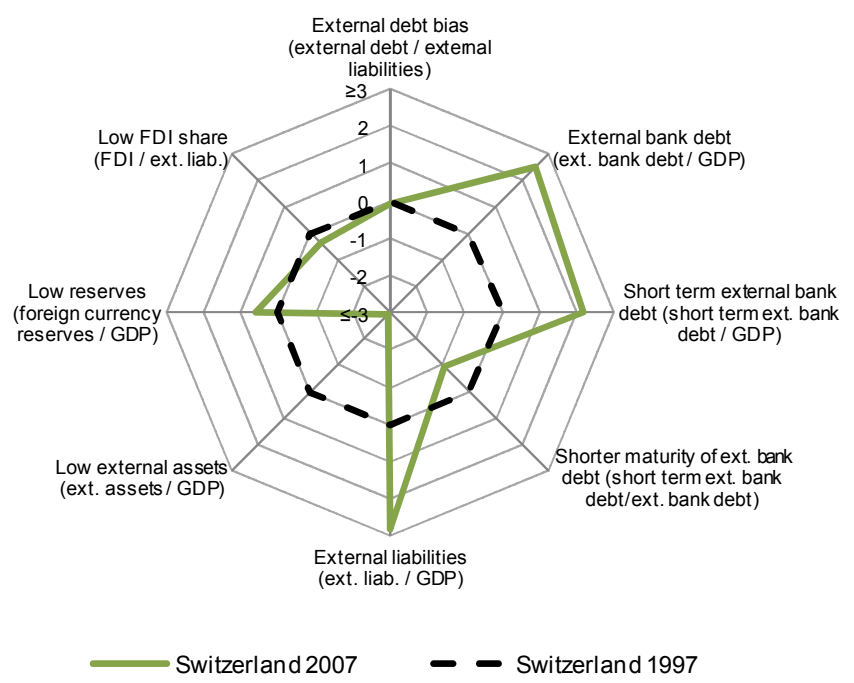

Each variable is presented in 2007 relative to the its situation in 1997 (which is normalised to zero).

Note: For each variable, a larger value indicates a riskier financial account position. Indicators are measured in multiples of the standard deviation across countries for the variable in question.

\section{Selected structural policies conducive to financial stability}

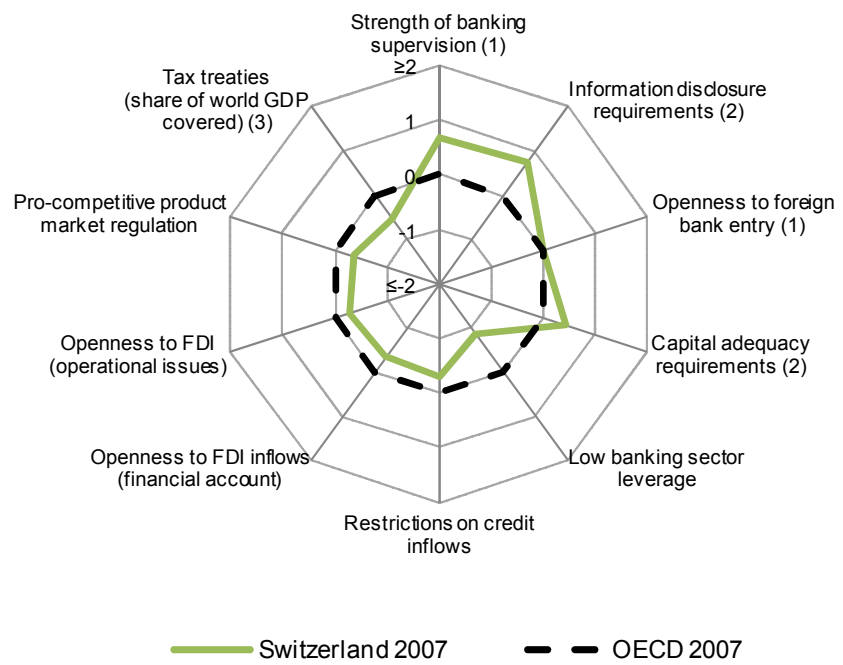

Note: For each variable, a larger value indicates a policy stance that is comparatively more conducive to financial stability. Indicators are measured in multiples of the standard deviation across countries for the variable in queation. Each variable is presented relative to the OECD average (which is normalised to zero).

(1) Last available data, 2005

(2) Last available data, 2006

(3) Last available data, 2002 


\section{TURKEY}

\section{Financial account related risk factors to financial stability}

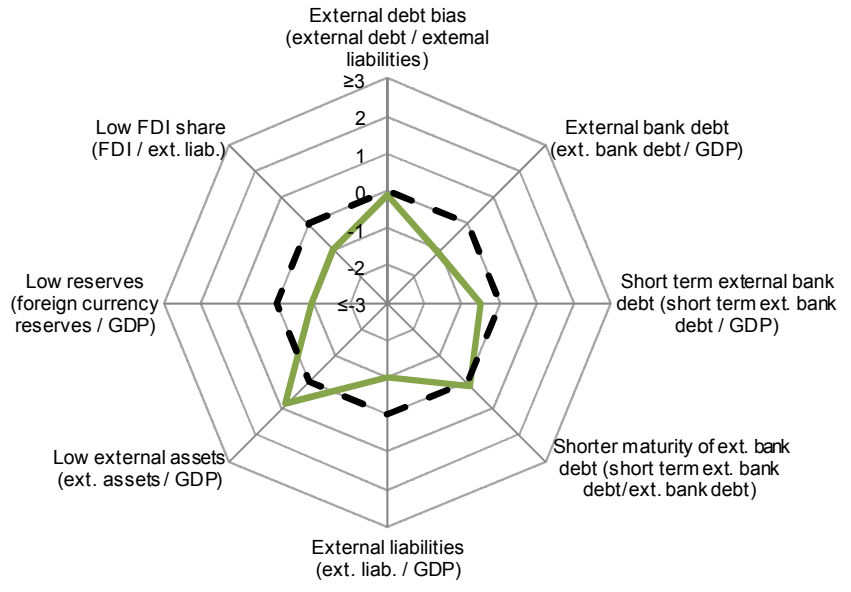

— Turkey $2007 \quad$ - O OECD 2007

Each variable is presented relative to the OECD median (which is normalised to zero).

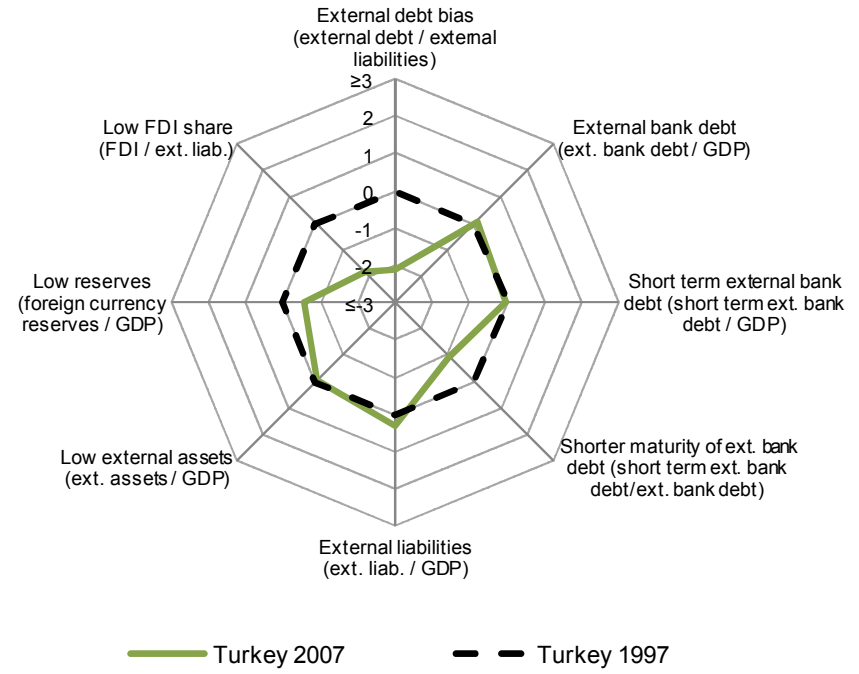

Each variable is presented in 2007 relative to the its situation in 1997 (which is normalised to zero).

Note: For each variable, a larger value indicates a riskier financial account position. Indicators are measured in multiples of the standard deviation across countries for the variable in question.

\section{Selected structural policies conducive to financial stability}

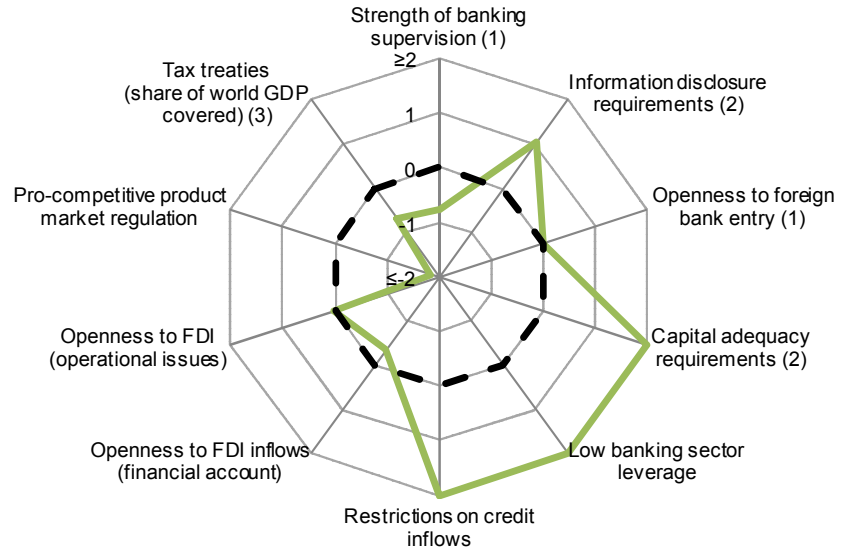

— Turkey $2007 \quad$ - OECD 2007

Note: For each variable, a larger value indicates a policy stance that is comparatively more conducive to financial stability. Indicators are measured in multiples of the standard deviation across countries for the variable in queation. Each variable is presented relative to the OECD average (which is normalised to zero).

(1) Last available data, 2005

(2) Last available data, 2006

(3) Last available data, 2002 


\section{UNITED KINGDOM}

\section{Financial account related risk factors to financial stability}

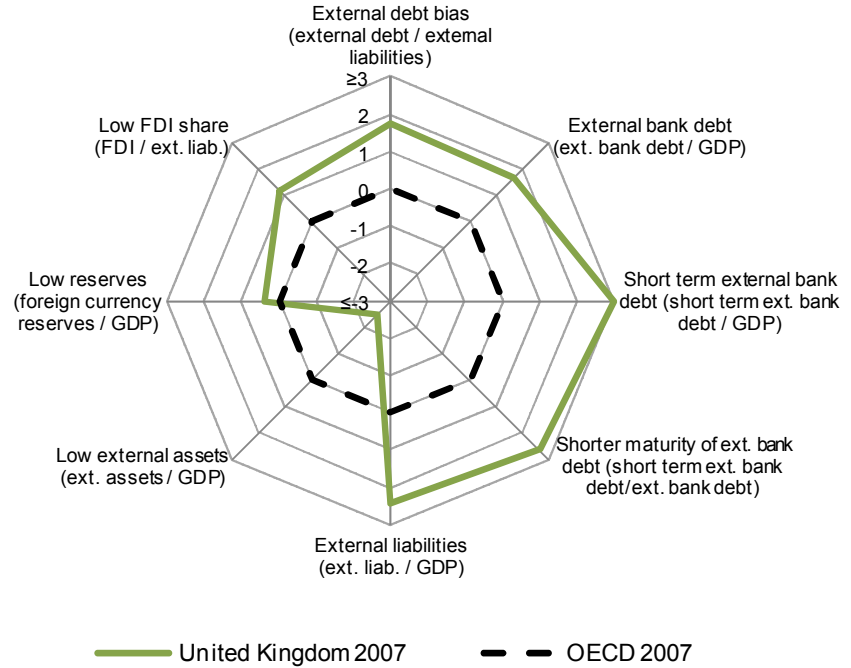

Each variable is presented relative to the OECD median (which is normalised to zero).

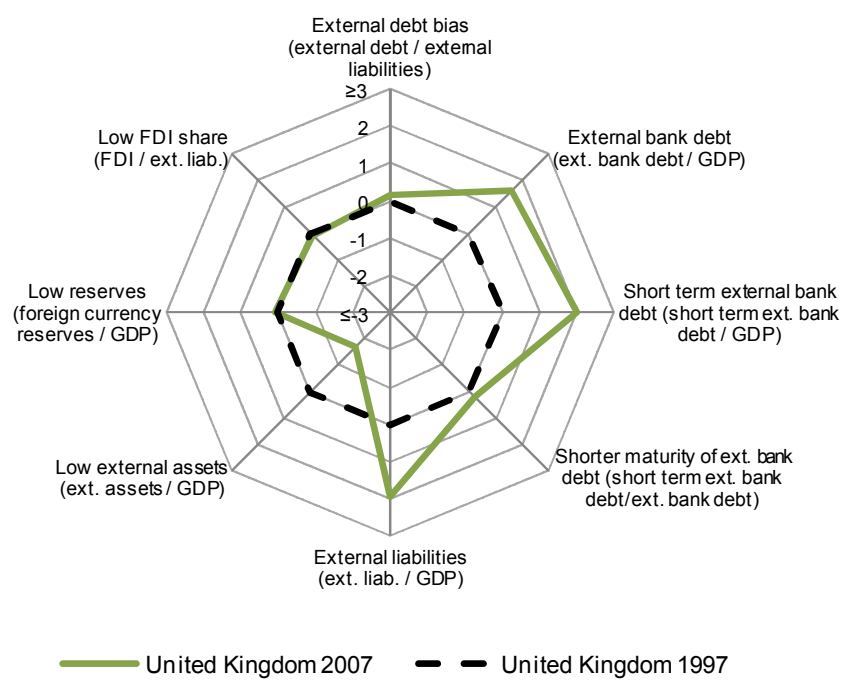

Each variable is presented in 2007 relative to the its situation in 1997 (which is normalised to zero).

Note: For each variable, a larger value indicates a riskier financial account position. Indicators are measured in multiples of the standard deviation across countries for the variable in question.

\section{Selected structural policies conducive to financial stability}

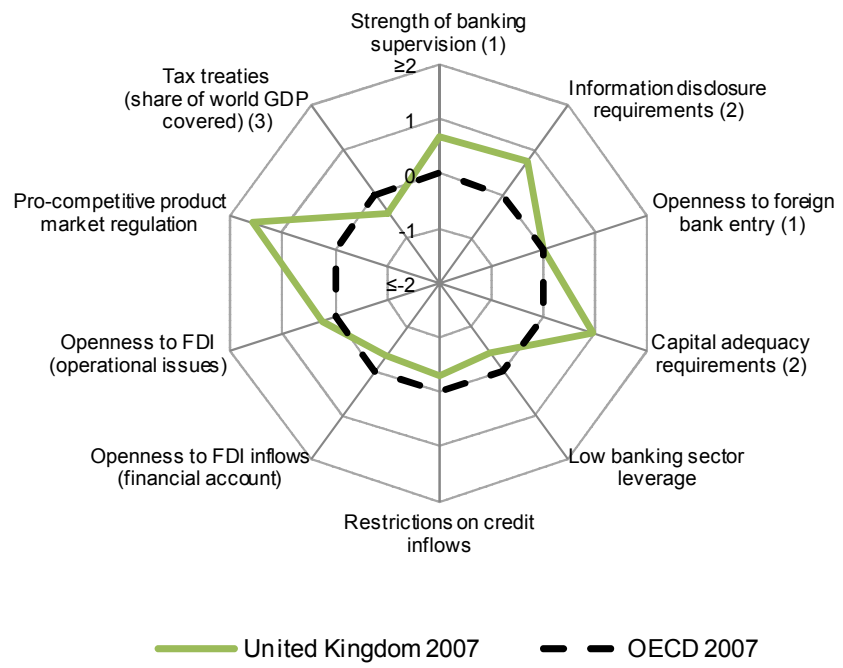

Note: For each variable, a larger value indicates a policy stance that is comparatively more conducive to financial stability. Indicators are measured in multiples of the standard deviation across countries for the variable in queation. Each variable is presented relative to the OECD average (which is normalised to zero).

(1) Last available data, 2005

(2) Last available data, 2006

(3) Last available data, 2002 


\section{UNITED STATES}

\section{Financial account related risk factors to financial stability}

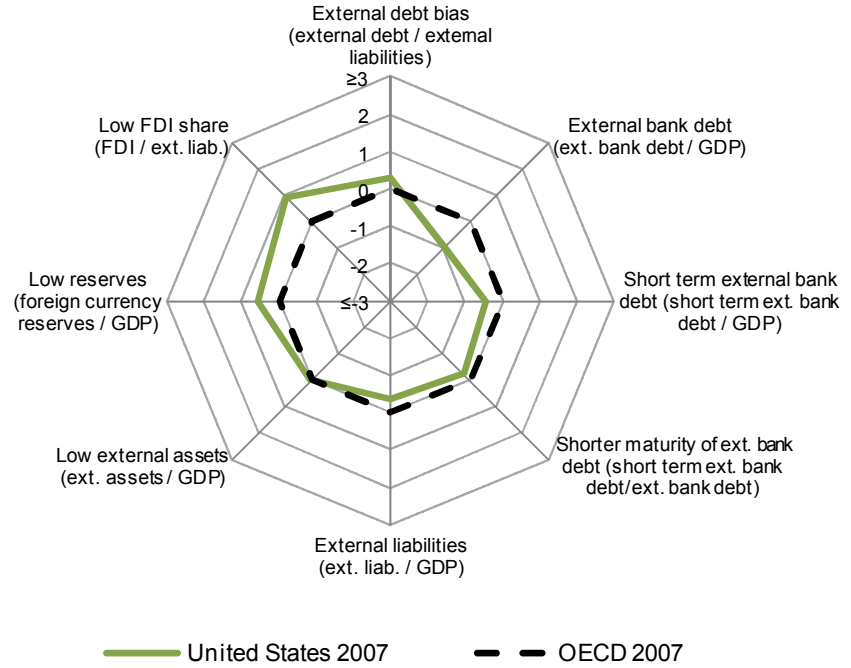

Each variable is presented relative to the OECD median (which is normalised to zero).

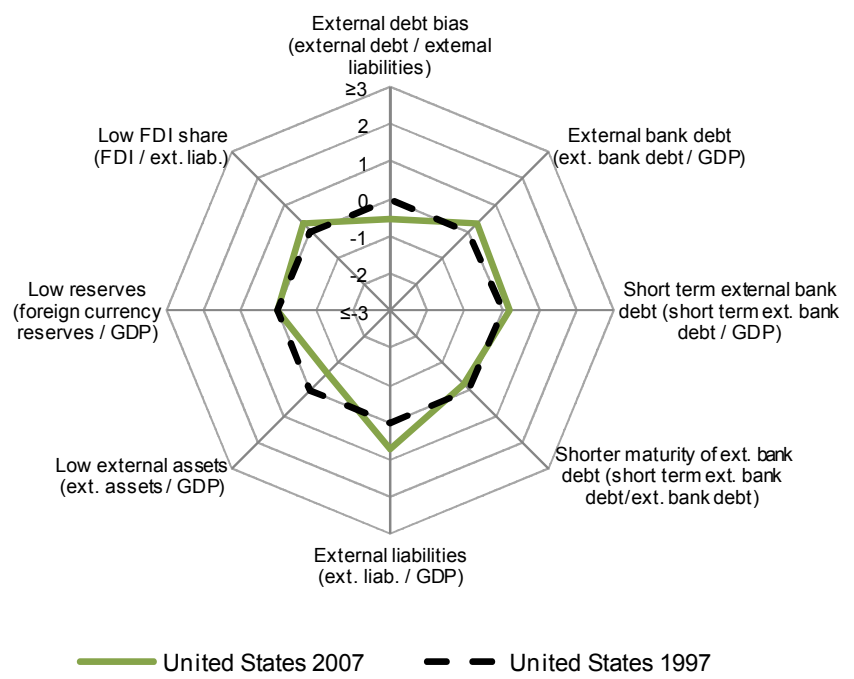

Each variable is presented in 2007 relative to the its situation in 1997 (which is normalised to zero).

Note: For each variable, a larger value indicates a riskier financial account position. Indicators are measured in multiples of the standard deviation across countries for the variable in question.

\section{Selected structural policies conducive to financial stability}

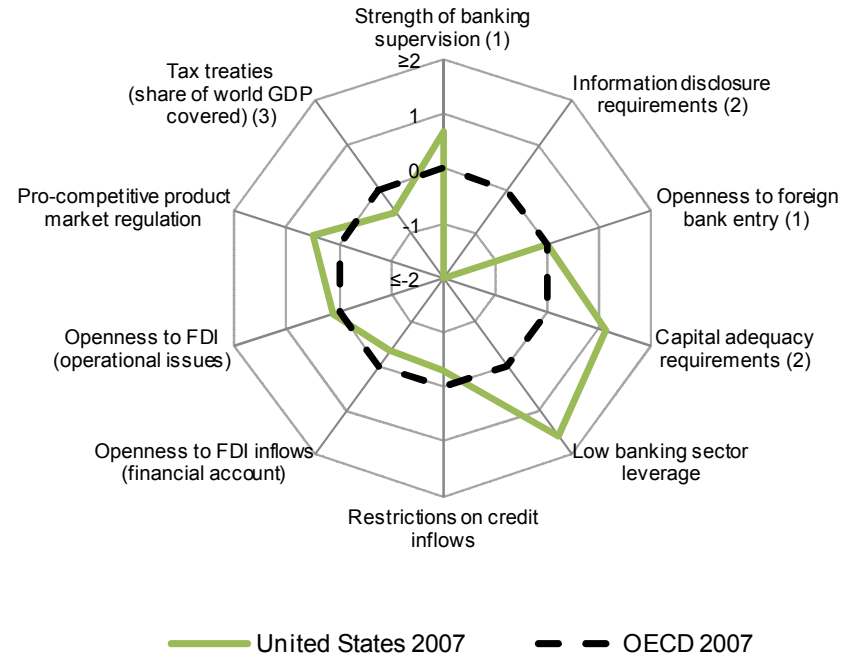

Note: For each variable, a larger value indicates a policy stance that is comparatively more conducive to financial stability. Indicators are measured in multiples of the standard deviation across countries for the variable in queation. Each variable is presented relative to the OECD average (which is normalised to zero).

(1) Last available data, 2005

(2) Last available data, 2006

(3) Last available data, 2002 


\section{WORKING PAPERS}

The full series of Economics Department Working Papers can be consulted at www.oecd.org/eco/workingpapers/

969. International Capital Mobility and Financial Fragility

Part 6. Are all Forms of Financial Integration Equally Risky in Times of Financial Turmoil? Asset Price Contagion during the Global Financial Crisis

(June 2012) by Rudiger Ahrend and Antoine Goujard

968. International Capital Mobility and Financial Fragility

Part 5. Do Investors Disproportionately Shed Assets of Distant Countries under Increased Uncertainty?

Evidence from the Global Financial Crisis

(June 2012) by Rudiger Ahrend and Cyrille Schwellnus

967. International Capital Mobility and Financial Fragility

Part 4. Which Structural Policies Stabilise Capital Flows when Investors Suddenly Change their Mind?

Evidence from Bilateral Bank Data

(June 2012) by Rudiger Ahrend and Cyrille Schwellnus

966. International Capital Mobility and Financial Fragility

Part 3. How do Structural Policies affect Financial Crisis Risk? Evidence from Past Crises across OECD and Emerging Economies

(June 2012) by Rudiger Ahrend and Antoine Goujard

965. Sustaining Korea's convergence to the highest-income countries

(June 2012) by Randall S. Jones and Satoshi Urasawa

964. Achieving the "low carbon, green growth" vision in Korea

(June 2012) by Randall S. Jones and Byungseo Yoo

963. Promoting social cohesion in Korea

(June 2012) by Randall S. Jones and Satoshi Urasawa

962. Housing price and investment dynamics in Finland

(May 2012) by Christophe André and Clara Garcia

961. Improving health outcomes and system in Hungary

(May 2012) by Mehmet Eris

960. Towards a more inclusive labour market in Hungary

(May 2012) by Rafał Kierzenkowski

959. Ensuring stability and efficiency of the Hungarian financial sector

(May 2012) by Olena Havrylchyk

958. Ensuring debt sustainability amid strong economic uncertainty in Hungary

(June 2012) by Pierre Beynet and Rafał Kierzenkowski

957. Improving the health-care system in Poland

(April 2012) by Hervé Boulhol, Agnieszka Sowa and Stanislawa Golinowska 
ECO/WKP(2012)47

956. Options for benchmarking infrastructure performance

(April 2012) by Mauro Pisu, Peter Hoeller and Isabelle Joumard

955. Greenhouse gas emissions and price elasticities of transport fuel demand in Belgium (April 2012) by Tom Schmitz

954. Bringing Belgian public finances to a sustainable path

(April 2012) by Tomasz Koźluk, Alain Jousten and Jens Høj

953. Climate change policies in Poland - minimising abatement costs

(April 2012) by Balázs Égert

952. Income inequality in the European Union

(April 2012) by Kaja Bonesmo Fredriksen

951. Reducing poverty in Chile: cash transfers and better jobs

(April 2012) by Nicola Brandt

950. Tax reform in Norway: A focus on capital taxation

(April 2012) by Oliver Denk

949. The short-term effects of structural reforms: an empirical analysis

(March 2012) by Romain Bouis, Orsetta Causa, Lilas Demmou, Romain Duval and

Aleksandra Zdzienicka

948. Short-term gain or pain? A DSGE model-based analysis of the short-term effects of structural reforms in labour and product markets

(March 2012) by Matteo Cacciatore, Romain Duval and Giuseppe Fiori

947. Do house prices impact consumption and interest rate?: Evidence from OECD countries using an agnostic identification procedure

(March 2012) by Christophe André, Rangan Gupta and Patrick T. Kanda

946. Assessing the sensitivity of Hungarian debt sustainability to macroeconomic shocks under two fiscal policy reactions

(March 2012) by Pierre Beynet and Edouard Paviot

945. Non-Keynesian effects of fiscal consolidation: an analysis with an estimated DSGE Model for the Hungarian economy

(March 2012) by Szilárd Benk and Zoltán M. Jakab

944. Work incentives and recent reforms of the tax and benefit system in Hungary

(March 2012) by Tímea Ladányi and Rafal Kierzenkowski

943. Building blocks for a better functioning housing market in Chile

(February 2012) by Aida Caldera Sánchez

942. The impact of changes in second pension pillars on public finances in Central and Eastern Europe (January 2012) by Balász Égert

941. Improving energy system efficiency in the Czech Republic

(January 2012) by Artur Radziwill 